\title{
LÚCIO ANDRÉ Noleto Magalhães
}

Análise digital da imunoexpressão compartimental de ciclina D1 em estádios III e IV de carcinoma epidermóide de laringe

São Paulo 2008 


\title{
LÚCIO ANDRÉ NOLETO MAGALHÃES
}

\author{
Análise digital da imunoexpressão \\ compartimental de ciclina D1 em \\ estádios III e IV de carcinoma \\ epidermóide de laringe
}

Tese apresentada à Faculdade de Medicina da Universidade de São Paulo para obtenção do título de Doutor em Ciências.

Área de Concentração: Clínica Cirúrgica Orientador: Dr. Pedro Michaluart J r.

São Paulo 


\section{Dados Internacionais de Catalogação na Publicação (CIP)}

Preparada pela Biblioteca da

Faculdade de Medicina da Universidade de São Paulo

Creprodução autorizada pelo autor

Magalhães, Lúcio André Noleto

Análise digital da imunoexpressão compartimental de ciclina D1 em estádios III e IV de carcinoma epidermóide de laringe /

Lúcio André Noleto Magalhães. -- São Paulo, 2008.

Tese(doutorado)--Faculdade de Medicina da Universidade de São Paulo.

Departamento de Cirurgia.

Área de concentração: Clínica Cirúrgica.

Orientador: Pedro Michaluart.

Descritores: 1.Carcinoma de células escamosas 2.Neoplasias laríngeas 3.Ciclina D1 4.Metástase linfática 5.Genes supressores de tumor 6.Gene bcl-1 7.Supressão genética 8.Estadiamento de neoplasias 9.Ciclo celular 10.Imunoistoquímica

USP/FM/SBD-215/08 
Dedico este trabalho aos meus pais, Ivadilson e Dorinha, à minha esposa Ângela e ao meu filho Estêvão. 


\section{AGRADECI MENTOS}

Ao Dr. Pedro Michaluart Júnior, pela orientação precisa, constante e minuciosa, sempre permeada por muita polidez.

Ao Dr. Fernando Luís Dias, pelo exemplo, ensinamentos transmitidos e oportunidades propiciadas.

Às Doutoras Gerúsia Ibiapina Santana e Lina Gomes dos Santos pela atenção dispensada, tempo consumido e solicitude irrestrita na avaliação histológica e imunoistoquímica do material do presente estudo.

Ao Dr. Carlos Bacchi pela orientação sensata e pragmática quando do preparo dos espécimes preservados para análise imunoistoquímica.

Ao Dr. Pedro Vítor Lopes Costa e Dr. Alesse Ribeiro dos Santos pela imprescindível orientação sobre a técnica de quantificação celular digital.

Ao Dr. Sabas Carlos Vieira pela análise crítica do escopo deste trabalho.

Ao Dr. Luiz Evaldo de Moura Pádua pela gentileza, precisão e paixão demonstradas na lide dos números que permeiam este estudo.

Ao Dr. Raimar Weber pelo auxílio, críticas e orientações relacionadas à análise estatística. 
Ao Dr. Fábio Luiz de Menezes Montenegro, Dr. Sérgio Samir Arap e Drạ. Elaine Stabenow pelas observações criteriosas e orientações quando da avaliação para qualificação.

À Srạ . Eliane Falconi Monico Gazetto personificação da solicitude, beirando o altruísmo, incansável e, sempre, cuidadosamente atenta às vicissitudes que cercaram o período da pós-graduação.

Ao Dr. Alcenor Barbosa de Almeida pelo exemplo; pelo árduo trabalho de toda uma vida com o propósito explícito de edificar os alicerces de honrada casa devotada à assistência dos pacientes, todos e quaisquer, portadores de câncer; pelo ânimo, que a vivacidade, bom humor e lucidez demonstrados, após alguns anos de vida, trazem aos mais jovens.

Ao Prof. Dr. Geraldo Matos de Sá (in memorian) pela firmeza, coerência e retidão que pontuaram toda uma vida, pelo acolhimento paternal dispensado aos seus aprendizes, pela comunhão dos bons momentos vividos e pelos ricos ensinamentos assimilados, meu muito obrigado.

Ao Dr. Emílson de Queiroz Freitas pelo amor e doação plena ao ensino médico, pelo acolhimento maternal dispensado aos seus aprendizes, por compartilhar, sem nenhum rasgo de vaidade, rico cabedal de conhecimentos em laringologia, meu muito obrigado.

Aos sujeitos deste estudo que gentilmente consentiram sua elaboração. 
“Conhece-te, aceita-te, supera-te"

Santo Agostinho de Hipona 
Esta tese obedece:

As recomendações do Serviço de Biblioteca e Documentação da Faculdade de Medicina da Universidade de São Paulo, segundo o Guia de Apresentação de Dissertações, Teses e Monografias, elaborado por Cunha AC, Freddi MJAL, Crestana MF, Aragão MS, Cardoso SC, Vilhena V. São Paulo. Serviço de Biblioteca e Documentação, 2005.

As normas de referências bibliográficas adaptadas do International Comittee of Medical J ournals Editors (Vancouver).

Abreviaturas dos títulos dos periódicos da List of Journals Indexed in the Index Medicus. 


\section{SUMÁRIO}

Lista de siglas e abreviaturas

Lista de tabelas

Lista de figuras

Resumo

Summary

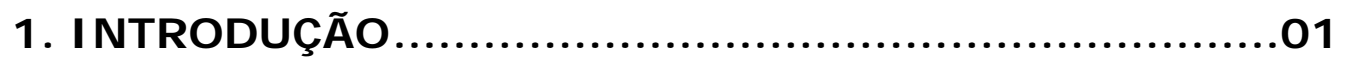

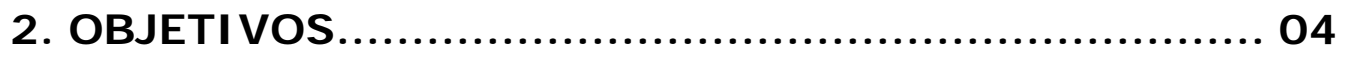

2.1. Hipótese primária...................................... 05

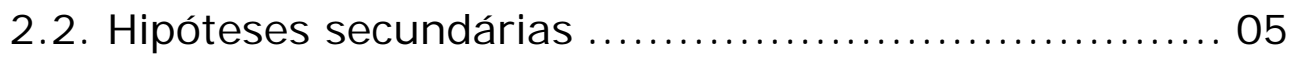

3. REVISÃO DE LITERATURA .................................. 06

3.1. Carcinoma epidermóide de laringe.................... 07

3.1.1. Fatores de risco ............................ 08

3.2. Ciclinas ............................................ 10

3.2.1. As ciclinas e as quinases dependentes de ciclina .

3.2.2. Ativação dos complexos CDK-ciclina............. 15

3.2.3. A degradação das ciclinas ........................ 16

3.2.4. Ciclina D1 .................................... 17

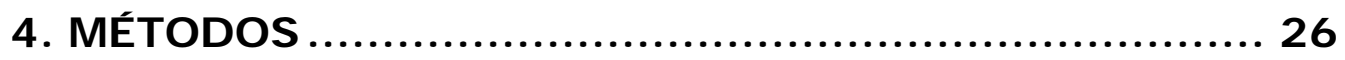

4.1. Casuística e desenho do estudo........................28

4.2. Critérios de elegibilidade e exclusão......................30 
4.3. Avaliação anatomopatológica............................ 31

4.4. Análise imunoistoquímica ............................. 31

4.4.1. Técnica de coloração............................. 31

4.4.2. Técnica de imunomarcação da ciclina D1 ....... 32

4.4.2.1. Silanização ................................. 32

4.4.2.2. Desparafinização .......................... 33

4.4.2.3. Recuperação antigênica, reação com anticorpos primário e secundário, e contracoloração

4.4.3. Análise semiquantitativa da expressão citoplasmática da cicllina D1....................34

4.4.4. Quantificação digital da imunoexpressão nuclear e citoplasmática da ciclina D1 ....... 36

4.4.4.1. Cálculo do índice de positividade (IP) . 37

4.5. Análise estatística ....................................... 39

5. RESULTADOS

5.1. Resultados descritivos relativos à casuística........... 41

5.2. Resultados relativos à técnica de imunomarcação celular por ciclina D1

5.3. Resultados relativos à análise semiquantitativa da imunoexpressão citoplasmática da ciclina D1.......... 51

5.4. Resultados relativos à análise quantitativa digital da imunoexpressão nuclear e citoplasmática da ciclina D1 . 
7.1. Conclusão Primária..................................... 71

7.1.1. ............................................... 71

7.2. Conclusões secundárias ............................... 71

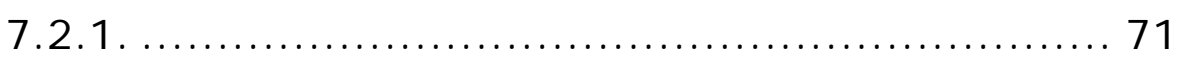

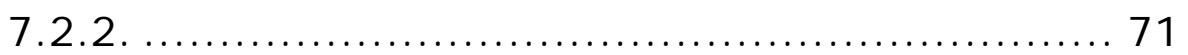

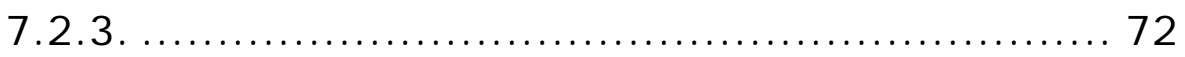

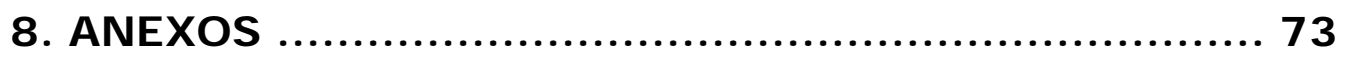

8.1. Anexo A ................................................. 74

8.2. Anexo B............................................ 82

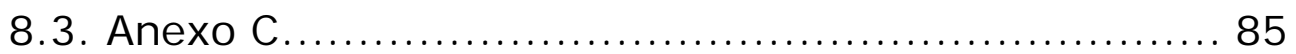

8.4. Anexo D ............................................ 92

8.5. Anexo E.............................................. 94

8.6. Anexo F .............................................. 100

8.7. Anexo G ............................................ 101

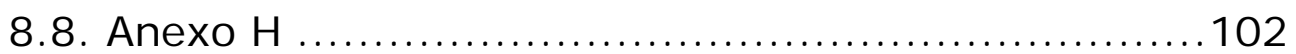

9. REFERÊNCIAS .................................................. 103

Apêndice 


\section{LISTA DE SI GLAS E ABREVI ATURAS}

APCC

APTS

BSA

CCND1

CEC

CDK

Cip1

$\mathrm{CO}_{2}$

DAB

DNA

EDTA

et al.

FISH

FMUSP

G0

G1

oC

HE

HSM

HN31

I C

I HQ

I PC

I Pn

RNAm
Associação Piauiense de Combate ao Câncer

3-aminopropiltrietoxisilano

albumina de soro bovino

gene da ciclina D1

carcinoma espino-celular

quinase dependente de ciclina

CDK-interacting protein 1

dióxido de carbono

3,3-diaminbenzidina

ácido desoxirribonucleico

Etylenediamine tetraacetic acid

e colaboradores

Fluorescence in situ hybridization

Faculdade de Medicina da Universidade de São

Paulo

intervalo de latência celular

intervalo entre a mitose e síntese de DNA

graus Celsius

hematoxilina e eosina

Hospital São Marcos

linhagem celular metastática de carcinoma

epidermóide de cabeça e pescoço

intervalo de confiança

imunoistoquímica

índice de positividade celular

índice de positividade nuclear

ácido ribonucleico mensageiro 


\begin{tabular}{ll}
$\mathbf{m I}$ & mililitro \\
$\mathbf{m M}$ & mili-molar \\
$\boldsymbol{\mu m}$ & micrômetro \\
$\boldsymbol{\mu g}$ & micrograma \\
$\mathbf{n}$ & freqüência \\
$\mathbf{N}$ & comprometimento linfático \\
$\mathbf{P C R}$ & reação em cadeia da polimerase \\
$\mathbf{p}$ & probabilidade de erro alfa \\
$\mathbf{P B S}$ & tampão fosfato de sódio \\
$\mathbf{p . e x .}$ & por exemplo \\
$\mathbf{p H}$ & potencial hidrogeniônico \\
$\mathbf{p R b}$ & proteína do retinoblastoma \\
S & período de síntese do DNA \\
TA & temperatura ambiente \\
TRI S & tris-hydroximetil-aminometano \\
UI CC & União Internacional Contra o Câncer \\
USP & Universidade de São Paulo \\
X & vorcentagem \\
\hline
\end{tabular}




\section{LISTA DE TABELAS}

Tabela 1 Dados compilados de estudos sobre a expressão da ciclina D1 e influência sobre metástase linfática e/ou sobrevida. 22

Tabela 2 Dados quantitativos e qualitativos para avaliação semiquantitativa da imunoexpressão de ciclina D1 35

Tabela 3 Características clínicas e epidemiológicas da casuística........................................41

Tabela 4 Distribuição da casuística segundo o estádio clínico..............................................42

Tabela 5 Distribuição da casuística segundo estádio anatomopatológico.

Tabela 6

Características anatomopatológicas do carcinoma epidermóide da população estudada.

Tabela 7 Evolução dos pacientes segundo estádio anatomopatológico.

.44

Tabela 8

Associação entre grau de diferenciação histológica e ocorrência de metástase linfática.

Tabela 9 Análise semiquantitativa da imunoexpressão citoplasmática de ciclina D1 comparada à presença de metástase linfática... 51

Tabela 10 Ocorrência de óbito comparada à superexpressão de ciclina D1 em análise semiquantitativa. 52 
Tabela 11 índices de positividade nuclear e citoplasmática em pacientes sem e com metástase linfática cervical por carcinoma epidermóide de laringe. .55

Tabela 12 Comparação dos índices de positividade para ciclina D1 no citoplasma e no núcleo de tumores de acordo com o grau de diferenciação histológica... 57

Tabela 13 Comparação dos índices de positividade para ciclina D1 no citoplasma e no núcleo de tumores que evoluíram, e que não evoluíram, com recidiva loco-regional e/ou metástase hematogênica.....59

Tabela 14 Resultado da avaliação semiquantitativa da imunoexpressão citoplasmática de ciclina D1 em carcinoma epidermóide de laringe.

Tabela 15 Quantificação digital randomizada, e cega quanto à ocorrência de metástase linfática, da imunoexpressão nuclear e citoplasmática de ciclina D1 em grupo de 1000 células para cada caso estudado.

Tabela 16 Dados de sobrevivência global em casos sem imunoexpressão citoplasmática de ciclina D1...99

Tabela 17 Dados de sobrevivência global em casos com superexpressão citoplasmática de ciclina

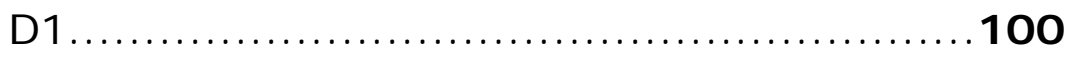

Tabela 18 TNM: grupamento por estádios de carcinoma laríngeo 


\section{STA DE FI GURAS}

Figura 1

Figura 2

Figura 3

Figura 4

Figura 5

Figura 6

Figura 7

Figura 8
Concentrações de diferentes ciclinas durante a progressão do ciclo celular (Adaptado de Jeannon, 1998) 12

Ativação do complexo ciclina D1-CDK durante a fase G1 do ciclo celular. (Adaptado de Tajara, 2004) 13

Formação dos complexos ciclina D e CDK4/6...16

Mapeamento da posição 11q13.3 do cromossomo 11 17

Representação sumária da atuação dos complexos ciclina-CDK durante a progressão do ciclo celular

Demonstração do uso do $\operatorname{Imagelab}^{\circledR}$ na identificação manual de núcleos positivos (pontos brancos) e núcleos negativos (pontos pretos) para o cálculo do IP nuclear para ciclina D1.....38 Fotomicrografia de lâmina corada por hematoxilina-eosina em aumento de 400x. Confirmação de carcinoma epidermóide pouco diferenciado em espécime de tumor primário de laringe 46

Fotomicrografia de lâmina corada por imunoistoquímica para ciclina D1 em aumento de 100x. Imunorreação citoplasmática em destaque 
Figura 9

Figura 10

Figura 11

Figura 12

Figura 13

Figura 14
Fotomicrografia de lâmina corada por imunoistoquímica para ciclina D1 em aumento de $200 x$ 48

Fotomicrografia de lâmina corada por imunoistoquímica para ciclina D1 em aumento de $400 x$ 49

Fotomicrografia de lâmina corada por imunoistoquímica para ciclina D1 em aumento de 400x. Destaque para a imunorreação nuclear e citoplasmática.

50

Gráfico de sobrevivência global (barra azul) e intervalo de confiança de 95\% (barras vermelhas) dos casos que apresentaram imunoexpressão citoplasmática de ciclina D1 por avaliação semiquantitativa. .53

Gráfico de sobrevivência global (barra azul) e intervalo de confiança de $95 \%$ (barras vermelhas) dos casos que não apresentaram imunoexpressão citoplasmática de ciclina D1 por avaliação semiquantitativa. .53

Gráfico de barras de erros representando as médias e respectivos intervalos de confiança de 95\% dos índices de positividade para ciclina D1 no núcleo e no citoplasma de indivíduos com (verde; $n=19$ ) e sem (azul; $n=28$ ) metástase linfática. Valores de $\mathrm{p}$ obtidos do teste não paramétrico U de Mann-Whitney 56 
Figura 15 Gráfico de barras de erros representando as médias e respectivos intervalos de confiança de 95\% dos índices de positividade para ciclina D1 no núcleo e no citoplasma de indivíduos e comparação com grau de diferenciação histopatológica ( $G 1, G 2$ e G3). Valores de $p$ obtidos do teste não paramétrico de KruskalWallis 58

Figura 16 Gráfico de barras de erros representando as médias e respectivos intervalos de confiança de 95\% dos índices de positividade para ciclina D1 no núcleo e no citoplasma de indivíduos e comparação com recidiva loco-regional e metástase hematogênica. Valores de $\mathrm{p}$ obtidos do teste não paramétrico $U$ de Mann-Whitney......60

Figura 17 Formulário para dados clínicos e laboratoriais...74 Figura 18 Formulário para dados anatomopatológicos......81

Figura 19 Formulário para dados de seguimento clínico....84

Figura 20 Parecer do Comitê de Ética em Pesquisa em Humanos da Associação Piauiense de Combate ao Câncer.

Figura 21 Parecer da Comissão para Avaliação de Ética em Pesquisa da Faculdade de Medicina da Universidade de São Paulo. 


\section{RESUMO}

Noleto L. Análise digital da imunoexpressão compartimental de ciclina D1 em estádios III e IV de carcinoma epidermóide de laringe [tese]. São Paulo: Faculdade de Medicina, Universidade de São Paulo; 2008.

Introdução: A ciclina D1 constitui um importante regulador do ciclo celular e pode funcionar como co-regulador de transcrição. A superexpressão da ciclina D1 tem sido associada ao desenvolvimento e progressão do câncer. A degradação irregular da ciclina D1 pode ser responsável pelos seus níveis elevados em algumas neoplasias malignas. A ciclina D1, além disso, modula indiretamente a estrutura da cromatina e transcrição de genes envolvidos na proliferação e diferenciação. Mutações, amplificação e superexpressão da ciclina D1, que alteram a progressão do ciclo celular, são observadas frequentemente em várias apresentações de neoplasias malignas, incluindo o carcinoma epidermóide de laringe, e as elucidações inferidas destas observações podem trazer melhor entendimento à oncogênese. Objetivo: $O$ objetivo deste estudo foi comparar a expressão imunoistoquímica de ciclina D1 e a ocorrência de metástase linfática em estádios III e IV de carcinoma epidermóide de laringe. Métodos: Estudo retrospectivo, coorte longitudinal, por avaliação imunoistoquímica e quantificação digital da imunoexpressão nuclear e citoplasmática de ciclina D1 em espécimes de tumor preservados em parafina oriundos de pacientes consecutivos submetidos à cirurgia oncológica radical, entre 1999 e 2004. A sobrevida global dos pacientes foi avaliada, bem como a idade, sexo, tabagismo, estado de comprometimento linfático, grau de diferenciação e estadiamento (pTNM). A análise 
estatística teve como significância valores de $p<0.05$. A curva de sobrevida foi elaborada utilizando o método de Kaplan-Meier. Resultados: Houve imunomarcação citoplasmática em 566 (1,2\%) células, imunomarcação nuclear em 13788 (29,6\%) células, a relação do IPc e IPn foi de 0,007 (0,7\%), ausência de imunomarcação celular foi observada em 32210 (69,1\%) células, perfazendo um total de 46554 (100\%) células investigadas. Entre os $28(59,5 \%)$ casos que não apresentaram metástase linfática, o IPn foi de $26,8(9,7-46,9)$ e o IPC foi de $0,1(0-0,3)$; naqueles $19(40,4 \%)$ em que foi observada metástase linfática, o IPn foi de $26,7(16,7-39,0)$ e o IPC foi de 0,3 $(0$ - 1,0). Conclusões: Não houve associação estatisticamente significante entre expressão nuclear e citoplasmática de ciclina D1, em carcinoma epidermóide primário de laringe, e ocorrência de metástase linfática cervical, graus de diferenciação histológica, bem como recidiva loco-regional e metástase hematogênica. O presente estudo não subsidia a superexpressão de ciclina D1 como fator limitante de sobrevida global.

Descritores: Oncologia, Ciclina D1, Laringe, Imunoistoquímica. 


\section{SUMMARY}

Noleto L. Digital analysis of cyclin D1 immunoexpression in subcellular compartments in squamous cell carcinoma of the larynx [thesis]. São Paulo: Faculdade de Medicina, Universidade de São Paulo; 2008.

Background: Cyclin D1 is an important regulator of cell cycle progression and can function as a transcriptional co-regulator. The overexpression of cyclin D1 has been linked to the development and progression of cancer. Abnormal cyclin D1 degradation appears to be responsible for the increased levels of cyclin D1 in several cancers. Recent findings have identified novel mechanisms involved in the regulation of cyclin D1 stability. Cyclin D1 belongs to the family of cyclin proteins which function as the regulatory subunits of cyclin/cyclin dependent kinase (Cdk) holoenzymes that regulate entry into and progression through the cell cycle. Cyclin D1 expression is induced upon stimulation by growth factors (e.g. EGF, IGF-I/II), aminoacids, hormones, and oncogenes such as Ras, Src, ErbB2, and SV40 T antigen. Cdk4 and Cdk6 can partner with cyclin D1 in early to mid-G1 phase to phosphorylate and inactivate the cell cycle inhibitory function of the retinoblastoma protein (pRB) in cooperation with cyclin E/Cdk2. Cyclin D1 is also known to modulate local chromatin structure and transcription of genes involved in proliferation and differentiation through CDKindependent association with histone acetylases (e.g. CBP, P/CAF) and deacetylases. Mutations, amplification or overexpression of cyclin D1, which alters cell cycle progression, are observed frequently in a variety of tumors, including laryngeal squamous cell carcinoma, and may contribute to oncogenesis. Methods: This was a retrospective study by immunohistochemical determination of cyclin D1 in fixated and paraffin-embedded tumour especimens from 47 consecutive patients with squamous cell carcinoma in larynx treated by curative oncological surgery from 1999 to 2004. Survival of patients was related to age, gender, nodal status and stage at termination of treatment. Significant differences were considered for $p<0.05$. Results: Cytoplasmic immunostain was observed in $566(1,2 \%)$ cell, nuclear immunostain in 13788 $(29,6 \%)$ cell, relationship between PIc and PIn was 0,007 $(0,7 \%)$, absent cell immunostain was observed in $32210(69,1 \%)$, and total $46554(100 \%)$. Among $28(59,5 \%)$ cases with no lymph node 
metastasis, PIn was 26,8 (9,7 - 46,9) and PIc was 0,1 (0 - 0,3); those $19(40,4 \%)$ with lymph node metastasis, had a PIn of 26,7 $(16,7-39,0)$ and PIC of $0,3(0-1,0)$. Conclusions: According to these results, it has been concluded that cyclin D1 showed nuclear and cytoplasmic expression in larynx squamous cell carcinoma; however, tumor cyclin D1 expression was not significantly associated with lymph node metastasis when quantified by quantitative or semiquantitative methods. Besides, cyclin D1 expression showed no influence in overall survival.

Subject Headings: 1. Medical oncology, 2. Cyclin D1, 3. Larynx, 4. Immunohistochemistry. 
1. I NTRODUÇÃO 


\section{I NTRODUÇÃO}

O câncer se caracteriza por proliferação descontrolada e mutações em genes que controlam o ciclo celular. As alterações afetando a função da ciclina D1 são apenas um exemplo conhecido. A completa definição das bases moleculares que regulam as atividades desses e de outros membros da maquinaria do ciclo celular tem um papel fundamental para o conhecimento dos mecanismos envolvidos na tumorigênese. Além disso, deve abrir caminhos para o desenvolvimento de drogas contra alvos específicos e para tratamentos efetivos contra o câncer.

O carcinoma epidermóide responde por aproximadamente $2 \%$ de todas as neoplasias malignas diagnosticadas anualmente no ocidente, e representa a mais comum em cabeça e pescoço (Batsakis JG, 1979). Apesar dos avanços no entendimento da expressão de proteínas que regulam o ciclo celular e sua conseqüente influência sobre a oncogênese, evolução do tratamento cirúrgico e técnica de radioterapia, bem como emprego combinado de radioterapia e quimioterapia, aproximadamente $50 \%$ apresentam recidiva loco-regional, metástase hematogênica ou segundo tumor primário que, em conjunto, representam as falhas de tratamento (Spafford MF, 1996; Rodrigo JP, 2003; Lazaris AC, 2000); além disso, tumores com características clínicas e histopatológicas similares podem apresentar evoluções clínicas bastante distintas. Fatores prognósticos tradicionais como sítio primário do tumor, estadiamento TNM (Anexo G) e graduação histológica, parecem ser insuficientes em predizer a evolução do carcinoma epidermóide de laringe (Brine M, 1991; Ziwei Yu et al., 2005). 
A ciclina D1 é codificada pelo gene CCND1 localizado no cromossomo 11q. Essa atua no ciclo celular acelerando a fase G1 descrita em 1991 por Motokura et al. ao observarem que o aumento da ciclina desregula o ciclo celular e contribui para a gênese do tumor. A superexpressão dessa pode estar implicada em má evolução clínica, expressa por recidiva local ou metástase linfática e hematogênica, em pacientes com carcinoma epidermóide de cabeça e pescoço.

No intuito de melhorar o entendimento da oncogênese do carcinoma epidermóide de laringe, e sua evolução clínica, tentativas têm sido realizadas em identificar novos marcadores prognósticos capazes de distinguir pacientes com bom prognóstico daqueles com maior probabilidade de apresentarem falha no controle oncológico (Chen FF et al., 1996). 


\section{OBJETIVOS}

O objetivo da presente pesquisa foi verificar:

\subsection{HI PÓTESE PRI NCI PAL}

2.1.1. Avaliar a imunoexpressão da ciclina D1 nos compartimentos celulares do carcinoma epidermóide de laringe e comparar com a ocorrência de metástase linfática.

\subsection{HI PÓTESES SECUNDÁRI AS}

2.2.1. Avaliar a imunoexpressão nuclear e citoplasmática da ciclina D1 e comparar com os graus de diferenciação histológica em carcinoma epidermóide de laringe.

2.2.2. Avaliar a imunoexpressão nuclear e citoplasmática da ciclina D1 e comparar com a ocorrência de recidiva locoregional em pacientes tratados por carcinoma epidermóide de laringe.

2.2.3. Avaliar a sobrevivência global dos pacientes tratados por carcinoma epidermóide de laringe comparada à imunoexpressão da ciclina D1. 


\section{REVI SÃO DE LITERATURA}

\subsection{CARCI NOMA EPI DERMÓI DE DE LARI NGE}

O câncer de laringe é responsável por aproximadamente 136.000 novos casos e 73.500 mortes no mundo a cada ano, ocorrendo predominantemente no sexo masculino. Representa 2,7\% de todos os casos de câncer e 2,2\% dos óbitos por câncer. A relação de incidência por sexo é de 7:1 (masculino/ feminino), a maior diferença em comparação com qualquer outro sítio anatômico do corpo humano, segundo Gallus (2003).

Aproximadamente dois terços desses tumores surgem na glote e um terço acomete a laringe supraglótica (Dias FL et al., 2001).

Conforme dados do Instituto Nacional de Câncer (2005), do Ministério da Saúde, o câncer da laringe é o segundo mais freqüente do trato aerodigestivo superior, sendo responsável por $25 \%$ dos tumores malignos da cabeça e pescoço e $2 \%$ do total das neoplasias malignas.

O câncer de laringe pode ser prevenido, pois menos de 5\% dos carcinomas de laringe ocorrem em não-fumantes e o risco diminui com a cessação do tabagismo após cinco anos e aproximase do risco de não-fumantes por volta dos dez anos após o fim do hábito de fumar (Tincani AJ, 2004).

O câncer de laringe responde por $2,8 \%$ dos novos casos de câncer em homens no mundo, e constitui a décima primeira neoplasia maligna mais freqüente, tendo uma estimativa de incidência ajustada por idade pela população mundial de 
$5,7 / 100.000$. Entre mulheres ele é menos freqüente, com uma estimativa de incidência ajustada por idade pela população mundial de 0,7/100.000. O maior coeficiente de incidência, no sexo masculino, foi observado em Saragoza, Espanha (coeficiente ajustado por idade pela população mundial de 18,0/100 mil por ano) (Parkin DM, 2002).

O câncer de laringe é responsável por aproximadamente 73.500 mortes por ano no mundo. Na América do Sul tropical (inclui todos os países do continente, com exceção do Chile, Argentina e Uruguai); em 1990, o coeficiente de mortalidade por câncer de laringe padronizado por idade foi estimado em 3,9 para homens e 0,7 para mulheres (por 100 mil) (Pisani Pet al., 1999).

Em levantamento realizado no Estado de São Paulo, na década de 90, o câncer de laringe aparece como a oitava neoplasia mais freqüente entre as mortes por neoplasias malignas, com uma taxa bruta de 4,5/100 mil homens (Wunsch V, 2004).

O tratamento desta doença gera mudanças importantes nas atividades diárias dos pacientes, causando conseqüências severas na qualidade de vida dos mesmos (Dworkin JP, 2003).

\subsubsection{FATORES DE RISCO}

Fumo e álcool: o câncer de laringe é extremamente raro em não-fumantes e incomum em mulheres (Licitra L, 2003). O risco é proporcional ao número de cigarros fumados por dia e o risco de adquirir câncer de laringe pode ter uma razão de chances 13,2 vezes maior em fumantes do que em não-fumantes. Considerado um risco de 4,4 vezes maior de câncer de laringe para quem fuma 
10 cigarros por dia e até 10,4 para quem fuma 40 cigarros por dia. Há uma relação nítida entre o câncer de laringe e o álcool, com o dobro de risco para os etilistas. Também ocorre um sinergismo entre o álcool e o fumo, aumentando em 20 vezes o risco de desenvolvimento de câncer de laringe (Lazarus P, 2000).

Ocupação: há algumas atividades de risco para o câncer de laringe, entre elas estão aquelas em que ocorre exposição ao níquel e gás mostarda, além de maquinistas e trabalhadores de granja e marcenaria. Desde 1970, a exposição ao asbesto tem sido considerada como fator de risco, inclusive por meio de estudos de caso-controle. Exposição ao ácido sulfúrico pode ocasionar, também, câncer de laringe, assim como trabalhadores expostos à madeira e ao cimento (Dietz A, 2004).

Radiação: principalmente em altas doses, tem sido identificada como cancerígena, especialmente para os tecidos moles (glândulas salivares e tireóide); entretanto, também, são relatados casos de indução de carcinoma escamoso e fibrossarcoma de laringe devido à radiação (Boffeta $P, 2003$ ).

Nutrição e dieta: estudos caso-controle indicaram que alto consumo de alimentos salgados e gordurosos são associados com câncer de laringe. Por outro lado, o consumo de legumes e vegetais in natura, frutas, tem efeito protetor em outros estudos caso-controle (Bosetti C, 2002).

Vírus: HPV tipos 16, 18 e 33 podem estar relacionados com câncer de laringe, porém, após estudos grupo-controle, sem tabagismo ou etilismo, não houve diferença estatisticamente significativa (Herrero R, 2003).

Refluxo gastro-esofágico: um estudo tipo caso-controle, em que foram controlados idade, gênero e tabagismo, demonstrou 
aumento significativo de câncer de laringe em pacientes com RGE (Weaver EM, 2003). No entanto, metanálise de 18 artigos mostrou pouco suporte a esse possível fator etiológico (Galli J, 2002).

Genético: estudo brasileiro caso-controle, mostrou um alto risco de carcinoma epidermóide entre indivíduos com parentes de primeiro grau com câncer de via aerodigestiva superior (Tincani AJ, 2006).

\subsection{CLI NAS}

\subsubsection{AS CI CLI NAS E AS QUI NASES DEPENDENTES DE CICLI NAS.}

As células malignas apresentam danos aos genes envolvidos no controle do ciclo celular, particularmente no ponto de restrição entre G1/S (Sherr CJ , 1996). Há uma série de evidências indicando que o principal evento na progressão da fase G1/S é a fosforilação do gene do retinoblastoma (pRb), a qual propicia a inibição dos fatores de transcrição da família E2F (Weinberg RA et al., 1995; Herwig S et al., 1997).

A atividade dos fatores de transcrição E2F permite a expressão dos genes específicos $d a$ fase $S$ necessários à progressão do ciclo celular.

Este ponto crítico é primariamente modulado por uma subunidade de ciclina reguladora e uma subunidade catalítica de quinase dependente de ciclina (CDK) (Hunter T et al., 1994), estas quinases acabam por regular a fosforilação do pRb (Sherr C) et al., 1996). 
Quando não há a fosforilação do $\mathrm{pRb}$, há inativação dos fatores de transcrição e impedimento da progressão da transição $\mathrm{Gl} / \mathrm{S}$; entretanto, o pRb fosforilado, isoladamente, não pode promover a progressão do ciclo celular (Weinberg RA et al., 1996).

Pelo menos nove classes de ciclina e sete de CDK já foram identificadas (Nakamura T et al., 1995). Duas subunidades de CDK (CDK4 e CDK6) conjugadas a três ciclinas D (D1, D2 e D3), além da CDK2 conjugada a ciclina $E$, estão envolvidas na regulação da progressão G1/S (Franklin DS et al., 1998). Há estudos biomoleculares que revelam que as CDK são negativamente reguladas por um grupo numeroso de inibidores de CDK, os quais podem ser divididos em dois subgrupos conforme suas propriedades funcionais e estruturais: INK4 que inclui p15, p16, p18 e p19 e formam complexos com CDK4 e CDK6 e ciclinas D, e o subgrupo Cip/Kip que inclui p21, p27 e p57, conhecidos como inibidores universais de CDK por inibirem a atividade quinase de vários complexos CDK (Lloyd RV et al., 1999).

Alguns estudos têm demonstrado a relação entre alterações de oncogênese e a expressão destas ciclinas, CDK e inibidores de CDK que levam a perda de controle sobre o ciclo celular, particularmente na fase G1/S (Sherr CJ , 1996; Motokura AA, 1993; Bartkova J, 1996).

As ciclinas são um grupo chave de proteínas reguladoras do ciclo celular. Estas são enzimas que estimulam a célula a realizar a divisão celular. Durante a fase G0 elas encontram-se inativas e, ao se unirem com suas respectivas quinases dependentes de ciclina (CDK), tornam-se ativas. É o complexo ciclina/CDK que estimula a célula a realizar a mitose. Para cada fase do ciclo celular existe um desses complexos envolvido; além disso, durante todo o ciclo celular, ocorre sucessivamente a formação, ativação e inativação 
desses diferentes complexos ciclina/CDK, cujas concentrações aumentam e decrescem num padrão regular (Jeannon JP et al., 1998).

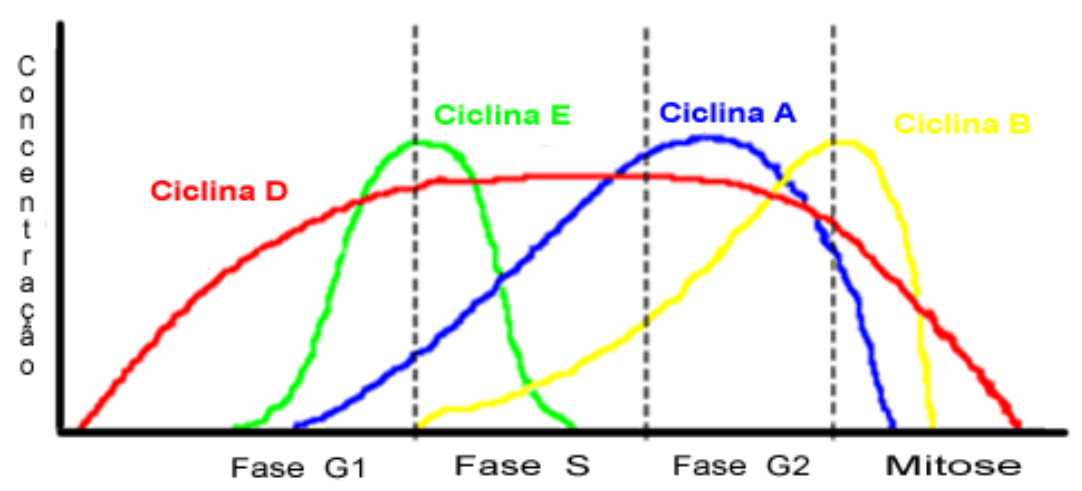

Figura 1 - Concentrações de diferentes ciclinas durante a progressão do ciclo celular (Adaptado de Jeannon, 1998).

Durante a elucidação da base genética do câncer, naturalmente, o foco é o que faz a célula cancerosa ser diferente da célula normal e como isto deve ser explorado para interferir na história natural da doença. A pesquisa para o fator determinante no desenvolvimento de câncer laríngeo tem levado a vários genes implicados, incluindo aqueles envolvidos na regulação do ciclo celular (como TP16, TP21 e CCND1), além dos genes supressores tumorais (como o TP53 e RB), oncogenes (RAS e NYC), receptores de fatores de crescimento (como o EGF e HER-2/neu), enzimas proteolíticas (colagenase e matriz metaloproteinase) e o antígeno do carcinoma de células escamosas (SCCA1 e SCCA2) (Cataltepe S, 2000). 
Embora haja um grande número de descrições destes genes, até o momento, nenhum destes candidatos mostrou-se consistente como marcador prognóstico (Cervantes O, 2005).

Os proto-oncogenes são genes envolvidos nos quatro mecanismos básicos que regulam o crescimento celular normal: fatores de crescimento, receptores dos fatores de crescimento, transdutores de sinal e fatores de transcrição nuclear. Acredita-se que os oncogenes ativem ciclinas e quinases dependentes de ciclina $(C D K)$ _ que desencadearão a proliferação desregulada (Cervantes O et al., 2005).

A progressão do ciclo celular de eucariotos superiores depende de uma classe especial de enzimas do tipo quinase de serina/ treonina, cuja subunidade catalítica é conhecida como CDK (cyclindependent kinase) e a subunidade regulatória é a ciclina, esta última com um padrão cíclico de acúmulo e degradação (Murray, 2004; Sherr, 2004; Wang et al. 2004).

Segundo Tajara (2004), as células animais possuem várias ciclinas e CDK que combinam e atuam em fases específicas do ciclo celular. Por exemplo, a passagem pelo ponto de restrição em G1 é regulada principalmente por complexos de CDK4 e CDK6 e ciclinas do tipo D (D1, D2, D3).

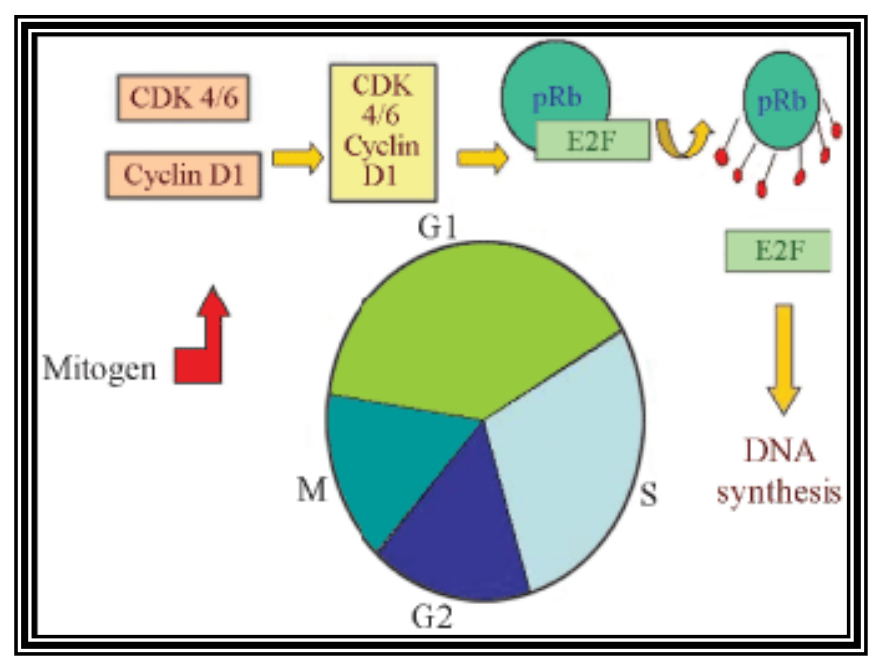


Figura 2 - Ativação do complexo ciclina D1CDK durante a fase $\mathrm{Gl}$ do ciclo celular (Adaptado de Tajara, 2004).

A ciclina $\mathrm{E}$ é expressa mais tarde em $\mathrm{G} 1$ e sua ligação à CDK2 faz-se importante para a transição G1-S e para o início da duplicação do DNA. Os complexos CDK2 - ciclina-A também participam da iniciação da síntese de DNA e da progressão da fase $\mathrm{S}$, enquanto a transição G2-M depende de CDK1 e ciclina B.

As CDK são muito conservadas na escala evolutiva e sua ativação compreende o evento central nas transições das diferentes etapas do ciclo celular. A sua regulação é determinada por quatro mecanismos moleculares básicos: a formação periódica de complexos CDK-ciclina, que é controlada pela síntese e degradação de seus componentes, por fosforilação e desfosforilação das CDK e pela ação de proteínas inibidoras de CDK (Tajara EH, 2004).

A ciclina D1 é codificada pelo gene CCND1 localizado no cromossomo 11q (Han S et al., 1999). Esta proteína atua no ciclo celular acelerando a fase $\mathrm{Gl}$ e foi descrita como um oncogene em 1991 por Motokura T et al., o qual observou que o aumento da ciclina desregula o ciclo celular e contribui para gênese do tumor. A ciclina D1 é um regulador do ciclo celular, cujo gene localiza-se na região 11q13, essencial para a progressão da fase G1 (Kastan MB et al., 2001), torna-se ativa após sua ligação com CDK4 ou CDK6. A função regulatória desses complexos ciclina D1/CDK ocorre através da fosforilação da proteína do retinoblastoma ( $p R b)$, inibe o ciclo celular e impede que a célula entre na fase $\mathrm{S}$. Quando fosforilada, a pRb se torna inativa e permite a dissociação do complexo E2F/Rb, possibilitando a progressão do ciclo celular.

A perda do gene do retinoblastoma está relacionada com diversos tipos de câncer, tais como osteossarcoma, carcinoma pulmonar de pequenas células, carcinoma de próstata, carcinoma 
de mama, alguns tipos de leucemia, carcinoma uterino e o próprio retinoblastoma, no qual foi inicialmente identificada a perda deste gene (Herwig $S$ et al., 1997). Existem outros fatores que participam dessa cadeia de regulação celular. O complexo ciclina D1-CDK é regulado negativamente pela p16, cuja inativação ou ausência é detectada em muitos tumores. Além disso, o gene supressor tumoral TP53 inibe a ciclina D1.

Fracchiolla et al. (1997), em 58 pacientes com câncer da laringe, constataram que em cerca de $40 \%$ desses casos ocorre aumento da expressão de ciclina D1 e, quando existem metástases para linfonodos, este número aumenta para aproximadamente $60 \%$.

\subsubsection{A ATI VAÇÃO DOS COMPLEXOS CDK-CICLINA}

A ativação das quinases depende de sua interação com as ciclinas, além da fosforilação de diferentes resíduos. A interação com as ciclinas induz mudanças conformacionais nas CDK, que resultam no deslocamento de um segmento de sua molécula, denominado alça $\mathrm{T}$, e traz para o sítio ativo um resíduo essencial para a função enzimática. A ativação do complexo depende ainda da fosforilação da treonina 160/161, da alça T e da desfosforilação dos resíduos de treonina-14 e tirosina-15 próximos ao terminal amino. A fosforilação da treonina 160/161 é catalisada por uma enzima (CAK ou CDK-activating kinase), ela própria formada por uma CDK (CDK7) e pela ciclina H. Essa enzima representa um importante fator de conexão entre os eventos do ciclo celular, a expressão gênica e o reparo do DNA, pois é um dos componentes 
do fator de transcrição TFIIH que trabalha na transcrição basal bem como no reparo por excisão (Araujo SJ et al., 2000).

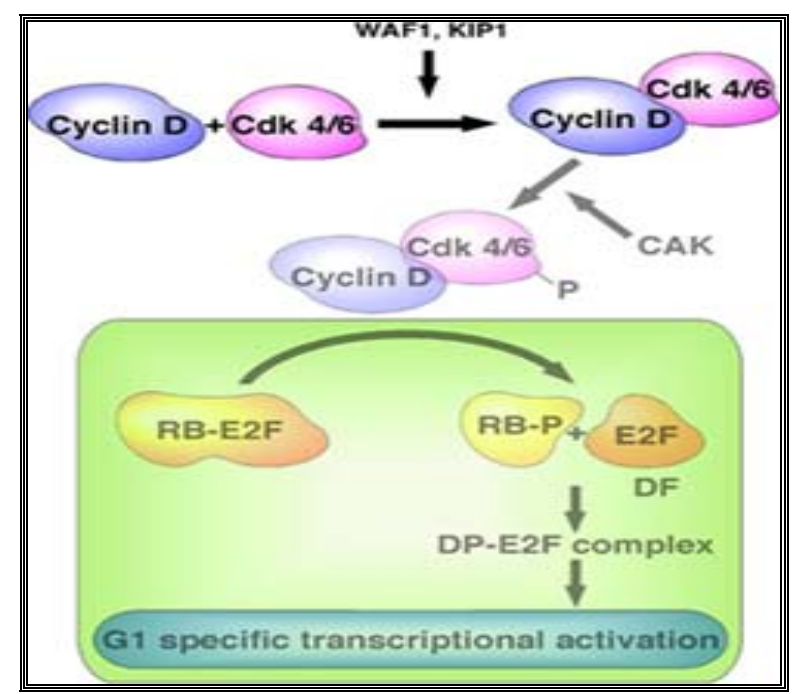

Figura 3 - Formação dos complexos ciclina D e CDK4/6 (Adaptado de LaBaer).

A desfosforilação dos resíduos de treonina-14 e tirosina-15, por sua vez, ocorre quando a atividade de fosfatases da família CDC25 ( $\mathrm{A}, \mathrm{B}$ e C) excede aquela das enzimas com função oposta, a Weel e a Myt1.

\subsubsection{A DEGRADAÇÃO DAS CI CLI NAS}

As ciclinas são proteínas instáveis, sendo necessárias apenas por períodos curtos de tempo (Keyomarsi K, 2002). No caso específico das ciclinas $\mathrm{D}$ a degradação é rápida, assim, sua concentração intracelular cai rapidamente se os fatores de crescimento forem removidos, o que revela uma integração 
eficiente dos sinais mitogênicos com a maquinaria do ciclo celular. No processo de degradação, tanto na transição G1-S como nas fases G2 e mitose, ocorrem eventos de proteólise iniciados pela adição, por meio de ligases, de cadeias de ubiquitina às moléculas de ciclinas, que são então degradadas pelo proteassomo 26S. Um importante sinal para degradação, conhecido como box de destruição, é encontrado em ciclinas mitóticas e em outros reguladores do ciclo celular. Esse box é formado por nove aminoácidos e é geralmente localizado 40 a 50 resíduos distante do $\mathrm{N}$ terminal (Ciechanover A, 1998).

Considerando seu importante papel no ciclo celular, não causa surpresa o fato de que muitos tumores mostram mutações que levam à expressão contínua das ciclinas ou à inativação de seus inibidores (Spruck CH et al., 2002).

\subsubsection{CICLINA D1}

A presença da ciclina D1 tem sido demonstrada por imunoistoquímica no câncer de cabeça e pescoço, e quanto maior sua expressão menor a sobrevida dos pacientes, sendo assim considerada um fator de prognóstico por muitos pesquisadores, em carcinomas de esôfago, mama, cérvix uterino, cólon, reto e melanomas (Quon H et al., 2001).

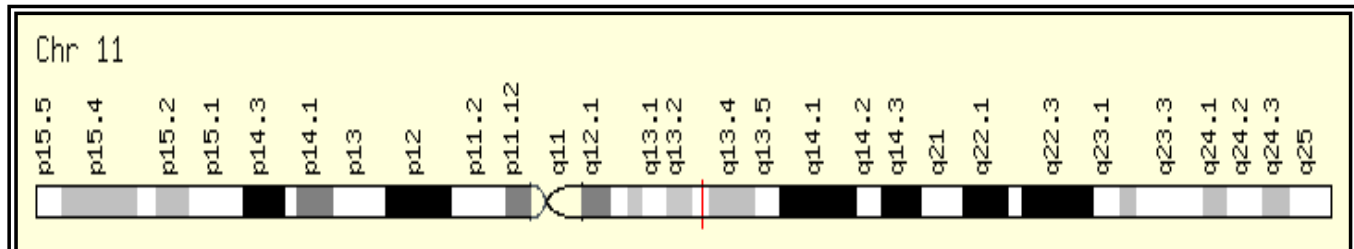

Figura 4 - Mapeamento da posição 11q13.3 do cromossomo 11 
A proteína ciclina $D 1$, depois que forma complexos com as proteínas CDK4 e CDK6, tem como principal função fosforilar a proteína retinoblastoma. Após sua fosforilação, a proteína libera um fator de transcrição, o E2F, que leva a célula à progressão da fase G1 para fase S do ciclo celular. A proteína c-jun, que faz parte do fator de transcrição AP-1, tem participação ativa no ciclo celular, principalmente durante a transcrição da fase G0 a G1. O gene retinoblastoma é um supressor de tumor. Este gene codifica uma fosfoproteína nuclear, que recebe o mesmo nome.

Essa proteína regula o ciclo celular através de múltiplas funções. Também regula outros processos que afetam a proliferação celular, a diferenciação terminal e a apoptose.

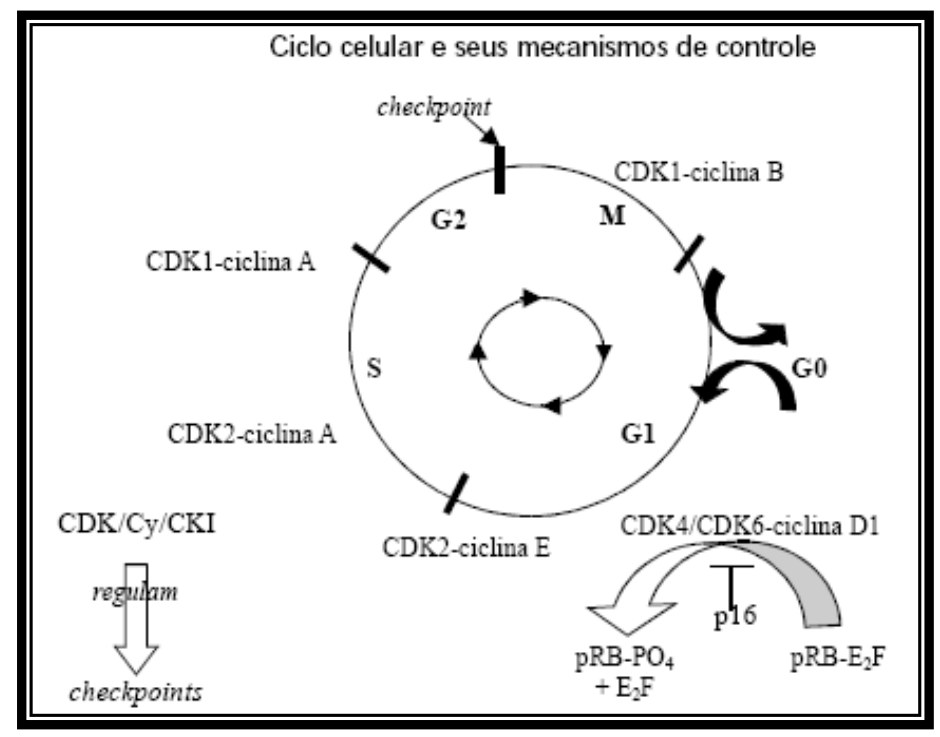

Figura 5 - Representação esquemática do ciclo celular. Em cada ciclo os cromossomos são replicados (fase $\mathrm{S}$ ou síntese do DNA) e segregados para criarem duas células filhas idênticas (fase $M$ ou mitose). Estes eventos são espaçados por intervalos de crescimento e reorganização (fases G1 e G2). As células podem sair do ciclo após a divisão e entrar em estado de quiescência $(\mathrm{G} 0)$. O ciclo celular é regulado por numerosos complexos CDK-ciclina, como indicado acima (Adaptado de Collins et al.) e descrito no texto. 
Em cada ciclo os cromossomos são replicados (fase $\mathrm{S}$ ou síntese do DNA) e segregados para criarem duas células filhas idênticas (fase $M$ ou mitose). Estes eventos são espaçados por intervalos de crescimento e reorganização (fases G1 e G2). As células podem sair do ciclo após a divisão e entrar em estado de quiescência (G0) (Collins K et al., 1997).

Amplificações, e conseqüente expressão exacerbada da ciclina D1, foram relatadas em 30 a $50 \%$ dos cânceres de cabeça e pescoço e têm sido relacionadas à progressão do tumor, recidiva, metástase ou óbito (Michalides R et al., 1995).

Mapeado no braço longo do cromossomo 11, o CCND1 transcreve a ciclina D1. A ativação dessa proteína inibe a transcrição de vários genes supressores de tumor, como o CDKN2A e o RB1, permitindo, portanto, a progressão do ciclo celular (Gleich LL et al., 2002).

Segundo Aburad AT (2006), cerca de 12 a 68\% dos pacientes com câncer bucal apresentaram aumento de expressão de ciclina D1.

O gene da ciclina D1 (CCND1) codifica a ciclina D1, que é expressa em resposta a sinais mitogênicos promovendo a transição através do ponto de restrição na fase G1 do ciclo celular (Scherr CJ, 1994).

Aumento da expressão da ciclina D1 tem sido associado a aumento de proliferação celular (Quelle DE et al., 1993; Musgrove et al., 1994). A amplificação do CCND1 levando a desregulação de 
sua expressão é comum em tumores de cabeça e pescoço (Callender T et al., 1994; Jares $P$ et al., 1994).

Outros estudos têm demonstrado que a superexpressão de ciclina D1 está associada a pior prognóstico em câncer primário de hipofaringe, esôfago e cavidade oral (Masuda $M$ et al., 1995; Pignatora L et al., 1998; Ishikawa T et al., 1998; Nakashima T et al., 2000).

Holley et al., em 2001, ao analisarem o polimorfismo do gene da ciclina D1 em carcinoma escamoso de cabeça e pescoço concluíram que o gene CCND1 é importante no desenvolvimento do CEC de cabeça e pescoço e tem potencial tanto como fator prognóstico, como adjuvante no desenvolvimento de terapia célulaalvo, ao demonstrar a importância dos alelos CCND1 G/C1722 como marcadores prognósticos independentes em CEC de cabeça e pescoço.

Em 2005, Pruneri $G$ et al. ao avaliarem o papel das ciclinas, mormente da ciclina D3, na oncogênese laríngea, concluíram que a imunorreatividade, possivelmente devido à ocorrência de cópias extras de genes, pode representar um fator prognóstico adjunto em CEC laríngeo, além de contribuir para identificar as ciclinas tipo D como potenciais alvos no desenvolvimento de novas terapias.

A superexpressão de ciclina D1 tem sido detectada em 35$64 \%$ dos carcinomas epidermóides de cabeça e pescoço (Nagasawa S, 2001; Callender T, 1994; Jones P, 1994; Michalides R, 1995; Fracchiolla NS, 1997), com diferenças bastante significativas entre tumores de sítios distintos; além disso, a superexpressão de ciclina D1 tem sido relacionada ao desenvolvimento de segundo tumor primário no trato aerodigestivo superior. 
Há estudos de autores que têm encontrado correlação entre a expressão da ciclina D1, recidiva loco-regional e sobrevida em carcinoma de cabeça e pescoço (Bova RJ, 1999; Mineta H, 2000).

Apenas um número reduzido de estudos foi direcionado à investigação da importância clínica da superexpressão da ciclina D1, e os dados aferidos são díspares entre si. Em estudo retrospectivo de 102 pacientes, Dong et al. (2001) concluíram que a superexpressão foi significativamente associada com o sítio e dimensões do tumor primário, metástase linfática, estádio clínico avançado e sobrevida global limitada, a análise multivariada demonstrou ser este um fator preditivo independente de sobrevida livre de doença (Fuji M, 2002).

Em 2004, resultados semelhantes foram obtidos por Krecicki et al., e Bellacosa et al. (1996), que encontraram relação significante entre amplificação da expressão da ciclina D1 e sobrevida global reduzida.

Wang et al., em 1998, desenvolveram estudo imunoistoquímico sobre a expressão de ciclina D1 em 92 pacientes com carcinoma laríngeo, e encontraram níveis elevados naqueles que evoluíram com recidiva local.

Ao contrário, em 2004, Ioachim et al. não encontraram diferenças significativas entre risco de recidiva, bem como sobrevida, em tumores com expressão positiva ou negativa, tanto em análise univariada como em análise multivariada; entretanto os níveis de ciclina D1 eram mais elevados no carcinoma invasivo que nas apresentações in situ. Resultados semelhantes foram obtidos por El-Naggar et al. (1999) e Vielba et al. (2003), embora os 
primeiros tenham estudado carcinoma de boca e laringe em conjunto.

De Falco et alli (2004) ao analisarem a expressão subcelular da ciclina D1, através de Western Blot, descreveram que a ciclina D1 apresentou vasta distribuição em tecidos de ratos adultos, sendo seu nível de expressão tecido-dependente. A imunoistoquímica demonstrou ainda que a ciclina D1 pode estar presente no citoplasma, no núcleo ou em ambos os compartimentos celulares. Expressão citoplasmática foi observada tanto em tecidos em proliferação (p.ex.: rim, intestino, estômago e glândula salivar), como em neurônios maduros de encéfalo; enquanto a expressão nuclear foi observada notadamente nos neurônios do sistema nervoso embrionário. Os resultados obtidos por microscopia eletrônica indicaram que, em tecidos em que a ciclina D1 foi encontrada nos dois compartimentos (p.ex.: enterócitos intestinais), poderia haver migração através dos poros nucleares do núcleo para o citoplasma e vice-versa.

Conforme De Falco, os achados sugerem que a ciclina D1 pode exercer múltiplos papéis específicos por tipo de tecido, possivelmente interagindo com substratos diferentes, e que este trânsito entre núcleo e citoplasma pode auxiliar na manutenção da homeostase celular.

Segue-se tabela com resultados compilados de estudos de expressão de ciclina D1.

Tabela 1 - Dados compilados de estudos sobre a expressão de ciclina D1 e influência sobre metástases linfática e/ou sobrevida. 


\begin{tabular}{|c|c|c|c|c|c|}
\hline & & & $\begin{array}{c}\text { em Ciclina } \\
\text { D1 }\end{array}$ & & \\
\hline $\begin{array}{l}\text { Callender et al, } \\
1994\end{array}$ & 32 & $\begin{array}{c}\text { Southern } \\
\text { Blot }\end{array}$ & $34 \%$ & & \\
\hline Meredith et al, 1995 & 56 & $\begin{array}{c}\text { Southern } \\
\text { Blot }\end{array}$ & $39 \%$ & Sobrevida & $\begin{array}{c}\text { Piora com } \\
\text { superexpressão }\end{array}$ \\
\hline $\begin{array}{l}\text { Bellacosa et al, } \\
1996\end{array}$ & 51 & $\begin{array}{c}\text { Southern } \\
\text { Blot }\end{array}$ & $18 \%$ & Sobrevida & $\begin{array}{c}\text { Piora com } \\
\text { superexpressão }\end{array}$ \\
\hline Masuda et al, 1996 & 42 & IHQ & $55 \%$ & Sobrevida & Piora \\
\hline Akervall et al, 1997 & 75 & IHQ & $12 \%$ & Sobrevida & Piora \\
\hline $\begin{array}{l}\text { Capaccio et al, } \\
1997\end{array}$ & 96 & IHQ & $44 \%$ & $\begin{array}{l}\text { Metástase } \\
\text { linfática }\end{array}$ & Mais freqüente \\
\hline Fortin et al, 1997 & 50 & $\begin{array}{c}\text { Southern } \\
\text { Blot }\end{array}$ & $20 \%$ & Sobrevida & $\begin{array}{l}\text { Não houve } \\
\text { correlação }\end{array}$ \\
\hline $\begin{array}{l}\text { Kyomoto et al, } \\
1997\end{array}$ & 45 & IHQ & $53 \%$ & Sobrevida & Piora \\
\hline $\begin{array}{l}\text { Michalides et al. } \\
1997\end{array}$ & 115 & IHQ & $49 \%$ & Sobrevida & Piora \\
\hline Muller et al., 1997 & 201 & $\begin{array}{c}\text { Southern } \\
\text { Blot }\end{array}$ & $58 \%$ & Sobrevida & $\begin{array}{l}\text { Não houve } \\
\text { correlação }\end{array}$ \\
\hline $\begin{array}{l}\text { Pignataro et al., } \\
1998\end{array}$ & 149 & IHQ & $32 \%$ & Sobrevida & Piora \\
\hline Bova et al., 1999 & 147 & IHQ & $68 \%$ & Sobrevida & Piora \\
\hline Gleich et al., 1999 & 24 & $\begin{array}{c}\text { Southern } \\
\text { Blot }\end{array}$ & $42 \%$ & Sobrevida & $\begin{array}{l}\text { Não houve } \\
\text { correlação }\end{array}$ \\
\hline
\end{tabular}




\begin{tabular}{|c|c|c|c|c|c|}
\hline Okami et al., 1999 & 11 & FISH & $36 \%$ & & \\
\hline Gleich et al., 1999 & 24 & $\begin{array}{c}\text { Southern } \\
\text { Blot }\end{array}$ & $42 \%$ & Sobrevida & $\begin{array}{l}\text { Não houve } \\
\text { correlação }\end{array}$ \\
\hline $\begin{array}{l}\text { Koontongkaew et } \\
\text { al., } 2000\end{array}$ & 53 & IHQ & $40 \%$ & & \\
\hline Mineta et al., 2000 & 94 & IHQ & $19 \%$ & Sobrevida & Piora \\
\hline $\begin{array}{l}\text { Nakahara et al., } \\
2000\end{array}$ & 78 & IHQ & $36 \%$ & & \\
\hline
\end{tabular}

As ciclinas são sintetizadas imediatamente antes de sua atuação no ciclo celular e, após sua ação, seus níveis decrescem abruptamente por ubiquitinação (De Falco e Giordano, 1998; Simone e Giordano, 2001). As ciclinas-D, em particular, funcionam como sensores do meio extracelular que ligam as vias mitogênicas à maquinaria do ciclo celular (Ciemerych et al., 2002). Uma vez induzidas, as ciclinas-D associam-se as CDK4 e CDK6 conduzindo a fosforilação e subseqüente inativação do gene de supressão tumoral do retinoblastoma (Mac Lachlan et al., 1995). A superexpressão da ciclina D1 contribui para as transformações oncogênicas de células in vitro e in vivo (Fu et al., 2004) e a ciclina D1 é seletivamente induzida em neurônios pós-mitóticos em curso de autólise (Sumrejkanchanakij et al., 2003).

Segundo Alao JP et al. (2006), a ciclina D1 demonstrou por abordagens experimentais distintas ser uma proteína predominantemente citoplasmática quando avaliada em carcinoma de mama de diferentes tipos histológicos. Os dados aferidos 
suportam ainda que o seqüestro citoplasmático da ciclina D1 pode resultar da inibição de sua importação nuclear.

Sumrejkanchanakij, 2003; Alt, 2000; Ino, 2001 apud Alao têm sugerido através dos resultados obtidos em seus estudos que o seqüestro citoplasmático da ciclina D1 previne a apoptose em células nervosas.

Em estudo que investigou a relação entre o pleomorfismo do gene CCND1 A870G e amplificação com desenvolvimento e progressão de CEC laríngeo, considerando as implicações da localização do tumor e associação com tabagismo, a partir de uma população de 66 pacientes com câncer laríngeo, não houve relação entre amplificação e estádio, grau de diferenciação, recidiva ou sobrevida livre de doença; entretanto, outro genótipo (GG870) foi associado a menor intervalo livre de doença e sobrevida global reduzida (Monteiro et al. 2004). Outrossim, esta constitui a primeira descrição de correlação entre o polimorfismo e aumento da suscetibilidade para o desenvolvimento de tumor laríngeo na região glótica, o que subsidia a teoria da prevalência sítioespecífica das alterações genéticas. 
4. Métodos 


\section{MÉTODOS}

Faz-se mister assinalar que:

O presente estudo foi aprovado pelo Comitê de Ética em Pesquisa do Hospital São Marcos - Associação Piauiense de Combate ao Câncer (Protocolo de pesquisa no. 0401/07) (Apêndice I).

O presente estudo foi aprovado pela Comissão de Ética para Análise de Projetos de Pesquisa da Faculdade de Medicina da Universidade de São Paulo (Protocololo de pesquisa no. 1070/07) (Apêndice II).

O estudo está em conformidade com os itens III.3.i e II.3.t das Diretrizes e Normas Regulamentadoras de Pesquisas envolvendo Seres Humanos (Resolução CNS 196/96), bem como as Diretrizes Éticas Internacionais para Pesquisas Biomédicas Envolvendo Seres Humanos (CIOMS, 1993).

Foram respeitados os princípios enunciados na Declaração de Helsinki (World Medical Association, 1996), mantendo-se em sigilo a identidade dos pacientes, cujos dados foram identificados apenas pelo número de registro no projeto.

Todos os pacientes elegíveis, ou seu representante instituído, foram previamente esclarecidos e convidados a participar, de modo voluntário, deste estudo. Foram informados da intenção da pesquisa, dos métodos empregados, dos direitos a sigilo e de exclusão a qualquer tempo. 
O aluno contou com Bolsa de Estudo para Doutorado da Coordenação para Aperfeiçoamento de Pessoal de Nível Superior (CAPES).

Não houve durante a elaboração do presente estudo, e nos dois anos anteriores à data de seu início, quaisquer relações ou expedientes que incorressem em conflito de interesses.

\subsection{CASUÍ STI CA E DESENHO DO ESTUDO}

Trata-se de estudo retrospectivo, coorte longitudinal para a análise da ocorrência de metástase linfática e de sobrevivência global, em pacientes consecutivos.

Foram elegíveis para o estudo, pacientes portadores de neoplasia localmente avançada de laringe (estádios III ou IV), tratados por cirurgia radical padronizada, a saber, laringectomia total e esvaziamento cervical seletivo ou radical, no período de 1999 a 2004, no Hospital São Marcos - Associação Piauiense de Combate ao Câncer.

O estádio da doença foi determinado seguindo as recomendações da U.I.C.C. (2004) considerando os dados clínicos, radiológicos, anatomopatológicos e os achados intra-operatórios para determinar os parâmetros $\mathrm{T}$, $\mathrm{N}$ e $\mathrm{M}$ (Anexo H).

Todos os pacientes, em qualquer estádio da doença, foram submetidos a seguimento ambulatorial por médico-assistente do serviço de Cirurgia de Cabeça e Pescoço do Hospital São Marcos Associação Piauiense de Combate ao Câncer. 
Os sujeitos da pesquisa haviam sido submetidos à ressecção do tumor primário e esvaziamento cervical. A cirurgia dos linfonodos cervicais incluiu pacientes que clinicamente não apresentavam metástases (N0), submetidos então a esvaziamentos cervicais laterais, e pacientes que, por exame físico ou subsidiário, apresentavam linfonodos cervicais sob suspeição de metástase (N1-3), candidatos estes a esvaziamentos cervicais radicais modificados ou clássicos.

A pesquisa da expressão da ciclina D1 foi realizada em lâminas histológicas obtidas do tumor primário.

Em retrospectiva, foram revisados os prontuários com coleta de dados clínicos admissionais (Anexo A), coleta de dados do exame anatomopatológico da peça cirúrgica (Anexo B) e evolução pós-operatória (Anexo C). Os dados de anamnese, exame físico, exames laboratoriais, exames radiológicos, exames endoscópicos, descrição cirúrgica, achados intra-operatórios, terapêutica adjuvante e seguimento foram obtidos da revisão desses prontuários arquivados no serviço de prontuários do Hospital São Marcos - Associação Piauiense de Combate ao Câncer. Quando o paciente havia perdido o seguimento, foi convidado, por contato telefônico, a retornar para seguimento adequado na clínica de origem. História clínica detalhada de todos os pacientes incluídos na casuística, em que não houve perda de seguimento, foi obtida de arquivo nosológico uni-institucional.

O estadiamento TNM seguiu rigorosamente a classificação orientada pela União Internacional de Combate ao Câncer (2004). 


\subsection{CRITÉRIOS DE ELEGI BI LI DADE E EXCLUSÃO.}

Entre os critérios gerais de inclusão, considerou-se a confirmação do diagnóstico histológico de carcinoma epidermóide de laringe no tumor primário, assim como a disponibilidade dos dados referentes ao tratamento cirúrgico e dados para elucidação do estadiamento inicial. Incluíram-se os casos que atendiam aos critérios para classificação em estádios III ou IV.

Foram excluídos os casos cujos blocos de espécimes ressecados não possuíam mais área de tecido representativa de carcinoma epidermóide.

Foram excluídos do estudo os casos que apresentavam uma ou mais das seguintes situações:

- História de tumores prévios

- Terapia prévia (quimioterapia e radioterapia)

- Pacientes cujos dados de prontuário estavam incompletos

- Impossibilidade de definir o estadiamento clínico

- Ocorrência de tumor sincrônico

- Margem cirúrgica comprometida

- Não consentimento do sujeito da pesquisa ou seu representante legal após esclarecimento.

Os casos elegíveis foram separados em dois grupos: (1) com diagnóstico de metástase linfática confirmado por exame anatomopatológico e (2) sem metástase linfática (ausência clínica, radiológica ou anatomopatológica de metástase linfática). 


\subsection{ESTUDO ANATOMOPATOLÓGI CO}

Os exames histopatológicos dos espécimes ressecados haviam sido realizados por médico patologista experiente do Departamento de Patologia do HSM-APCC. A graduação histológica foi realizada de acordo com os critérios propostos por Broders AC (1926). Foram avaliadas ainda a localização e profundidade de invasão do tumor primário, a ocorrência e o número de linfonodos comprometidos por metástase, invasão angiolinfática e perineural, infiltrado inflamatório perineural e estadiamento TNM (Anexo B).

Os fragmentos do tumor primário emblocados em parafina foram recuperados no Departamento de Patologia do HSM-APCC e lâminas com coloração de hematoxilina-eosina, referentes a cada um dos blocos, foram reexaminadas por microscopia óptica, de forma independente, por dois médicos patologistas do Departamento de Patologia do HSM-APCC para seleção de material adequado à análise imunoistoquímica.

\subsection{ESTUDO I MUNOI STOQUÍ MI CO}

\subsubsection{TÉCNI CA DE COLORAÇÃO}

Após a confirmação da presença de tecido tumoral, pela análise das lâminas com coloração por hematoxilina-eosina, foram obtidos novos cortes de cada um dos blocos para realização de reação de imunoistoquímica com anticorpos anti-ciclina D1, desta feita no Laboratório de Imunoistoquímica da Consultoria em Patologia do Dr. Carlos Bacchi. A partir dos blocos de parafina obtidos no Departamento de Patologia do HSM-APCC, foram 
preparadas lâminas contendo cortes de tecido com espessura de 3 $\mu \mathrm{m}$.

As lâminas haviam sido coradas com hematoxilina-eosina conforme descrição que se segue: repousaram em álcool a 95\% por 20 minutos, foram lavadas em baixo fluxo de água corrente, expostas à hematoxilina por 20 segundos, novamente lavadas em baixo fluxo de água corrente e descansaram em cuba com água por cinco minutos, a seguir, foram expostas à eosina por 20 segundos, lavadas em água corrente, passaram então por cinco baterias de álcool a 99,5\% para retirar o excesso de corante, e, por fim, passagem por três fases de xilol.

A análise imunoistoquímica de ciclina D1 foi processada a partir de blocos de tecido fixados em formalina-parafina, sendo utilizada a técnica de peroxidase, método do polímero (ENVISIONDAKO ${ }^{\circledR}$ ), e cortes de $3 \mu \mathrm{m}$, submetidos aos anticorpos anti-ciclina D1 (Neomarkers ${ }^{\circledR}$ ) em diluição de 1:100. Como controle externo negativo, foi utilizada lâmina, que passou por todas as fases da reação, sem receber o anticorpo primário, e linfonodo com hiperplasia reacional foi utilizado como controle externo positivo.

\subsubsection{TÉCNI CA DE I MUNOMARCAÇÃO DA CICLI NA D1}

\subsubsection{SI LANI ZAÇÃO}

Antes de colocar os cortes de tecido, as lâminas haviam sido imersas em cuba contendo acetona durante dois minutos, em seguida imersas em cuba contendo APTS (Sigma A3648) a $4 \%$ por dois minutos, novamente, imersas em cuba com acetona por quatro vezes e, por fim, secadas em estufa. 


\subsubsection{DESPARAFI NI ZAÇÃO}

As lâminas contendo cortes de tecido foram então colocadas em xilol durante 20 minutos, em estufa aquecida a $60 \stackrel{\circ}{ }$. Posteriormente as lâminas foram submetidas a banho de xilol frio por três vezes com duração de um minuto cada banho. Em seqüência, as lâminas passaram por quatro cubas contendo xilol, durante cinco minutos cada, passaram por quatro cubas contendo álcool etílico, repousaram por cinco minutos em uma cuba contendo tampão PBS, foram submetidas a duas cubas contendo PBS com $\mathrm{H}_{2} \mathrm{O}_{2} 3 \%$ _ cinco minutos cada, e, por fim, passaram por uma cuba contendo PBS para, posteriormente, iniciar a recuperação antigênica.

\subsubsection{RECUPERAÇÃO ANTI GÊNI CA, REAÇÃO COM ANTI CORPOS PRI MÁRIO E SECUNDÁRIO, E CONTRACOLORAÇÃO.}

As lâminas foram posicionadas em suportes contendo tampão Trizma $^{\circledR} 0,61 \%$ pH 10.00 (Trizma Base T $1503^{\circledR}$ - Sigma). Colocou-se a cuba no vaporizador e incubou-se durante 40 minutos, após estar aquecido. Ao término do tempo prédeterminado, foi mantida em temperatura ambiente por aproximadamente 20 minutos. Após este período, retiraram-se as lâminas da cuba contendo $\operatorname{Trizma}^{\circledR}$, foram colocadas nas bandejas e gotejou-se PBS sobre as lâminas. O excesso de PBS foi retirado e instilado o anticorpo primário Cyclin-D1 (clone SP4) Neomarkers ${ }^{\circledR}$, diluído em 1:100, a seguir manteve-se em incubação por toda a noite a $4-8 \stackrel{\circ}{\circ}$. 
Conforme procedimento padronizado, seguiu-se:

As lâminas expostas ao PBS foram lavadas com Tween, aspirou-se o excesso de PBS e foi instilado o anticorpo secundário Envision Rabbit ${ }^{\circledR}$ (Ref. K4003-Dako ${ }^{\circledR}$ ). Em temperatura ambiente, foram então encubadas por 45 minutos. As lâminas impregnadas por PBS foram novamente lavadas com Tween ${ }^{\circledR}$, o excesso de PBS foi aspirado, e em seguida foi instilado o DAB (Diaminobenzidine tetra-hydrochloride - Ref. D-5637 - Sigma ${ }^{\circledR}$ ). O DAB empregado nas amostras foi preparado utilizando-se $10 \mathrm{ml}$ de Trizma ${ }^{\circledR}, 10 \mathrm{mg}$ de cromógeno $\mathrm{DAB}$ e $0,2 \mathrm{ml}$ de $\mathrm{H}_{2} \mathrm{O}_{2} 10 \%$. As lâminas, após terem recebido o DAB, foram incubadas durante cinco minutos; em seguida, foram lavadas abundantemente com água destilada, contracoradas com hematoxilina, destacadas em água amoniacal, desidratadas em seis cubas com álcool etílico absoluto, passadas em três cubas contendo xilol e, por último, montadas com resina Permount $^{\circledR}$.

\subsubsection{ANÁLI SE SEMI QUANTITATI VA DA I MUNOEXPRESSÃO CITOPLASMÁTI CA DA CI CLI NA DI.}

A análise semiquantitativa teve como parâmetros a intensidade e a quantidade da coloração na região considerada mais representativa da reação de imunoistoquímica (hot spot). A intensidade da coloração foi classificada em ausente, moderada (valor 1) e intensa (valor 2). O número de células com expressão citoplasmática foi classificado em ausente, abaixo de 10\% (valor 1 ), entre 10 e $50 \%$ de expressão (valor 2 ) e além de $50 \%$ (valor 3 ) (Perez RO, 2006). 
Associando os dois resultados, a classificação seguiu a ordem seguinte: negativo quando não houve células coradas; positivo 1 (+) quando houve células ocasionais positivas independente de sua intensidade; positivo $2(++)$ quando houve até $10 \%$ das células coradas com intensidade moderada; positivo $3(+++)$ quando houve até $10 \%$ das células coradas com intensidade elevada (valor 2) ou até $50 \%$ das células coradas com intensidade moderada ou alta, ou ainda, mais que $50 \%$ das células coradas em intensidade moderada; e positivo $4(++++)$ quando mais de $50 \%$ de expressão citoplasmática de alta intensidade (Perez RO, 2006).

Tabela 2 - Dados quantitativos e qualitativos para avaliação semiquantitativa da imunoexpressão de ciclina D1.

\begin{tabular}{||lllc||}
\hline Fração de células & \multicolumn{3}{c||}{ Intensidade de coloração } \\
& Ausente & Moderada & Alta \\
Nenhuma & Negativo & Negativo & Negativo \\
Ocasionais & Negativo & Positivo 1 & Positivo 2 \\
Até 10\% & Negativo & Positivo 2 & Positivo 3 \\
10 a 50\% & Negativo & Positivo 3 & Positivo 3 \\
$>50 \%$ & Negativo & Positivo 3 & Positivo 4 \\
\hline
\end{tabular}

Legenda: grafia sem destaque - baixa expressão; grafia em negrito - alta expressão. 
Conforme a classificação discriminada, considerou-se superexpressão da ciclina D1 apenas os casos classificados como positivo 3 e positivo 4; outrossim, a expressão baixa foi considerada quando os casos foram classificados em positivo 1 ou positivo 2 .

\subsubsection{QUANTI FI CAÇÃO DI GITAL DA I MUNOEXPRESSÃO NUCLEAR E CI TOPLASMÁTI CA DA CI CLI NA D1.}

Para a captura digital da imagem dos campos microscópicos, em aumento de 400x, foram realizadas fotomicrografias de $640 \times 480$ pixels, em 20 campos consecutivos e não coincidentes por lâmina, com câmera digital (Stabenow E, 2006).

Para a contagem das células coradas utilizou-se o sistema de processamento e análise digital de imagem Imagelab ${ }^{\circledR}$, versão 2.3, calibrado para utilizar a escala em micrômetro, desenvolvido pela Softium ${ }^{\circledR}$ Informática Ltda., ambientado no sistema operacional Windows ${ }^{\circledR} 98 \mathrm{SE}$, e disponibilizado pelo programa de pósgraduação em Clínica Ginecológica da Universidade Federal do Piauí. Para tal, utilizou-se um microscópio de luz Nikon Eclipse E400 ${ }^{\circledR}$ com objetivas de 4 a $100 x$ e oculares de $10 x$, perfazendo aumentos de 40 a 1000x, acoplado a uma vídeocâmera digital Samsung ${ }^{\circledR}$ modelo SCC-131 que, ao captar a imagem por meio do modo video capture, transferia a imagem para o software I magelab ${ }^{\circledR}$, no qual se procedeu a avaliação das lâminas.

O microcomputador utilizado na contagem apresentava as seguintes configurações: placa-mãe INTEL ${ }^{\circledR}$ Pentium $^{\circledR}$ IV $3.2 \mathrm{GHz}$, processador de $512 \mathrm{MB}, 80 \mathrm{~GB}$ de memória RAM com placa digitalizadora. 
O menor aumento permitido pelo microscópio $(40 x)$ foi utilizado para selecionar as áreas de maiores concentrações de células coradas (hot spots). Selecionada a área em cada caso, procedeu-se a contagem das células coradas em um aumento de 400x, em um total de 1000 células contadas por lâmina.

Para a quantificação da imunoexpressão foi realizado o cálculo do índice de positividade (IP) das expressões nuclear e citoplasmática da ciclina D1.

\subsubsection{CÁlCULO DO Í NDI CE DE POSITIVI DADE (I P).}

As células malignas com citoplasma positivo e negativo foram manualmente indicadas em cada fotomicrografia digital. A contagem parcial e total foi simultaneamente realizada pelo programa Imagelab ${ }^{\circledR}$ com a análise de 1000 células malignas por caso. Assim determinou-se o total de imagens que foram analisadas em cada caso e o índice de positividade (IP) citoplasmático segundo a equação (Gundersen HJ et al., 1988):

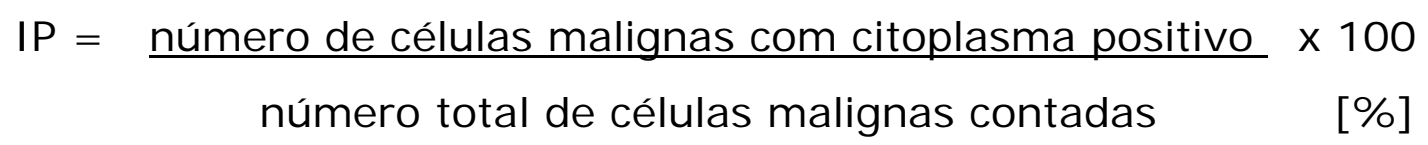

Para o cálculo do IP nuclear da ciclina D1, o mesmo expediente foi empregado.

Os núcleos positivos para a ciclina também foram marcados manualmente, nas mesmas fotomicrografias usadas para avaliação do IP citoplasmático, e contados de maneira semelhante. O IP nuclear foi calculado segundo a equação abaixo:

$I P=$ número de células malignas com núcleo positivo $\times 100$

número total de células malignas contadas 


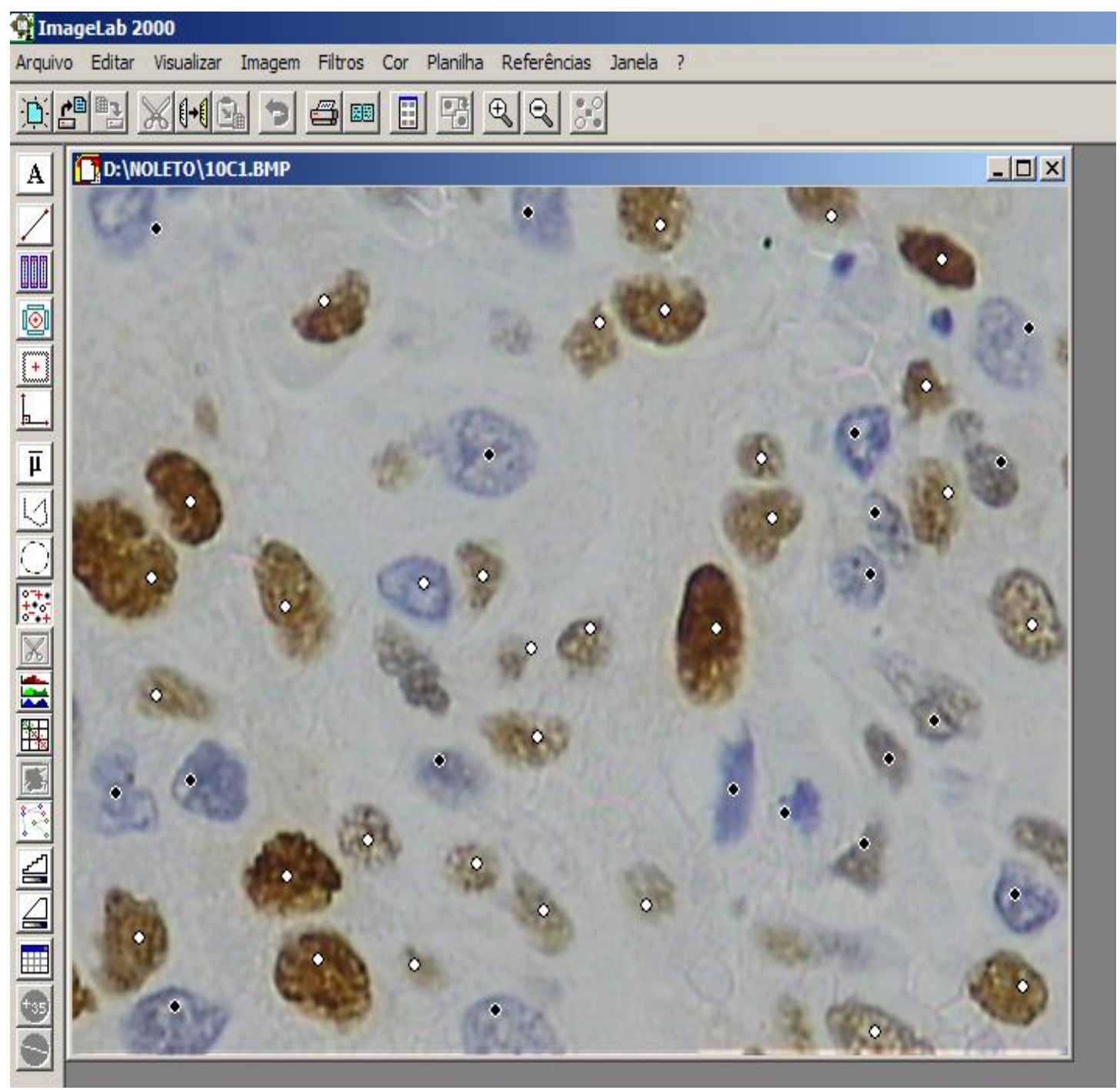

Figura 6 - Demonstração do uso do Imagelab $^{\circledR}$ na identificação manual de núcleos positivos (pontos brancos) e núcleos negativos (pontos pretos) para o cálculo do IP nuclear para ciclina D1. 


\subsection{ANÁLI SE ESTATÍ STI CA}

Os dados obtidos foram organizados e tabulados em planilhas do programa Excel ambientado em Windows XP (Microsoft ${ }^{\circledR}$ ).

Para a análise estatística, os dados foram processados e analisados com o auxílio do programa BioEstat 4.0.

A escolha das medidas de tendência central e dispersão dos valores que compõem as amostras baseou-se nos tipos de distribuição: paramétricas ou não paramétricas.

Os valores obtidos pelo estudo de cada variável contínua de distribuição paramétrica foram organizados e descritos através da média e do desvio padrão, para as não paramétricas foram utilizadas a mediana e amplitude interquartis. Para as categorizadas utilizaram-se freqüências absolutas e relativas (Stabenow E, 2006).

A comparação das medianas, em populações não paramétricas, foi feita pelo teste de Mann-Whitney ou KruskalWallis.

A correlação entre dois parâmetros foi calculada usando o coeficiente de correlação de Pearson.

O tempo de sobrevida foi avaliado usando o método de Kaplan-Meier e o teste de Breslow foi utilizado para acessar a significância das variáveis de prognóstico. As mortes que não foram decorrentes do tumor primário, ou suas metástases, não foram consideradas como falha de tratamento e sim como observações censuradas.

Adotou-se o valor de significância estatística menor ou igual a $5 \%$. 


\section{RESULTADOS}

\subsection{RESULTADOS DESCRI TI VOS RELATI VOS À CASUÍ STI CA}

Ante os 49 pacientes de uma amostra inicial, a disponibilidade dos blocos de parafina contendo adequado tecido tumoral representativo de CEC laríngeo somente foi possível em 47 (100\%).

A formação do grupo (1) ocorreu até a completude de 19 $(40,2 \%)$ casos com metástase linfática oriunda de carcinoma epidermóide de laringe. O grupo (2) foi formado por 28 (59,8\%) casos sem metástase linfática, ajustados pela data da operação para abranger o mesmo período de recrutamento do grupo caso, perfazendo uma casuística de 47 (100\%) indivíduos.

As características epidemiológicas e clínicas pré-operatórias dos pacientes estão apresentadas na tabela 3.

Tabela 3 - Características clínicas e epidemiológicas da casuística.

\begin{tabular}{|c|c|}
\hline Variáveis & $\mathbf{n}$ \\
\hline Idade & \\
\hline$\geq 55$ & $42(89,3 \%)$ \\
\hline$<55$ & $5(10,6 \%)$ \\
\hline Média de idade & $\begin{array}{c}64 \pm 14,6 \\
\text { anos }\end{array}$ \\
\hline Sexo & \\
\hline Masculino & $43(91,4 \%)$ \\
\hline Feminino & $4(8,5 \%)$ \\
\hline
\end{tabular}




\begin{tabular}{|c|c|}
\hline \multicolumn{1}{|c|}{ Tabagismo } & \\
\hline \hline Sim & $45(95,7 \%)$ \\
\hline \hline Não & $2(4,2 \%)$ \\
\hline \hline Sintomas & $47(100 \%)$ \\
\hline \hline Disfonia & $31(65,9 \%)$ \\
\hline \hline Perda ponéia & $28(59,5 \%)$ \\
\hline \hline Tempo de sintomas & $4,6 \pm 1,9$ \\
& meses \\
\hline \hline
\end{tabular}

O estadiamento TNM (UICC) foi avaliado no atendimento inicial do paciente e após conclusão de estudo anatomopatológico, conforme segue transcrito em tabelas 4 e 5 .

Tabela 4 - Distribuição dos tumores segundo o estádio clínico.

\begin{tabular}{||c||c|}
\hline \hline Estádio & n \\
\hline \hline III & $26(55,4 \%)$ \\
\hline \hline IV & $21(44,6 \%)$ \\
\hline
\end{tabular}

Tabela 5 - Distribuição dos tumores segundo o estádio anatomopatológico.

\begin{tabular}{|c||c|}
\hline \hline Estadiamento UICC & $\mathbf{n}$ \\
\hline \hline III & $18(18,2 \%)$ \\
\hline \hline IV & $29(61,7 \%)$ \\
\hline
\end{tabular}


Os procedimentos cirúrgicos realizados nos 47 (100\%) pacientes estudados incluíram laringectomia total e esvaziamento cervical seletivo (níveis II, III e IV) unilateral em 31 (65,9\%) pacientes, laringectomia total e esvaziamento cervical seletivo bilateral em $2(4,2 \%)$ pacientes, laringectomia total e esvaziamento cervical radical clássico em 9 (19,1\%) pacientes, laringectomia total e esvaziamento cervical radical modificado em 4 $(8,4 \%)$, e laringectomia total em $1(2,1 \%)$ paciente. Em $3(6,3 \%)$ pacientes a ressecção do tumor primário envolveu a ressecção de glândula tireóide por suspeita de invasão por contigüidade.

As características anatomopatológicas dos tumores ressecados seguem compiladas na Tabela 6.

Tabela 6 - Características anatomopatológicas do carcinoma epidermóide da população estudada.

\begin{tabular}{|c||c|}
\hline \hline \multicolumn{1}{|c|}{ Variáveis } & $\mathbf{n}$ \\
\hline \hline Grau de diferenciação (Broders) & \\
\hline \hline G1 & $24(51 \%)$ \\
\hline \hline G3 & $12(25,5 \%)$ \\
\hline \hline Metástase linfática & $11(23,4 \%)$ \\
\hline \hline N0 & $28(59,5 \%)$ \\
\hline \hline N1-3 & $19(40,4 \%)$ \\
\hline \hline Invasão perineural & $28(59,5 \%)$ \\
\hline \hline Invasão vascular & $2(4,2 \%)$ \\
\hline \hline
\end{tabular}

Foram observados 7 (14,8\%) óbitos em decorrência de recidiva local, recidiva loco-regional ou metástase, e nenhum óbito por outras causas foi verificado. 
Tabela 7 - Evolução dos pacientes segundo estádio anatomopatológico.

\begin{tabular}{|l|c||c||c||}
\hline \hline Estádio & $\begin{array}{c}\text { Óbito por câncer } \\
\text { de laringe }\end{array}$ & $\begin{array}{c}\text { Câncer laríngeo } \\
\text { controlado }\end{array}$ & Total \\
\hline \hline III & $2(4,2 \%)$ & $16(34 \%)$ & $18(38,2 \%)$ \\
\hline \hline IV & $5(10,6 \%)$ & $24(51 \%)$ & $29(61,7 \%)$ \\
\hline
\end{tabular}

\begin{tabular}{|cc|}
\hline Parâmetros & Resultados \\
Tabela de contigência & $2 \times 2$ \\
Qui-quadrado de Pearson & 5,31 \\
Graus de liberdade & 2 \\
$\mathrm{p}$ & 0,07 \\
\hline
\end{tabular}

Quando realizada a análise de associação entre o grau de diferenciação do tumor e a ocorrência de metástase linfática, houve associação estatisticamente significante entre grau de diferenciação G1 e ausência de ocorrência de metástase linfática $(p=0,05)$, conforme apresentado na tabela 8 .

Pacientes com grau de diferenciação G2 ou G3 apresentaram risco relativo de desenvolver metástase linfática de 2,0 (IC95\%: $1,0-4,2)$ vezes o risco daqueles com grau de diferenciação G1. 
Tabela 8 - Associação entre grau de diferenciação histológica e ocorrência de metástase linfática.

\begin{tabular}{|c||c||c|c|}
\hline \hline $\begin{array}{c}\text { Grau de } \\
\text { diferenciação }\end{array}$ & N0 & N1-3 & Total \\
\hline \hline G1 & $18(38,2 \%)$ & $6(12,7 \%)$ & $24(51 \%)$ \\
\hline \hline$G 2$ & $5(10,6 \%)$ & $7(14,8 \%)$ & $12(25,5 \%)$ \\
\hline \hline G3 & $5(10,6 \%)$ & $6(12,7 \%)$ & $11(23,4 \%)$ \\
\hline TOTAL & $\mathbf{2 8 ( 5 9 , 5 \% )}$ & $\mathbf{1 9 ( 4 0 , 4 \% )}$ & $\mathbf{4 7 ( 1 0 0 \% )}$ \\
\hline
\end{tabular}

\subsection{RESULTADOS RELATIVOS À TÉCNICA DE I MUNOMARCAÇÃO CELULAR POR CICLI NA D1.}

As imagens obtidas por microscopia de lâminas coradas com hematoxilina-eosina, bem como representativas da imunorreação, tanto nuclear, como citoplasmática, da ciclina D1, seguem representadas nas figuras subseqüentes. Não foi observada expressão nucleolar em nenhum dos casos avaliados. 


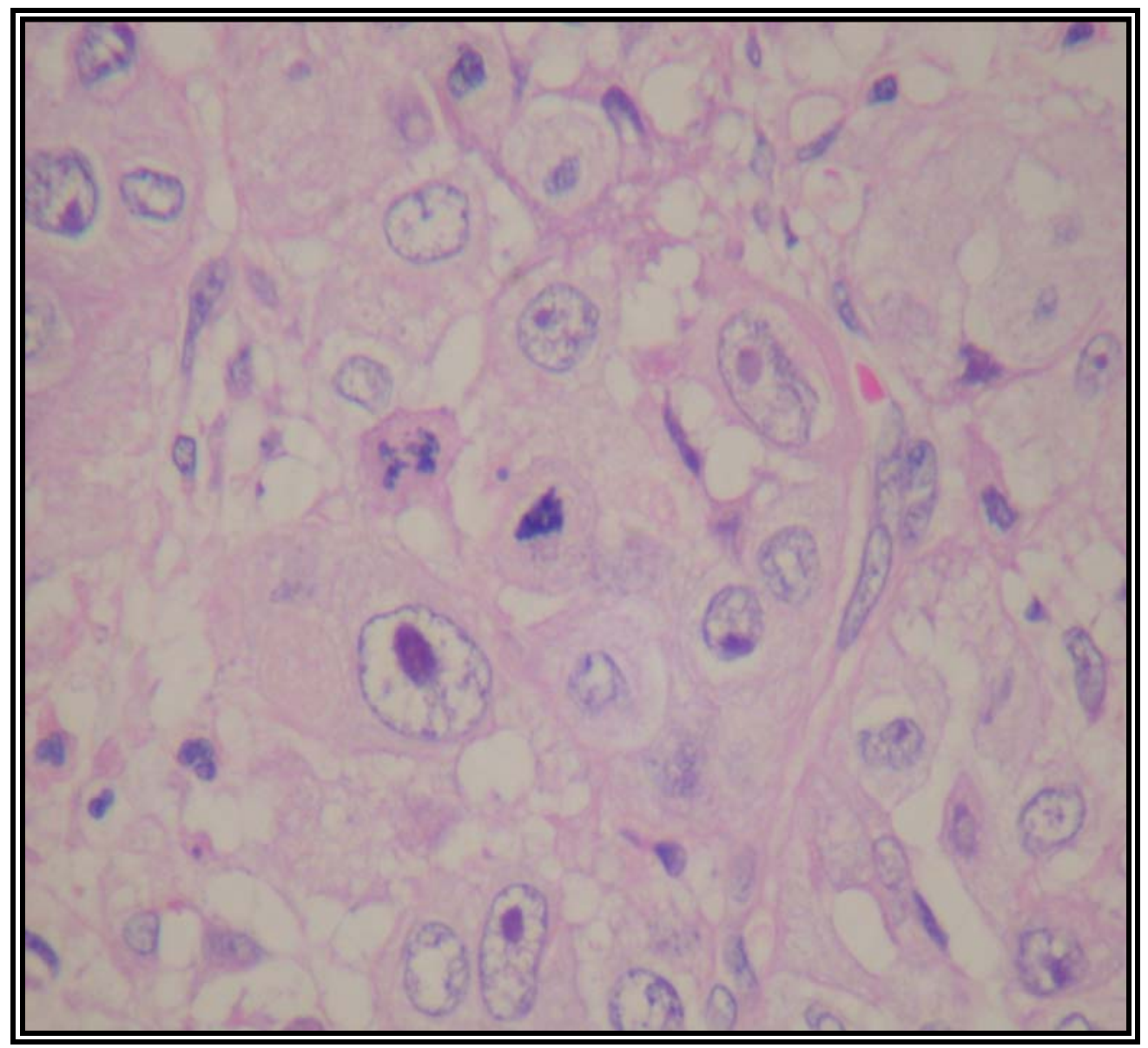

Figura 7 - Fotomicrografia de lâmina corada por hematoxilina-eosina em aumento de 400x. Confirmação de carcinoma epidermóide pouco diferenciado em espécime de tumor primário de laringe. 


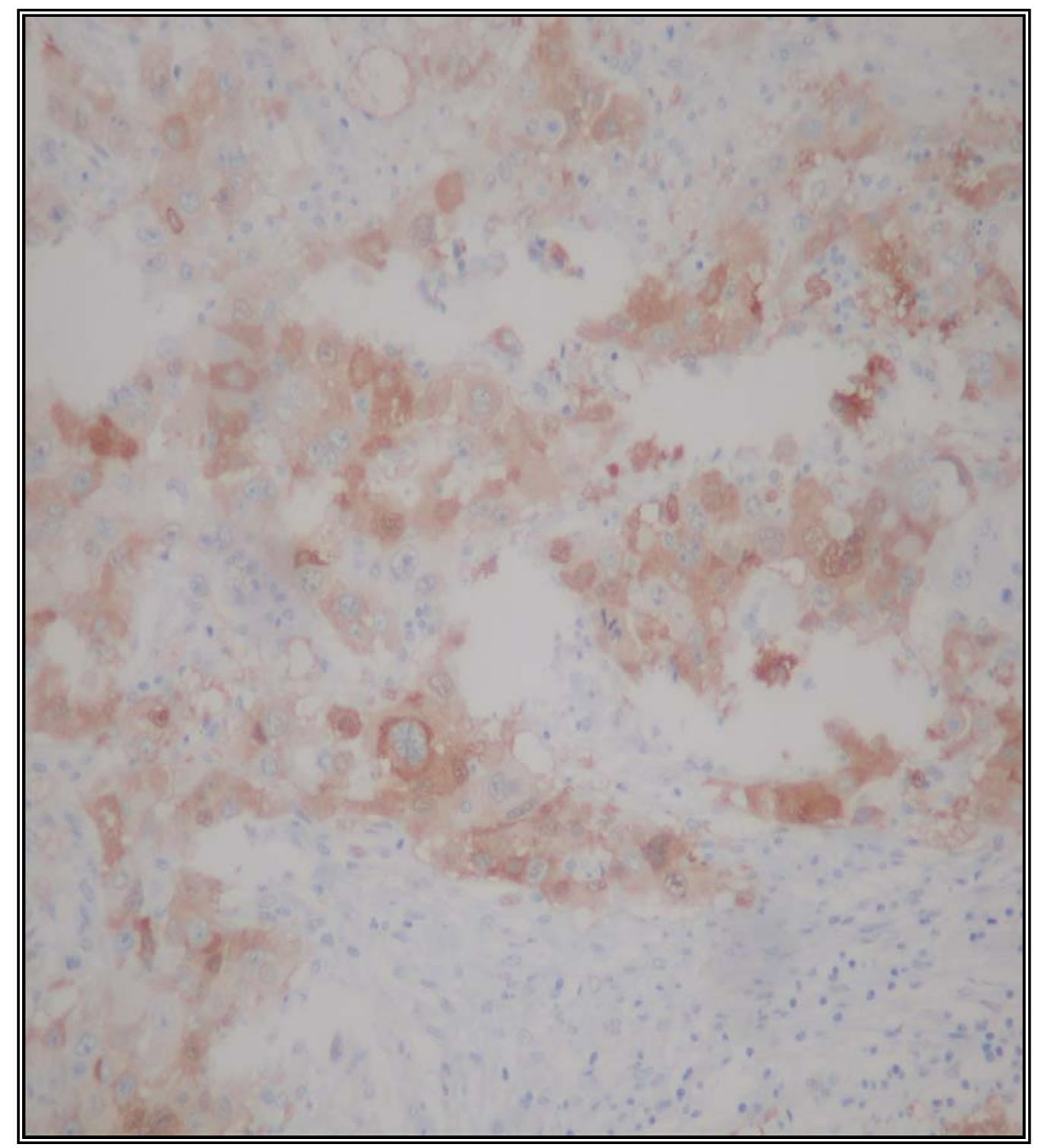

Figura 8 - Fotomicrografia de lâmina corada por imunoistoquímica para ciclina D1 em aumento de 100x. I munorreação citoplasmática em destaque. 


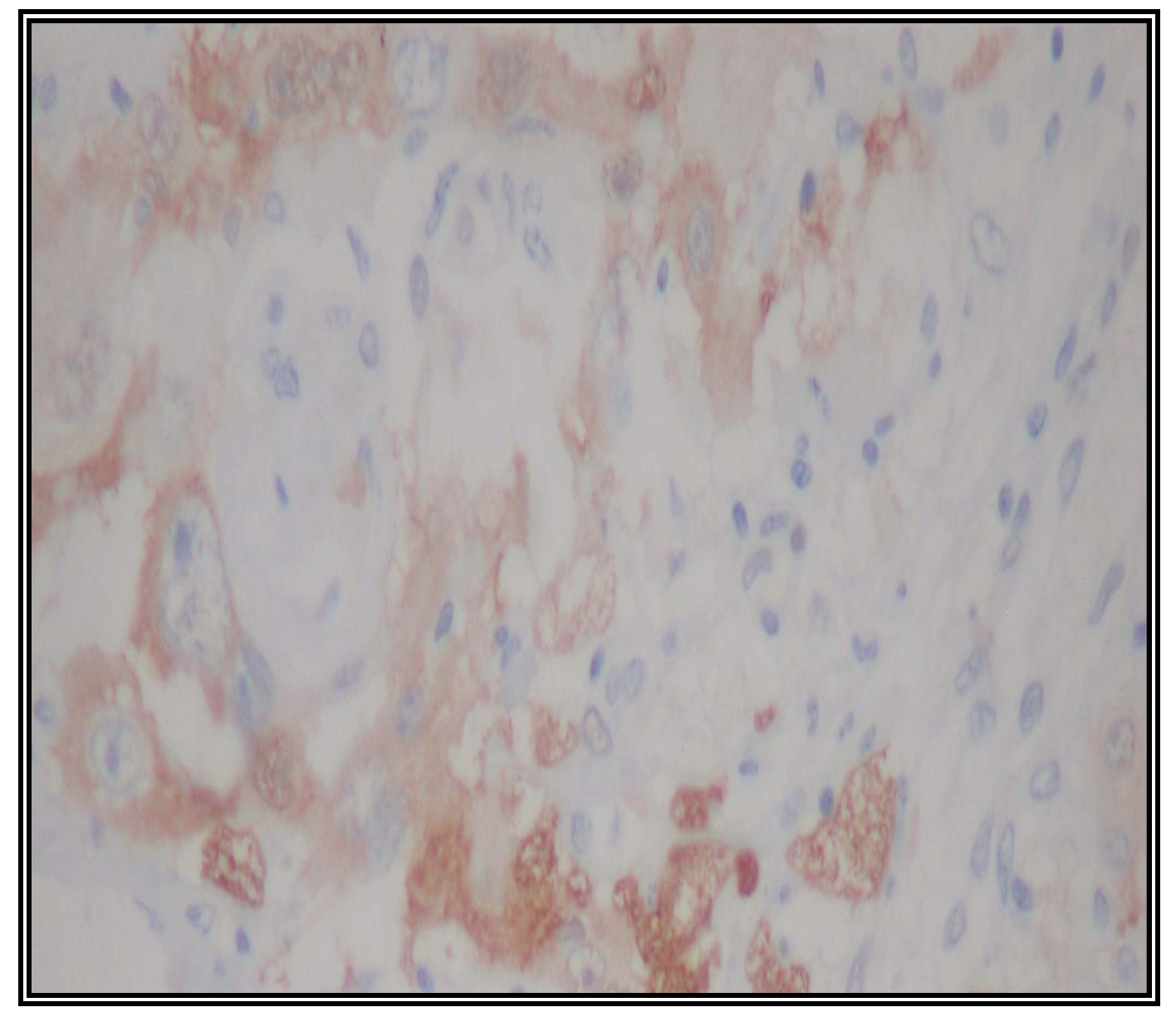

Figura 9 - Fotomicrografia de lâmina corada por imunoistoquímica para ciclina D1 em aumento de 200x. 


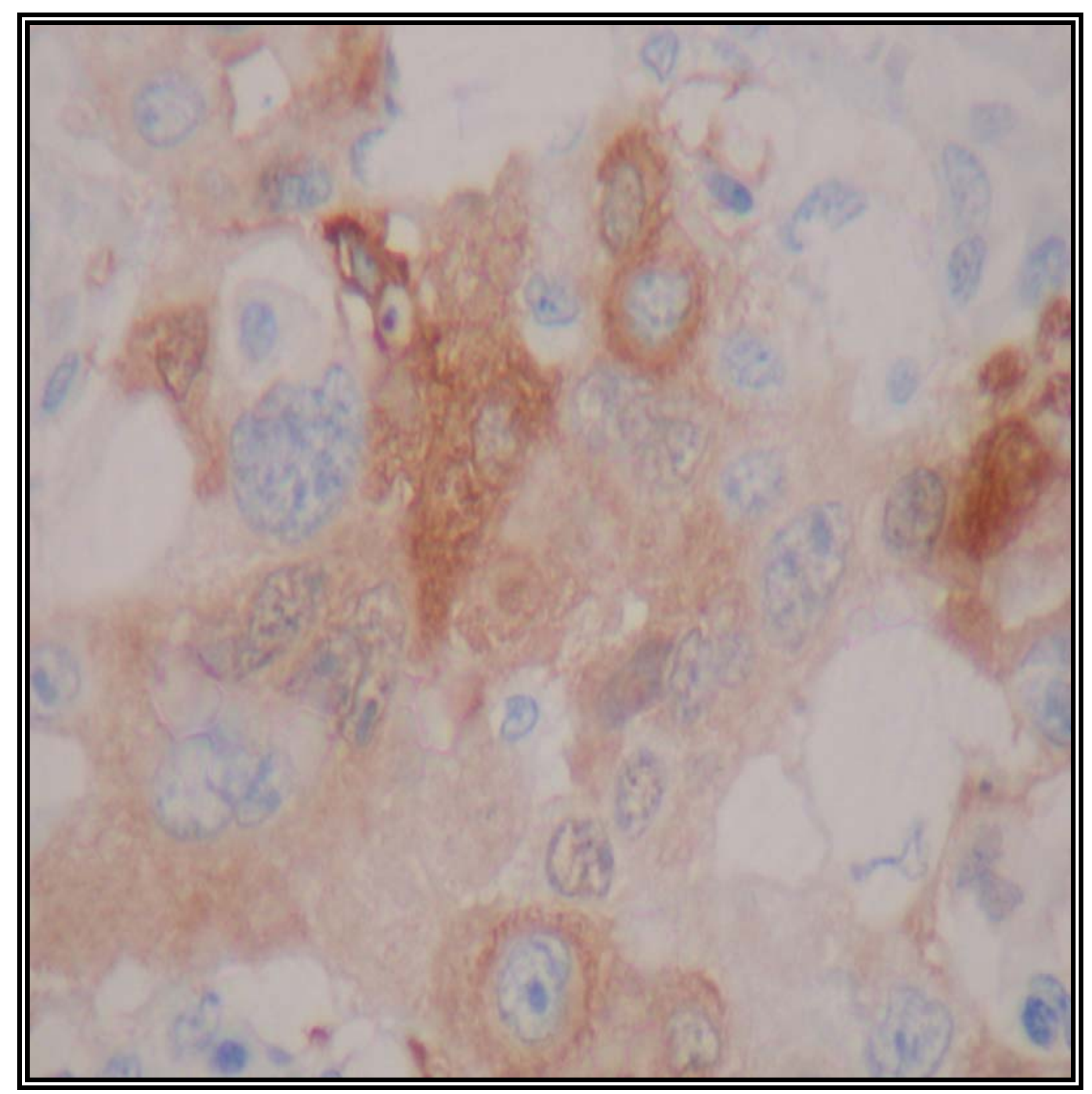

Figura 10 - Fotomicrografia de lâmina corada por imunoistoquímica para ciclina D1 em aumento de 400x. 


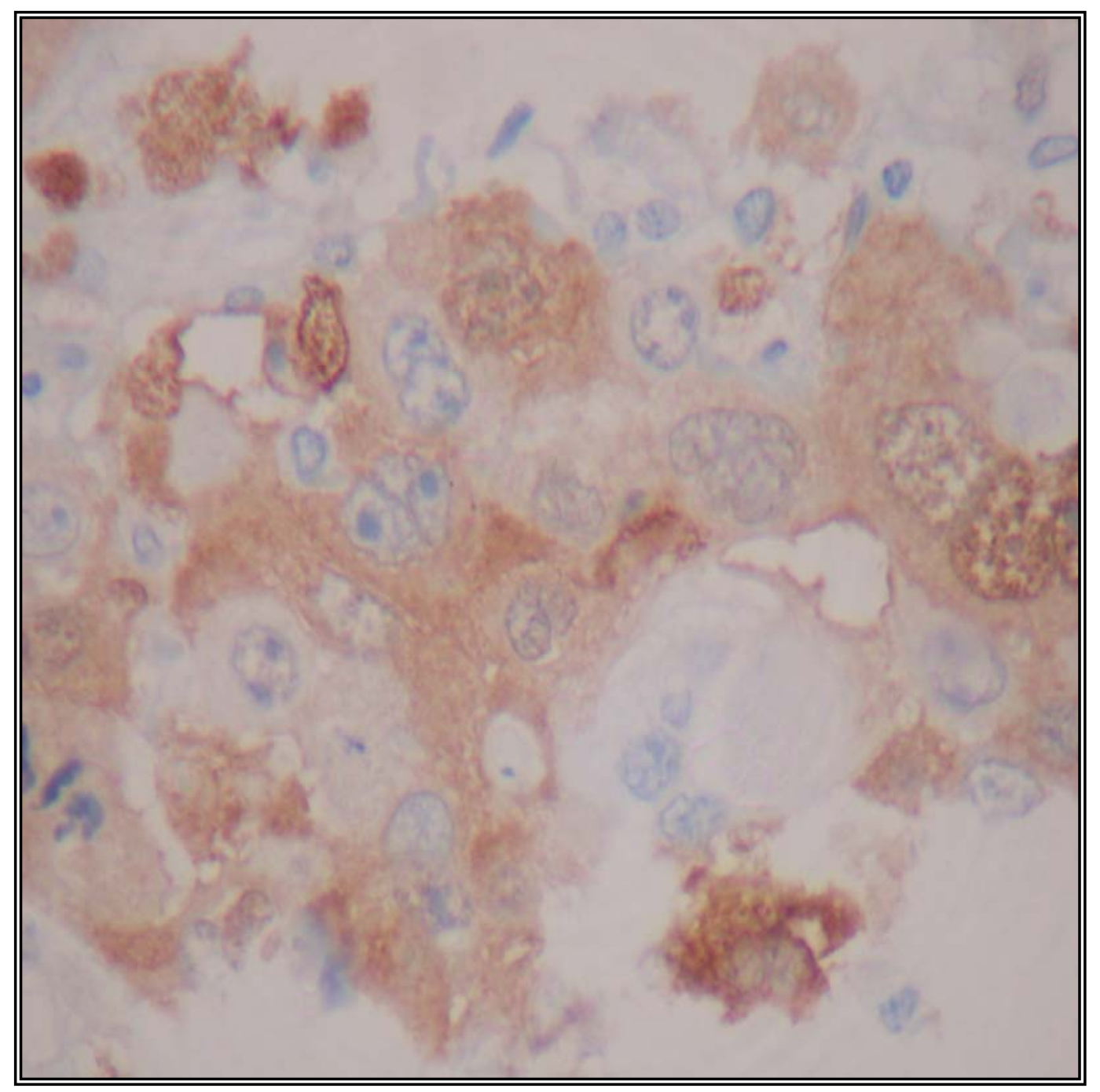

Figura 11 - Fotomicrografia de lâmina corada por imunoistoquímica para ciclina D1 em aumento de 400x. Destaque para a imunorreação nuclear e citoplasmática. 


\subsection{RESULTADOS RELATIVOS À ANÁLISE SEMI QUANTITATIVA DA IMUNOEXPRESSÃO CI TOPLASMÁTI CA DA CI CLINA DI.}

Tabela 9 - Análise semiquantitativa da imunoexpressão citoplasmática de ciclina D1 comparada à presença de metástase linfática.

\begin{tabular}{|c|l|c||l|}
\hline $\begin{array}{c}\text { Expressão de ciclina } \\
\text { D1 }\end{array}$ & \multicolumn{1}{|c|}{ N0 } & N1-3 & Total \\
\hline \hline 0 & $20(42,5 \%)$ & $12(25,5 \%)$ & $32(68 \%)$ \\
\hline$<10 \%$ & $5(10,6 \%)$ & $7(14,8 \%)$ & $12(25,5 \%)$ \\
\hline $10-50 \%$ & $2(4,2 \%)$ & 0 & $2(4,2 \%)$ \\
\hline$>50 \%$ & $1(2,1 \%)$ & 0 & $1(2,1 \%)$ \\
\hline Total & $\mathbf{2 8 ( 5 9 , 5 \% )}$ & $\mathbf{1 9 ( 4 0 , 4 \% )}$ & $\mathbf{4 7 ( 1 0 0 \% )}$ \\
\hline
\end{tabular}

\begin{tabular}{|cc|}
\hline Variáveis & Resultados \\
Tabela de contigência & $4 \times 2$ \\
Qui-quadrado de Pearson & 0,355 \\
Grau de liberdade & 1 \\
$\mathrm{P}$ & 0,551 \\
\hline
\end{tabular}


O tempo médio de seguimento foi de 708,47 $( \pm 587,72)$ dias em pacientes sem imunoexpressão citoplasmática por análise semiquantitativa (Anexo F), e 634,13 ( \pm 735,52) dias em pacientes com superexpressão citoplasmática de ciclina D1 por análise semiquantitativa (Anexo G).

Tabela 10 - Ocorrência de óbito pela doença comparada à superexpressão citoplasmática de ciclina D1 em análise semiquantitativa. $\mathbf{N}$ representa comprometimento linfático.

\begin{tabular}{|l|c||c||c||}
\hline & Ciclina D1 (-) & Ciclina D1(+) & Total \\
\hline \hline Óbito & $\mathbf{3 ( 6 , 3 \% )}$ & $\mathbf{4 ( 8 , 5 \% )}$ & $\mathbf{7 ( 1 4 , 8 \% )}$ \\
& $(3 \mathrm{~N}+)$ & $(4 \mathrm{~N}+)$ & \\
\hline \hline Não óbito & $29(61,7 \%)$ & $11(23,4 \%)$ & $40(85,1 \%)$ \\
& $(15 \mathrm{~N}+/ 14 \mathrm{~N} 0)$ & $(6 \mathrm{~N}+/ 5 \mathrm{~N} 0)$ & \\
\hline Total & $\mathbf{3 2 ( 6 8 \% )}$ & $\mathbf{1 5 ( 3 1 , 9 \% )}$ & $\mathbf{4 7}(100 \%)$ \\
\hline
\end{tabular}

\begin{tabular}{|cc|}
\hline Variáveis & Resultados \\
Tabela de contigência & $2 \times 2$ \\
Qui-quadrado de Pearson & 2,409 \\
Graus de liberdade & 1 \\
$P$ & 0,12 \\
\hline
\end{tabular}




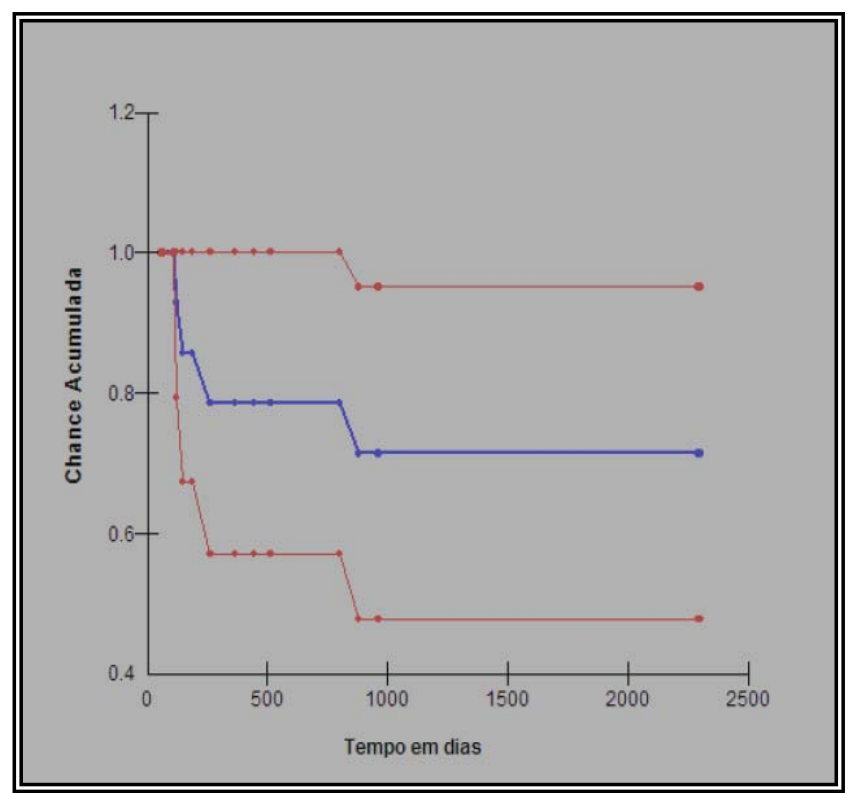

Figura 12 - Gráfico de sobrevivência global (barra azul) e intervalo de confiança de $95 \%$ (barras vermelhas) dos casos que apresentaram imunoexpressão citoplasmática de ciclina D1 por avaliação semiquantitativa (Anexo F) (Breslow; $p=0,084$ ).

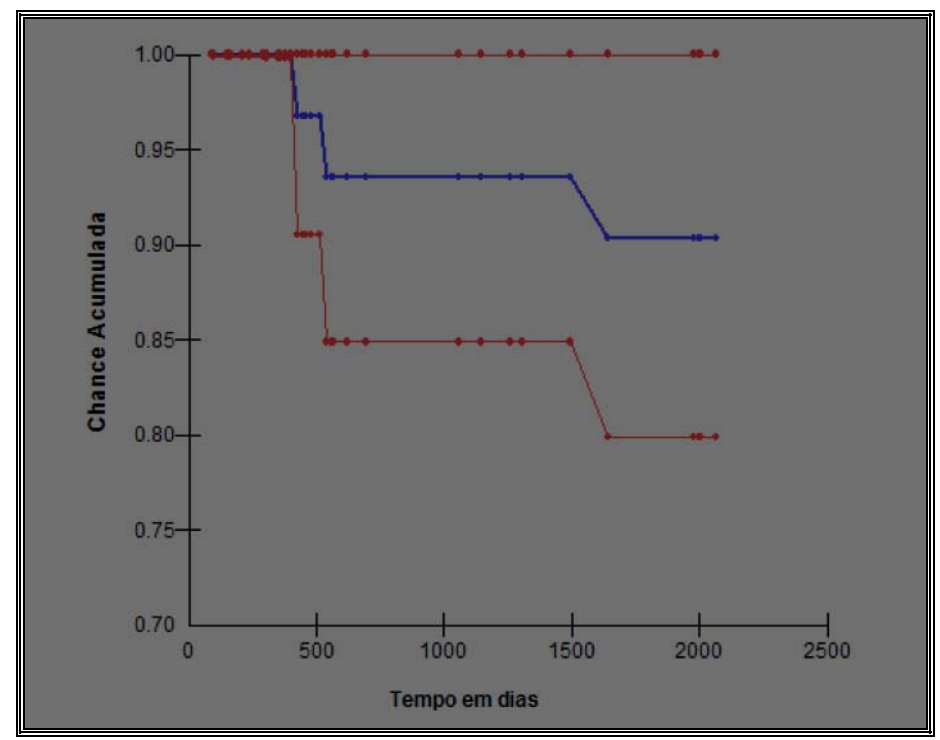

Figura 13 - Gráfico de sobrevivência global (barra azul) e intervalo de confiança de $95 \%$ (barras vermelhas) dos casos que não apresentaram imunoexpressão citoplasmática de ciclina D1 por avaliação semiquantitativa (Anexo G) (Breslow; $p=0,084$ ). 


\subsection{RESULTADOS RELATIVOS À ANÁLISE QUANTITATIVA DIGITAL DA IMUNOEXPRESSÃO NUCLEAR E CITOPLASMÁTICA DA CI CLINA DI.}

Todos os $47(100 \%)$ casos analisados apresentaram marcação positiva para a ciclina D1 no núcleo, enquanto que apenas $29(61,7 \%)$ apresentaram pelo menos uma célula com citoplasma positivo em 1000 analisadas (Anexo E).

Houve imunomarcação citoplasmática em 566 (1,2\%) células, imunomarcação nuclear em 13788 (29,6\%) células, a relação do IPC e IPn foi de 0,007 $(0,7 \%)$, ausência de imunomarcação celular foi observada em $32210(69,1 \%)$ células, perfazendo um total de 46554 (100\%) células investigadas.

Os índices de positividade no núcleo e no citoplasma para a ciclina D1 de acordo com a ocorrência de metástase linfática estão apresentados na tabela 11 e representados graficamente na figura 14.

Não houve diferença estatisticamente significante entre os índices de positividade para ciclina D1 de indivíduos com e sem metástase linfática tanto no citoplasma como no núcleo. 
Tabela 11 - Índices de positividade nuclear e citoplasmática em pacientes sem e com metástase linfática cervical a partir de carcinoma epidermóide primário de laringe. Dados apresentados como mediana (p25 - p75).

\begin{tabular}{lcccc}
$\begin{array}{l}\text { Índice de } \\
\text { Positividade }\end{array}$ & $\mathbf{N 0}$ & $\mathbf{N 1 - 3}$ & $\mathbf{T}$ & $\begin{array}{c}\text { Total } \\
(\mathbf{n}=\mathbf{2 8})\end{array}$ \\
\hline No Núcleo & $26,8(9,7-46,9)$ & $26,7(16,7-39,0)$ & 0,9 & $26,7(14,8-44,9)$ \\
No Citoplasma & $0,1(0,0-0,3)$ & $0,3(0,0-1,0)$ & 0,17 & $0,2(0,0-0,6)$ \\
\hline \hline
\end{tabular}

N representa ausência (N0) ou presença (N1-3) de comprometimento linfático. 


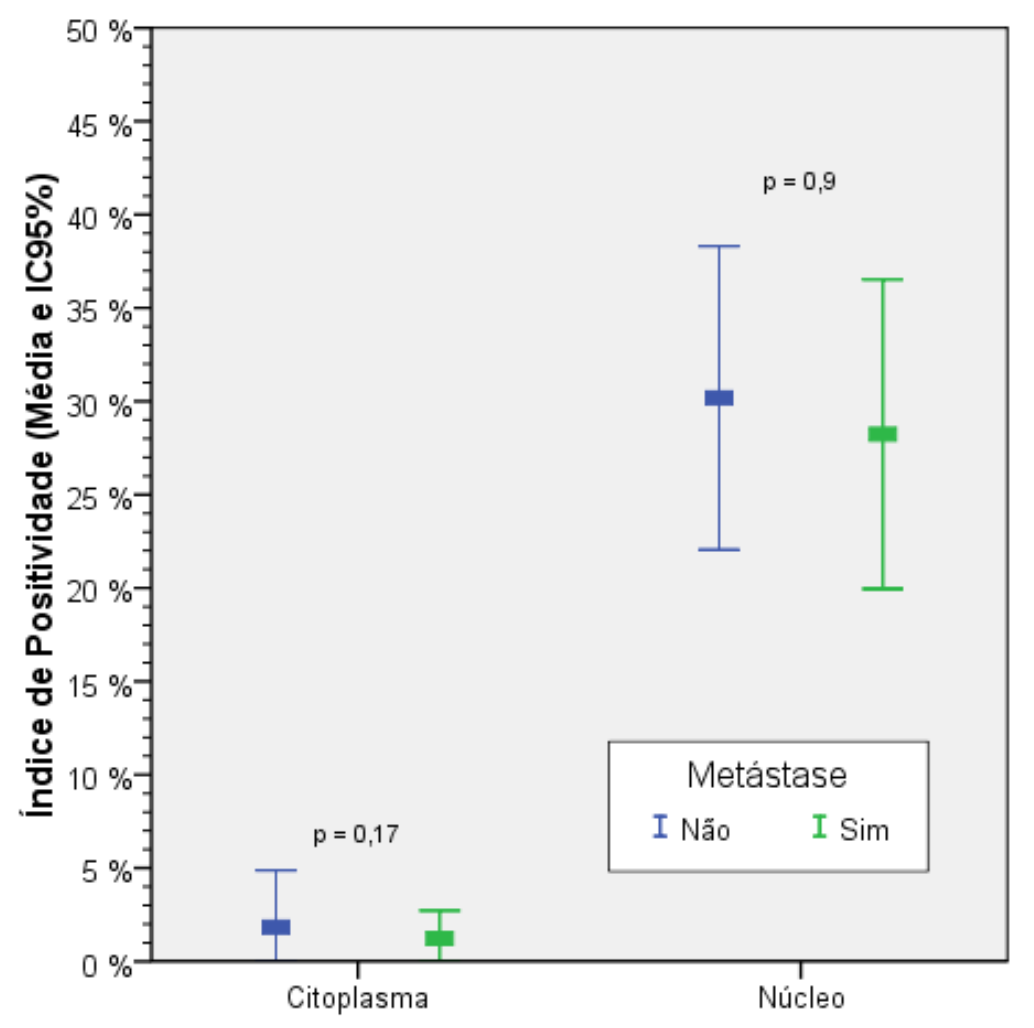

Figura 14 - Gráfico de barras de erros representando as médias e respectivos intervalos de confiança de $95 \%$ dos índices de positividade para ciclina D1 no núcleo e no citoplasma de indivíduos com (verde; $\mathrm{n}=19$ ) e sem (azul; $\mathrm{n}=28$ ) metástase linfática. Valores de $\mathrm{p}$ obtidos do teste não paramétrico $U$ de Mann-Whitney. 
Os índices de positividade no núcleo e no citoplasma para a ciclina D1, comparados com os graus de diferenciação histológica, estão apresentados na tabela 12 e representados graficamente na figura 15.

Não houve diferença estatisticamente significante entre os índices de positividade para ciclina D1 de indivíduos e graus de diferenciação histológica, tanto no citoplasma, como no núcleo.

Tabela 12 - Comparação dos índices de positividade para ciclina D1 no citoplasma e no núcleo de tumores de acordo com o grau de diferenciação histológica. Dados apresentados como mediana (p25 - p75).

Grau de Diferenciação Histológica

\begin{tabular}{lcccc}
$\begin{array}{l}\text { Índice de } \\
\text { Positividade }\end{array}$ & $\mathbf{G 1}$ & $\mathbf{G 2}$ & $\mathbf{G 3}$ & $\mathbf{2 4 )}$ \\
\hline No Núcleo & $36,0(10,6-48,0)$ & $18,2(6,2-25,6)$ & $30,2(20,6-44,9)$ & 0,11 \\
No Citoplasma & $0,1(0,0-0,3)$ & $0,1(0,0-1,2)$ & $0,2(0,1-1,9)$ & 0,16 \\
\hline \hline
\end{tabular}




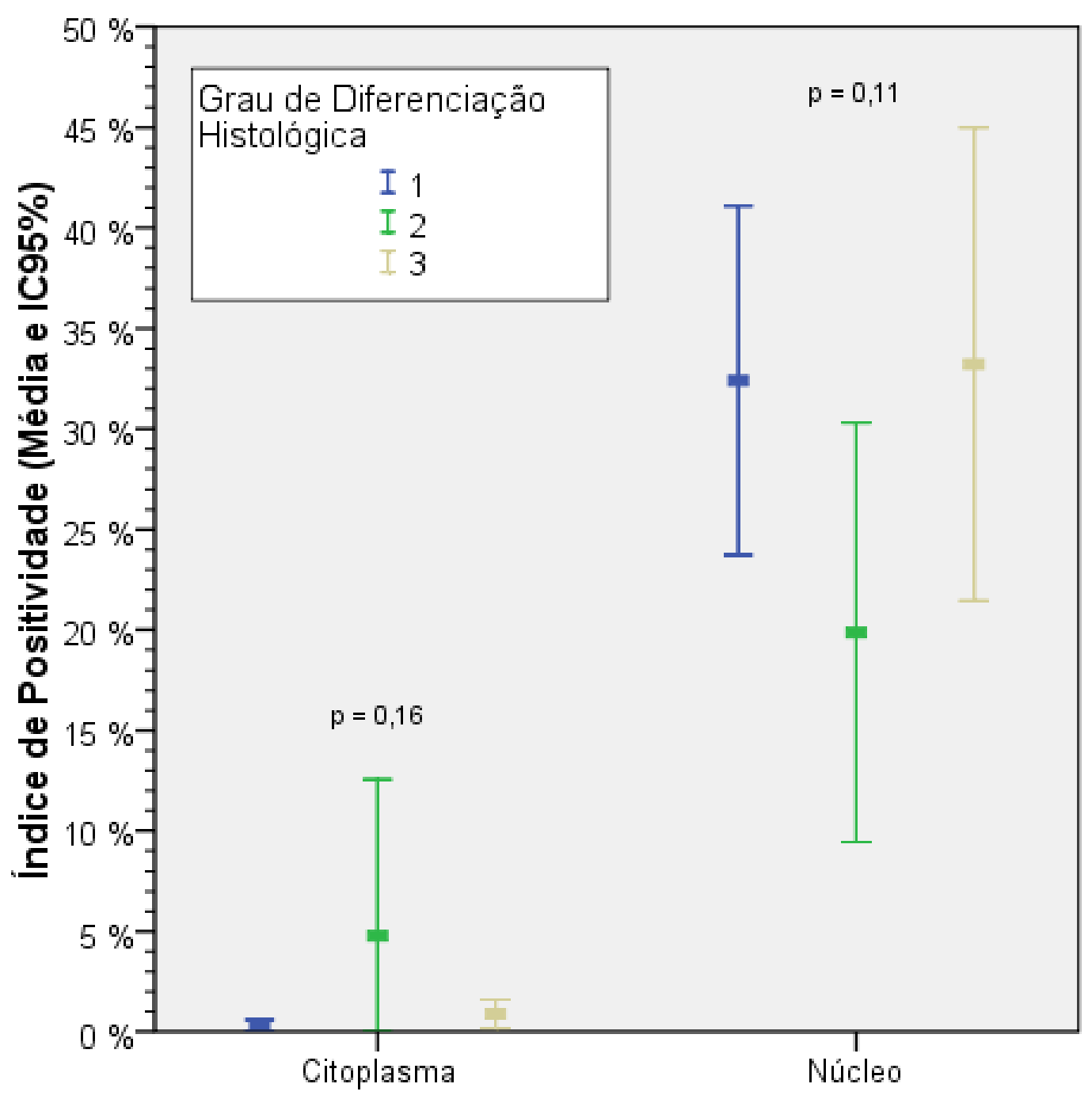

Figura 15 - Gráfico de barras de erros representando as médias e respectivos intervalos de confiança de $95 \%$ dos índices de positividade para ciclina D1 no núcleo e no citoplasma de indivíduos e comparação com grau de diferenciação histopatológica ( $G 1, \mathrm{G} 2$ e G3). Valores de p obtidos do teste não paramétrico de Kruskal-Wallis. 
Os índices de positividade no núcleo e no citoplasma para a ciclina D1, comparados com a recidiva loco-regional e metástase hematogêncica, estão apresentados na tabela 13 e representados graficamente na figura 16.

Não houve diferença estatisticamente significante entre os índices de positividade para ciclina D1 de indivíduos e a ocorrência de recidiva loco-regional e/ou metástase hematogênica, tanto no citoplasma, como no núcleo.

Tabela 13 - Comparação dos índices de positividade para ciclina D1 no citoplasma e no núcleo de tumores que evoluíram, e que não evoluíram, com recidiva loco-regional e/ou metástase hematogênica. Dados apresentados como mediana (p25 - p75).

Recidiva Loco-Regional e/ ou

Metástase hematogênica

Índice de Sim Não $\quad$ Total

$\begin{array}{lllll}\text { Positividade } \quad(n=12) & (n=35) & p & (n=47)\end{array}$

No Núcleo $\quad 28,9(12,2-52,4) \quad 14,8(24,6-40,4) \quad 0,5 \quad 26,7(14,8-44,9)$

No Citoplasma $\quad 0,5(0,0-2,2) \quad 0,1(0,0-0,3) \quad 0,08 \quad 0,2(0,0-0,6)$ 


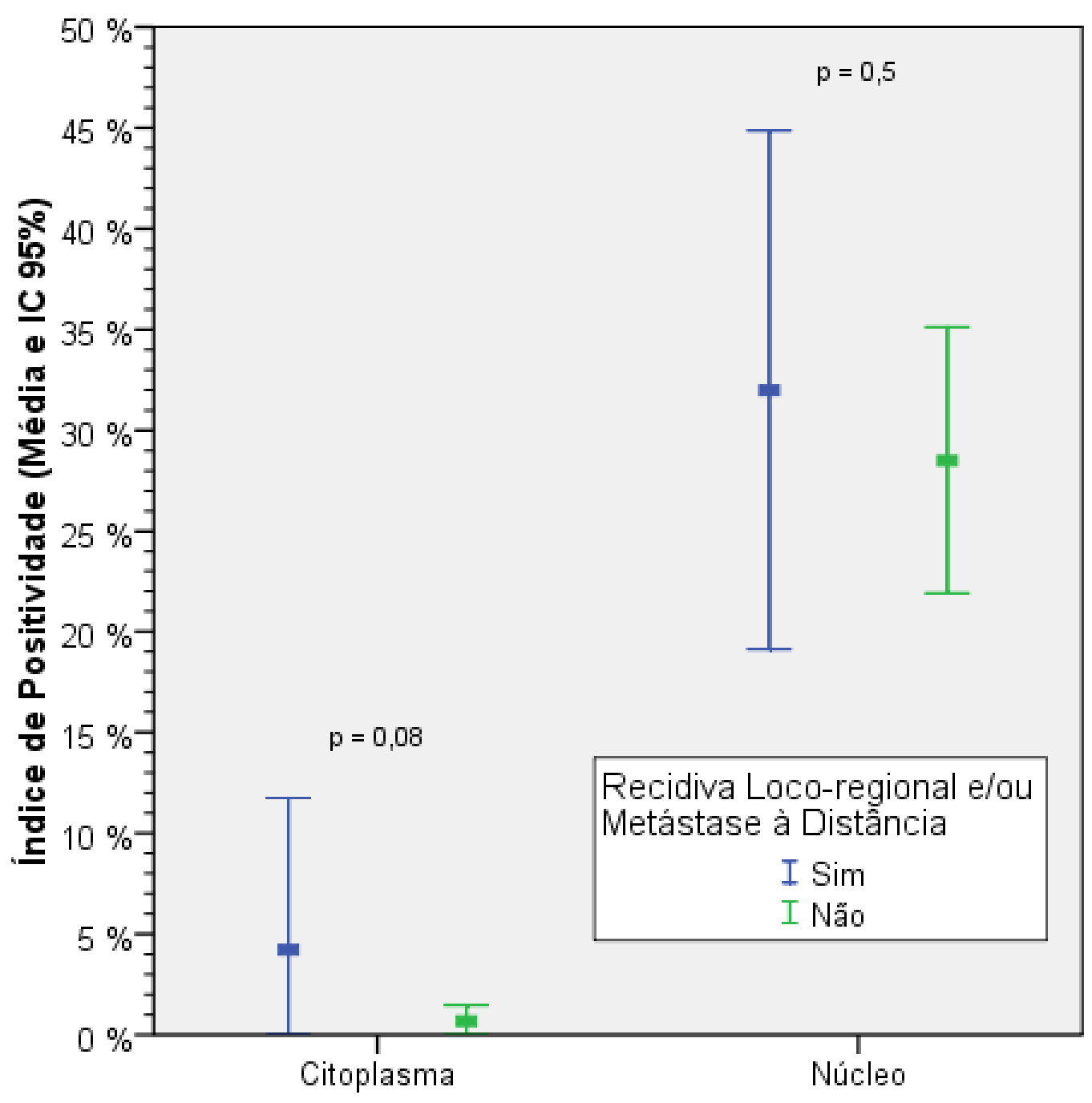

Figura 16 - Gráfico de barras de erros representando as médias e respectivos intervalos de confiança de 95\% dos índices de positividade para ciclina D1 no núcleo e no citoplasma de indivíduos e comparação com recidiva loco-regional e metástase hematogênica. Valores de $\mathrm{p}$ obtidos do teste não paramétrico $U$ de Mann-Whitney. 


\section{DISCUSSÃO}

Apesar dos avanços recentes alcançados no tratamento cirúrgico e na radioterapia, falhas no controle oncológico de pacientes com carcinoma epidermóide de laringe continuam a ocorrer.

Mesmo quando são analisados pacientes e tumores que apresentam características clínicas e patológicas similares, são observadas evoluções clínicas distintas.

A aparente ineficiência, ou incompletude, dos fatores prognósticos tradicionais em predizer a evolução clínica de pacientes com carcinoma epidermóide laríngeo tem levado a tentativas em desenvolver marcadores adicionais capazes de distinguir pacientes com bom prognóstico daqueles com maior probabilidade de descontrole da doença.

Alguns estudos têm demonstrado a relação entre oncogênese e alterações de expressão das ciclinas, quinases dependentes de ciclinas e inibidores das quinases dependentes de ciclinas, mas os dados disponíveis concernentes ao carcinoma epidermóide de laringe são conflituosos (Dong, 2000; Fuji, 2001; loachim, 2004).

Novos fatores prognósticos, como a expressão de reguladores do ciclo celular, têm sido investigados na tentativa de melhorar a acurácia em predizer o comportamento biológico desses tumores (Michaluart, 2005), já que transformações malignas podem ocorrer como resultado de alterações de genes, ciclinas e inibidores de quinases dependentes de ciclina que influenciam diretamente no controle das mitoses e do ciclo celular. 
Múltiplas anormalidades genéticas descritas estão relacionadas aos cânceres de cabeça e pescoço e, mormente, laringe (Michaluart $\mathrm{P}, 1999$ ).

O número exato e o tipo de anormalidade diferem de tumor para tumor, resultando em diferentes fenótipos. A este fato, vem acrescida a heterogeneidade genética observada, tornando praticamente impossível a utilização de dados moleculares em genes únicos na caracterização da doença e na identificação de marcadores moleculares.

Apesar dos conhecimentos que têm sido gerados nos últimos anos sobre os mecanismos que conduzem uma célula à duplicação e à segregação de seu material genético para as células filhas, ainda existem muitas questões a serem respondidas. Algumas dessas questões referem-se aos reguladores da citocinese, à identidade e ao modo de ação dos sensores de lesões do DNA e à sua ligação com os efetores e aos sítios de fosforilação de vários substratos.

Os marcadores tumorais identificados até o momento têm aplicação clínica limitada. Não apenas a diversidade observada no comportamento biológico dos tumores, em diferentes subsítios anatômicos e em diferentes estadiamentos, mas também a diversidade encontrada nos pacientes explica a dificuldade para que sejam identificados marcadores tumorais fidedignos quanto ao prognóstico individual. Na laringe, a descoberta de marcadores de radio e quimiossensibilidade terá grande importância para a indicação de preservação deste órgão tão nobre (Cervantes 0 , 2004).

Levando-se em consideração o número de pessoas expostas ao tabaco e ao álcool, existem poucos casos de câncer de cabeça e pescoço. Isto sugere que os fatores genéticos são importantes para o desenvolvimento da doença. 
Estudos recentes tentam correlacionar alterações genéticas a uma maior susceptibilidade ao aparecimento do câncer na laringe, bem como ao prognóstico destes pacientes. Os possíveis marcadores tumorais estão relacionados às alterações funcionais no nível celular (Cervantes O, 2004).

A identificação de marcadores relacionados ao risco de disseminação regional e à distância, seria de grande auxílio no planejamento terapêutico. Além disso, podem proporcionar uma melhor compreensão da doença e o conseqüente desenvolvimento de novas terapias.

Há evidências que a atividade alterada das ciclinas e CDK apresenta papel decisivo na patogênese do carcinoma epidermóide em cabeça e pescoço e, portanto, podem servir à programação de terapias célula-alvo e outras abordagens terapêuticas (Nakashima, 2000; Holley, 2001; Pruneri, 2005).

Quanto ao modelo de estudo, os métodos de quantificação podem incluir a contagem simples de células, medição quantitativa e qualitativa da reação e, até mesmo, o emprego de mensuração computadorizada (Seidal, 2001; Stabenow, 2006). Qualquer que seja a metodologia empregada, há a imperiosa necessidade de padronização da quantificação para permitir a reprodutibilidade e pareamento adequado dos resultados.

Algumas variáveis podem interferir na reação ou resultado da reação imunoistoquímica e devem ser reconhecidas para se compreender a validade dos métodos de mensuração. Algumas variáveis podem ser consideradas modificáveis ou extrínsecas e incluem a diluição, o clone do anticorpo, o método de detecção da coloração e cromógeno, recuperação antigênica e interpretação de resultados. Este aumento da sensibilidade deve ser interpretado com cuidado, pois com isto, quase qualquer antígeno pode ser detectado em qualquer tecido, e, portanto, a diferenciação do que é 
positivo e negativo deve ter sua sensibilidade também incrementada (Rishi, 1993).

Neste aspecto diversos tipos de enzimas proteolíticas têm sido empregados pelos laboratórios com objetivo de evitar o efeito da formalina nestes tecidos. Não somente variam os tipos de enzimas, bem como as concentrações e temperaturas recomendadas são fatores que interferem de maneira significativa no resultado da reação imunoistoquímica (Fetsh, 1999).

A recuperação antigênica também é influenciada por grande variedade de técnicas, principalmente no que diz respeito à exatidão da temperatura e o tempo de aquecimento que podem levar a resultados significativamente diferentes.

Aspectos físico-químicos como a osmolaridade e pH da solução também devem ser considerados na análise final (Fetsh, 1999).

Isto posto, torna-se mandatória a realização de estudo imunoistoquímico em condições técnicas padronizadas.

Ante estas considerações, no presente estudo, os detalhes técnicos da reação foram padronizados e a casuística foi analisada de forma agrupada com o intuito de minimizar a interferência das variantes citadas.

Há, no entanto, uma variável inconstante que é a própria interpretação do observador. A ausência de padronização na interpretação de resultados tem levado a variações expressivas entre os estudos prejudicando de maneira significativa a interpretação destes estudos.

Quanto à análise qualitativa não há consenso sobre a região do tumor a ser pesquisada: periferia ou central, área invasiva ou carcinoma in situ, áreas aleatórias ou áreas consideradas mais representativas. Além disso, a localização intracelular deve também ser considerada já que a coloração de alguns antígenos no núcleo 
não tem o mesmo significado de seu encontro no citoplasma (De Falco, 2004).

A análise semiquantitativa da ciclina D1 revelou expressão em 15 (31,9\%) pacientes da amostra estando de acordo com os resultados publicados que variam entre 12 e $68 \%$, embora estes por metodologias distintas de leitura da imunoistoquímica.

A literatura sobre câncer e ciclina D1 avalia a presença da ciclina através da contagem de núcleos marcados por grupo de células neoplásicas, que geralmente variam entre 500 e 1000 células, em percentuais. Por este método o pesquisador procede à contagem de um total de células neoplásicas, independente de estarem marcadas ou não, e a seguir, recontar as células que expressam a proteína, calculando o percentual. A escolha do ponto de corte, para separar a expressão positiva da negativa da ciclina D1, é arbitrária. Han et al., consideram a positividade quando ocorrer mais de $5 \%$ de núcleos marcados. Ravi et al., Itami et al. e Capaccio et al., consideram a expressão da ciclina D1 significante quando presente em mais de $10 \%$ das células tumorais. El-Naggar et al. consideram valores superiores a $50 \%$ como uma superexpressão desta proteína. Mineta et al. consideram valores entre $0-50 \%$ de baixa expressão e acima de $50 \%$ de alta expressão. Schoelch et al. utilizam o escore negativo quando não há expressão, + para até $33 \%$ de expressão, ++ entre 33 e $66 \%$ e +++ acima de $66 \%$ de expressão da proteína nas células tumorais.

Na literatura, a associação entre a expressão da ciclina D1 e a presença de metástase cervical é ambígua.

Os resultados do presente estudo concordam com os obtidos por Han et al., Michalides et al. e Bellacosa et al. 
Os trabalhos de Frachiolla, Itami, Masuda, Tapia et al., Capaccio et al. e Mineta et al., entretanto, demonstraram que a ciclina D1 está associada à presença de metástase cervical.

Os resultados são contraditórios e os motivos podem ser: diferenças de expressão da ciclina D1 nos diferentes órgãos, o estado da peça cirúrgica, como emblocamento e tempo no formal até ser fixado, o ponto de corte para definir o que é superexpressão da proteína e uma metodologia padrão de leitura evitando subjetividade na interpretação (Michaelses VS, 2007).

A curva de sobrevida dos 47 pacientes da amostra demonstra que os pacientes positivos para ciclina D1 apresentam uma tendência de menor sobrevida que os pacientes negativos, embora não tenha um marcado significado estatístico.

Neste estudo a presença de metástase cervical foi significativa para diminuir a sobrevida, enquanto que a ciclina D1 não teve a mesma significância estatística, mostrando apenas uma tendência de que os pacientes com maior expressão da ciclina tiveram pior sobrevida global.

Os resultados obtidos no presente estudo assemelham-se aos descritos por De Falco et alli (2004) em que a ciclina D1 mostrouse presente no citoplasma, no núcleo ou em ambos os compartimentos celulares.

Segundo Alao JP et al. (2006), em casuística de carcinoma de mama, a ciclina D1 demonstrou por abordagens experimentais distintas ser uma proteína predominantemente citoplasmática. 
No presente estudo, os índices de positividade aferidos em núcleo $(26,7(14,8-44,9))$ e citoplasma $(0,2(0,0-0,6))$, demonstram claramente que houve expressão nestes compartimentos celulares, mas com predomínio da imunoexpressão nuclear em detrimento da imunoexpressão citoplasmática, e ausência de reação nucleolar.

Em estudo retrospectivo de 102 pacientes, Dong et al. (2001) concluíram que a superexpressão foi significativamente associada com o sítio e dimensões do tumor primário, metástase linfática, estádio clínico avançado e sobrevida global limitada, a análise multivariada demonstrou ser este um fator preditivo independente de sobrevida livre de doença (Fuji M, 2002).

Não foi observada diferença estatisticamente significante entre os índices de positividade nuclear da ciclina D1 em casos em que havia metástase linfática e naqueles em que não foi observada disseminação linfática cervical $(p=0,9)$, nem tampouco os índices de positividade citoplasmática guardaram significância estatística $(p=0,17)$. Estes dados aferidos no corrente estudo contrariam as conclusões dos autores citados anteriormente e aproximam-se daquelas encontradas por loachim et al. (2004) que não encontraram diferenças significativas entre risco de recidiva, bem como sobrevida, em tumores com expressão positiva ou negativa, tanto em análise univariada como em análise multivariada; além disso, resultados semelhantes foram obtidos por El-Naggar et al. (1999) e Vielba et al. (2003), embora os primeiros tenham estudado carcinoma de boca e laringe em conjunto.

Não houve diferença estatisticamente significante entre os índices de positividade para ciclina D1 na casuística investigada e graus de diferenciação histológica, tanto no citoplasma $(p=0,16)$, como no núcleo $(p=0,11)$. Assemelham-se aos resultados obtidos 
por Monteiro et al. (2004), em estudo que investigou a relação entre o pleomorfismo do gene CCND1 A870G e amplificação com desenvolvimento e progressão de CEC laríngeo, a partir de uma população de 66 pacientes com câncer laríngeo, em que não houve relação entre amplificação e estádio, grau de diferenciação, recidiva ou sobrevida livre de doença.

Krecicki et al. (2004) e Bellacosa et al. (1996), encontraram relação significante entre superexpressão da ciclina D1 e sobrevida global reduzida. Wang et al., em 1998, desenvolveram estudo imunoistoquímico sobre a expressão de ciclina D1 em 92 pacientes com carcinoma laríngeo, e encontraram níveis elevados naqueles que evoluíram com recidiva local; entretanto, no presente estudo, não houve diferença estatisticamente significante entre os índices de positividade para ciclina D1 de indivíduos e a ocorrência de recidiva loco-regional e/ou metástase hematogênica, tanto no citoplasma $(p=0,08)$, como no núcleo $(0,5)$; assim como a sobrevivência global entre a população estudada que apresentou superexpressão citoplasmática não diferiu significantemente daquela em que não foi observada expressão citoplasmática $(p=0,084)$. 


\section{CONCLUSÕES}

Com base na metodologia empregada e nos resultados obtidos, é possível concluir que:

7.1. CONCLUSÃO PRINCIPAL

7.1.1. A análise quantitativa digital da expressão nuclear e citoplasmática do imunomarcador ciclina D1 não demonstrou risco relativo pronunciado de desenvolvimento de metástase linfática cervical em carcinoma epidermóide de laringe.

7.2. CONCLUSÕES SECUNDÁRIAS

7.2.1. A análise quantitativa digital da expressão nuclear e citoplasmática do imunomarcador ciclina D1 não apresentou associação estatisticamente significante com os graus de diferenciação histológica em carcinoma epidermóide de laringe.

7.2.2. A análise quantitativa digital da expressão nuclear e citoplasmática do imunomarcador ciclina D1 não apresentou relevância estatística comparada com a ocorrência de recidiva loco-regional e metástase hematogênica. 
7.2.3. A superexpressão citoplasmática da ciclina D1, comparada à ausência de imunoexpressão, apresentou tendência negativa quanto à sobrevida global, entretanto sem atender ao critério de significância estatística determinado. 


\subsection{Anexo A}

Q0 - No de Identificação:

Nome do Paciente:

::.Dados Clínicos e Laboratoriais ao Diagnóstico de Cabeça e Pescoço

PRIMEIRA CONSULTA

QUEIXA E DURAÇÄO

Q201-Nome da Mãe:

Q1 -Peso habitual

antes da doença:

Q2 -Altura:

(cm)

Q7 -IMC:

Q8 -Alterações

Visuais:

Sim Não Q9 -(dias)

Q10 -Dificuldade

Respiratória/Dispnéia Sim Não Q11 -(dias)

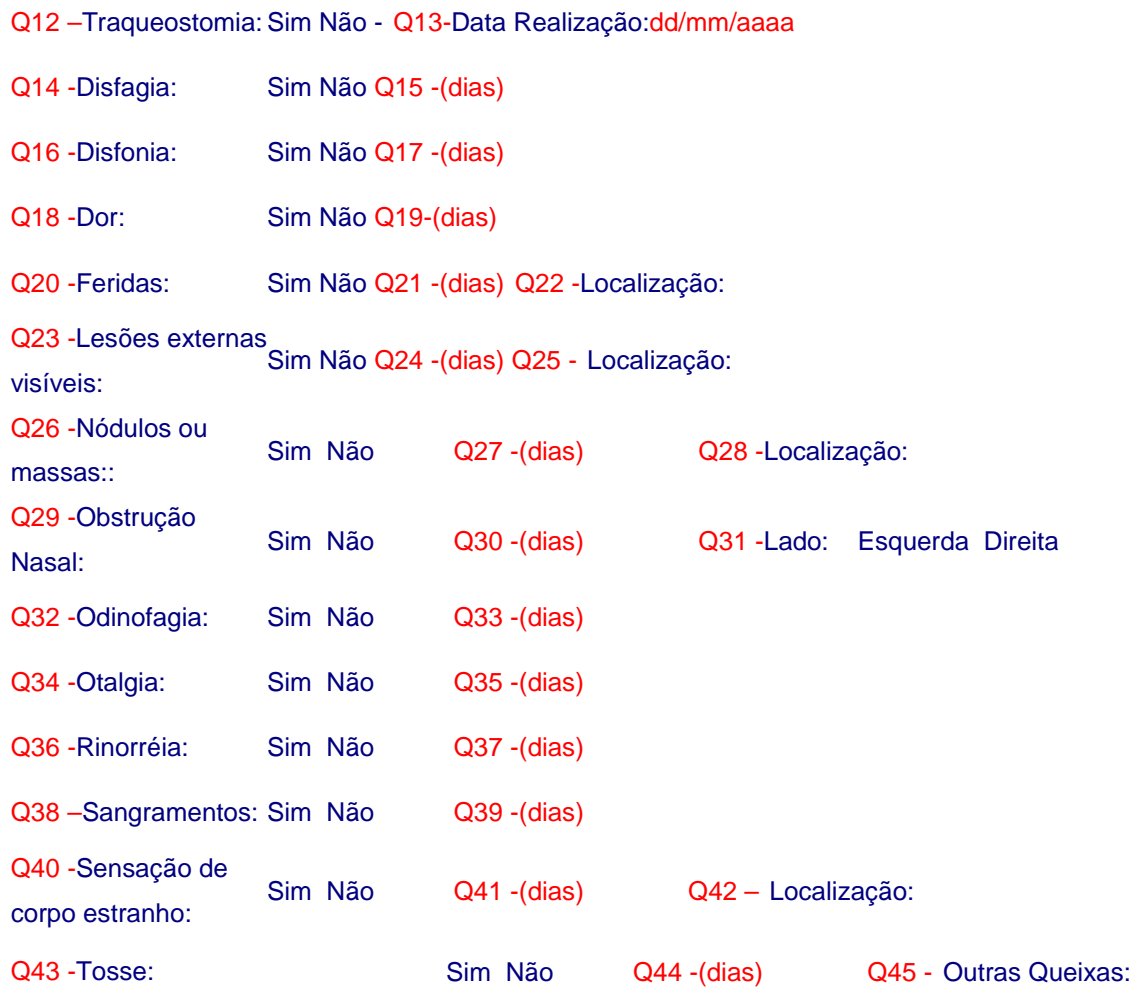


Q46 - C00 - Neoplasia maligna do lábio

Q47 -C00.0 - Lábio superior externo

Q48 -C00.1 - Lábio inferior externo

Q49 -C00.2 - Lábio externo, não especificado

Q50 -C00.3 - Lábio superior, face interna

Q51 -C00.4 - Lábio inferior, face interna

Q52 -C00.5 - Lábio, sem especificação, face interna

Q53 -C00.6 - Comissura labial

Q54 -C00.8 - Lesão invasiva do lábio

Q55 -C00.9 - Lábio, não especificado

Q56 - C01 - Neoplasia maligna de base de língua

Q57 - C02 - Neoplasia maligna de outras partes e partes não especificadas de língua

Q58 -C02.0 - Face dorsal da língua

Q59 -C02.1 - Borda da língua

Q60 -C02.2 - Face ventral da língua

Q61 -C02.3 - Dois terços anteriores da língua, parte não especificada

Q62 -C02.4 - Tonsila lingual

Q63 -C02.8 - Lesão invasiva da língua

Q64 -C02.9 - Língua, não especificada

Q65- C03 - Neoplasia maligna de gengiva

Q66 -C03.0 - Gengiva superior

Q67 -C03.1 - Gengiva inferior

Q68 -C03.9 - Gengiva, não especificada

Q69 - C04 - Neoplasia maligna de assoalho da boca

Q70 -C04.0 - Assoalho anterior da boca

Q71 -C04.1 - Assoalho lateral da boca

Q72 -C04.8 - Lesão invasiva do assoalho da boca 
Q73 -C04.9 - Assoalho da boca, não especificado

C05 - Neoplasia maligna de palato

Q74 -

Q75 -C05.0 - Palato duro

Q76 -C05.1 - Palato mole

Q77 -C05.2 - Úvula

Q78 -C05.8 - Lesão invasiva do palato

Q79 -C05.9 - Palato não especificado

Q80 - C06 - Neoplasia maligna de outras partes e de partes não especificadas da boca

Q81 -C06.0 - Mucosa oral

Q82 -C06.1 - Vestíbulo da boca

Q83 -C06.2 - Área retromolar

Q84 -C06.8 - Lesão invasiva de outras partes e de partes não especificadas da boca

Q85 -C06.9 - Boca, não especificada

Q86 - C09 - Neoplasia maligna da amígdala

Q87 -C09.0 - Fossa amigdaliana

Q88 -C09.1 - Pilar amigdaliano(anterior)(posterior)

Q89 -C09.8 - Lesão invasiva da amígdala

Q90 -C09.9 - Amígdala, não especificada

Q91 - C10 - Neoplasia maligna da orofaringe

Q92 -C10.0 - Valécula

Q93 -C10.1 - Face anterior da epiglote

Q94 -C10.2 - Parede lateral da orofaringe

Q95 -C10.3 - Parede posterior da orofaringe

Q96 -C10.4 - Fenda branquial

Q97 -C10.8 - Lesão invasiva da orofaringe

Q98 -C10.9 - Orofaringe, não especificada 
Q99 - C11 - Neoplasia maligna da nasofaringe

Q100 -C11.0 - Parede superior da nasofaringe

Q101 -C11.1 - Parede posterior da nasofaringe

Q102 -C11.2 - Parede lateral da nasofaringe

Q103 -C11.3 - Parede anterior da nasofaringe

Q104 -C11.8 - Lesão invasiva da nasofaringe

Q105 -C11.9 - Nasofaringe, não especificada

Q106 - C12 - Neoplasia maligna do seio piriforme

Q107 - C13 - Neoplasia maligna da hipofaringe

Q108 -C13.0 - Região pós-cricóidea

Q109 -C13.1 - Prega ariepiglótica, face hipofaríngea

Q110 -C13.2 - Parede posterior da hipofaringe

Q111 -C13.8 - Lesão invasiva da orofaringe

Q112 -C13.9 - Hipofaringe, não especificada

Q113 - C14 - Neoplasia maligna de outras localidades e de localidades mal definidas do lábio cavidade oral e faringe Q114 -C14.0 - Faringe, não especificada

Q115 -C14.1 - Laringofaringe, descrita como tal

Q116 -C14.2 - Anel de Waldeye

Q117 -C14.8 - Lesão invasiva do lábio, cavidade oral e faringe

Q118 - C30 - Neoplasia maligna da cavidade nasal e do ouvido médio

Q119 -C30.0 - Cavidade nasal

Q120 -C30.1 - Ouvido médio

Q121 - C31 - Neoplasia maligna dos seios da face

Q122 -C31.0 - Seio maxilar

Q123 -C31.1 - Seio etmoidal

Q124 -C31.2 - Seio frontal

Q125 -C31.3 - Seio esfenoidal

Q126 -C31.8 - Lesão invasiva dos seios da face 
Q127 -C31.9 - Seio da face, não especificado

C32 - Neoplasia maligna da laringe

Q128 -

Q129 -C32.0 - Glote

Q130 -C32.1 - Região supraglótica

Q131 -C32.2 - Região subglótica

Q132 -C32.3 - Cartilagens da laringe

Q133 -C32.8 - Lesão invasiva da laringe

Q134 -C32.9 - Laringe não especificada

Q135 - C77.0 - Neoplasia maligna secundária e não especificada dos gânglios linfáticos

Q136 - C44.9 - Neoplasia maligna da pele

TAMANHO DO TUMOR

Tamanho: $\quad$ Q137 $-\mathrm{cm} \quad \mathrm{X} \quad$ Q138 $-\mathrm{cm} \quad \mathrm{X} \quad$ Q139 $-\mathrm{cm}$

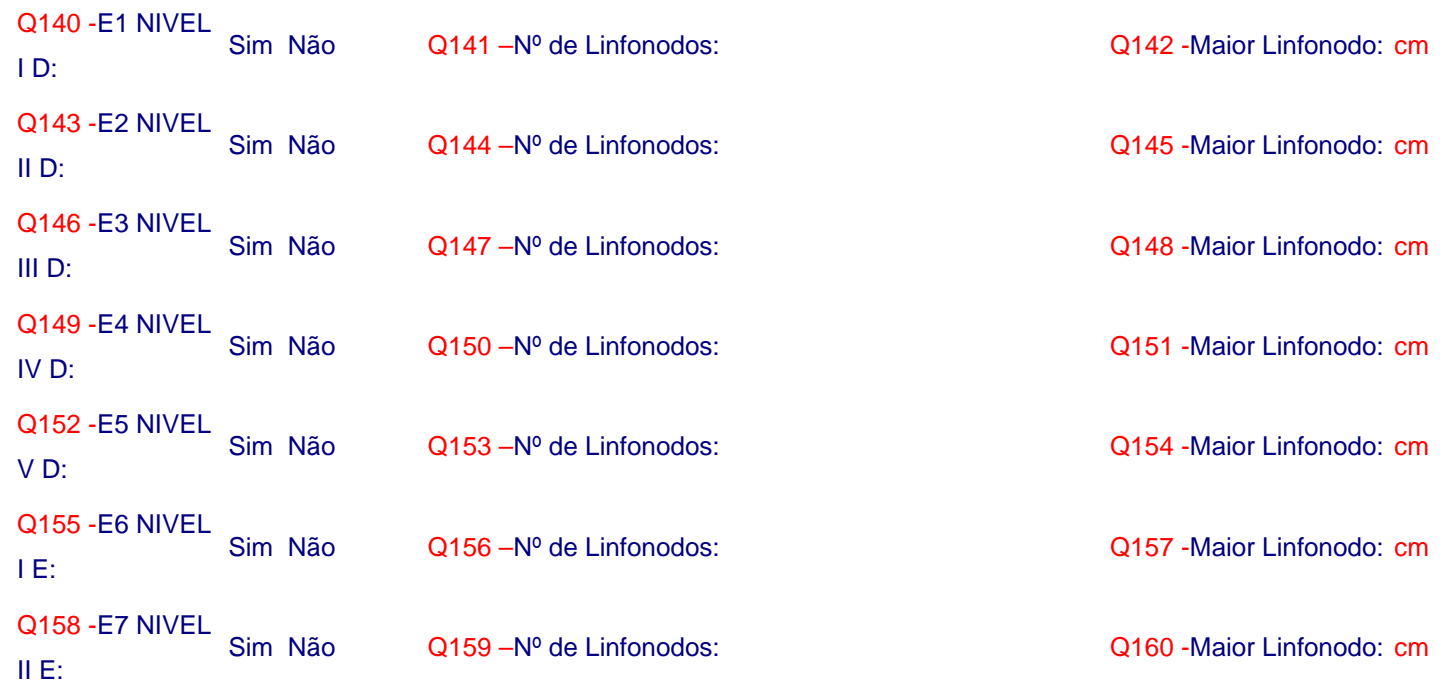




\begin{tabular}{|c|c|c|c|c|c|}
\hline Q161 -E8 NIVEL & $\mathrm{L}_{\mathrm{Sir}}$ & im Não & & Q162 -Nº de Linfonodos: & Q \\
\hline $\begin{array}{l}\text { Q164 -E9 NIVEL } \\
\text { IV E: }\end{array}$ & & im Não & & Q165 - No de Linfonodos: & \\
\hline $\begin{array}{l}\text { Q167 -E10 } \\
\text { NIVEL V E: }\end{array}$ & & im Não & & Q168 - No de Linfonodos: & \\
\hline $\begin{array}{l}\text { Q170 -E11 } \\
\text { NIVEL VI : }\end{array}$ & & im Não & & Q171 -Nº de Linfonodos: & \\
\hline $\begin{array}{l}\text { Q173 -E12 } \\
\text { NIVEL VII : }\end{array}$ & & im Não & & Q174 - $\mathrm{N}^{0}$ de Linfonodos: & \\
\hline METÁSTASES & À DIS & ISTÂNC & & & \\
\hline Q176 -SNC: & & Não & & Q177 -Data: dd/mm/aaaa & \\
\hline $\begin{array}{l}\text { Q178 - } \\
\text { Pulmão: }\end{array}$ & Sim & Não & & Q179 -Data: dd/mm/aaaa & \\
\hline Q180 -Fígado: & Sim & Não & & Q181 -Data: dd/mm/aaaa & \\
\hline Q182 -Ossos: & Sim & Não & & Q183 -Data: dd/mm/aaaa & Q184 - Qual ?: \\
\hline $\begin{array}{l}\text { Q185 -Outros } \\
\text { órgãos: }\end{array}$ & Sim 1 & Não & & Q186 -Data: dd/mm/aaaa & Q187 -Qual ?: \\
\hline & Q188 & $8-\mathrm{T} \quad \mathrm{C}$ & Q189 - N & V Q190-M & \\
\hline
\end{tabular}

Q163 -Maior Linfonodo: cm Q166 -Maior Linfonodo: cm Q169 -Maior Linfonodo: cm Q172 -Maior Linfonodo: cm Q175 -Maior Linfonodo: Cm

INFORMAÇÕES TERAPÊUTICAS

Q191 - Sim Não Q192- Data: dd/mm/aaaa
Cirurgia
realizada:

\section{Q193 - Notas:}

Q194 - 


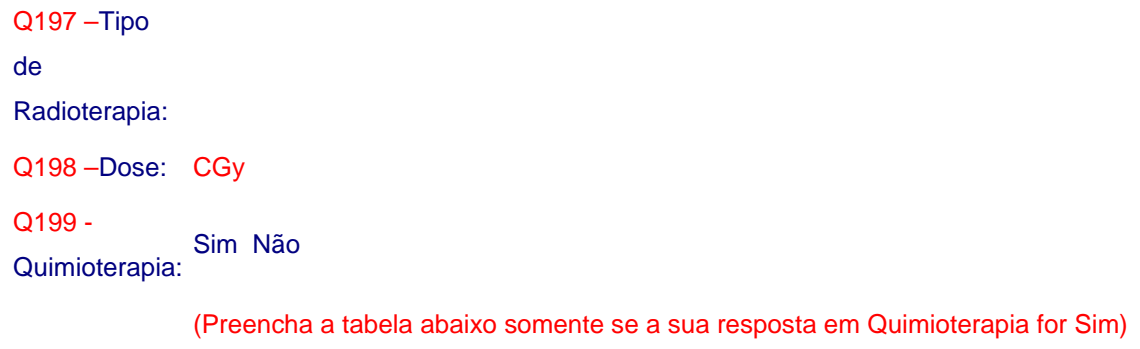

\begin{tabular}{|c|c|c|c|c|c|c|}
\hline & C1 & $\mathrm{C} 2$ & C3 & $\mathrm{C} 4$ & C5 & C6 \\
\hline T1 & Drogas & Dose & $N^{0}$ Dias & Ciclos & Data Ini. & Data Fim \\
\hline L1 & & & & & & \\
\hline L2 & & & & & & \\
\hline L3 & & & & & & \\
\hline L4 & & & & & & \\
\hline L5 & & & & & & \\
\hline Ln & T1_LnC1 & T1_LnC2 & T1_LnC3 & T1_LnC4 & T1_LnC5 & T1_LnC6 \\
\hline
\end{tabular}

OBS: No banco de dados esta tabela acima está codificada da seguinte forma: Tx_LyCz, onde " $x$ ", "y" e "z" representam, respectivamente, "x"o número da tabela, "y" o número das novas informações incluídas e "z" o número do campo de informações (drogas,dose, $n^{\circ}$ dias,ciclos, data inicio ou data fim). Desta forma, o Ly é a localização de uma nova linha e o Cz é a localização da coluna na tabela. Ex: T1_L3C2 - Tabela1 apresentando informações da linha $3(y=3)$ da tabela de quimioterapia, e da $2^{\mathrm{a}}$ coluna (C2), que representa o campo com informações de dose.

Q200 - Tipo

de

Quimioterapia

(especificar):

Figura 17 - Formulário para Dados Clínicos e Laboratoriais 


\title{
8.2. Anexo B
}

\author{
Q0 - No de Identificação: \\ Nome do Paciente:
}

::.Protocolo Anatomopatológico em Cabeça e Pescoço

1) tipo de material

Nota: Preencher o campo biópsia e as informações subseqüentes somente para os casos em que o paciente não foi submetido a cirurgia.

Q1 -Biópsia Peça Cirúrgica - Q2 - data do exame: dd/mm/aaaa

Tamanho do Tumor - dimensão máxima em centímetros

(maiores diâmetros e espessura tomada a partir da superfície mucosa normal)

Q3 -cm X Q4 -cm X Q5 -cm Q6 -Não-avaliável

Q7 -Crescimento:

Exofítico Endofítico Não-avaliável

Q8 - Área de comprometimento do tumor

\section{3) Exame Microscópico}

Tipo Histológico - Carcinoma Epidermóide

Verrucoso Adenoescamoso

Q9 -Variante Morfológica:

Linfoepitelial Escamoso Basalóide Escamoso

Adenóide Fusocelular (Sarcomatóide)

Não-avaliável Outro 
Para microinvasivo ( o componente in situ predomina, com invasão focal da lâmina própria)

Microinvasivo Lâmina Própria Plano

Muscular Cartilagem Outras Estruturas

Q12 -Profundidade de invasão do tumor:

Não-avaliável

Infiltração Vascular

Q13 -Sanguínea:

Q14 -Linfática:

Q15 -Invasão Peri-neural:
Ausente Presente Não-avaliável

Ausente Presente Não-avaliável

Ausente Presente Não-avaliável

Q16 -Infiltrado inflamatório peri-tumoral:

Ausente Escasso Moderado Intenso Não-avaliável

Q17- Margens Cirúrgicas: Com displasia de alto grau (especificar o local ):

Envolvida por tumor invasivo(especificar o local ):

Com carcinoma in situ (especificar o local):

Não avaliável

Livres de tumor

Q19-Lesões em órgãos adjacentes

\begin{tabular}{|c|c|c|}
\hline \multicolumn{3}{|l|}{ Linfonodos } \\
\hline \multicolumn{3}{|l|}{ Nível I D } \\
\hline Q20-No & Q21-no & Q22-invasão \\
\hline dissecado & comprometido & extracapsular \\
\hline \multicolumn{3}{|l|}{ Nível II D } \\
\hline Q23-No & Q24-n ${ }^{\circ}$ & Q25-invasão \\
\hline dissecado & comprometido & extracapsular \\
\hline \multicolumn{3}{|l|}{ Nível III D } \\
\hline Q26-No & Q27-no & Q28-invasão \\
\hline dissecado & comprometido & extracapsular \\
\hline \multicolumn{3}{|l|}{$\underline{\text { Nível IV D }}$} \\
\hline Q29-No & Q30-nº & Q31-invasão \\
\hline
\end{tabular}


dissecado

Nível V D

Q32-No

dissecado

Nível I E

Q35-No

dissecado

Nível II E

Q38-No

dissecado

Nível III E

Q41-No

dissecado

Nível IV E

Q44-No

dissecado

Nível VE

Q47-No

dissecado

Nível VI

Q50-No

dissecado

Nível VII

Q53-No

dissecado comprometido

Q33-n ${ }^{\circ}$

comprometido extracapsular

Q34-invasão

extracapsular
Q36- $\mathrm{n}^{\circ}$

comprometido

Q39-n ${ }^{\circ}$

comprometido

Q42-n ${ }^{\circ}$

comprometido

Q45- $n^{\circ}$

comprometido

Q48- $n^{\circ}$

comprometido

Q51-no

comprometido

Q54-n

comprometido
Q37-invasão

extracapsular

Q40-invasão

extracapsular

Q43-invasão

extracapsular

Q46-invasão

extracapsular

Q49-invasão

extracapsular

Q52-invasão

extracapsular

Q55-invasão

extracapsular

Estadiamento Patológico: Q56-Tcm X Q57-Ncm X Q58-Mcm Q59-Não-avaliável

Figura 18 - Formulário para Dados Anatomopatológicos 


\subsection{ANEXO C}

\section{::.Acompanhamento de Cabeça e Pescoço}

Q1-Sem evidências de doenças - Q2- Data:dd/mm/aaaa

Q3-Recidiva loco-regional ou residual

Q4-Metástase à distância

Q5-2 Tumor primário

Q6-Óbito

Q7-Paciente perdido do acompanhamento - Q8- Data:dd/mm/aaaa

Comentários referente aos campos mencionados acima:

Sem evidências de doenças - Ao clicar neste tópico será aberto somente o campo de inclusão de data de retorno dos paciente, ocultando os demais itens do questionário;

Recidiva loco-regional ou residual - Ao clicar neste tópico será aberto somente os itens A e B deste questionário, demais serão ocultados;

Metástase à distância - Ao clicar neste tópico será aberto somente os itens C e D deste questionário, demais serão ocultados;

$2^{\circ}$ Tumor primário - Ao clicar neste tópico será aberto somente os itens E e F deste questionário, demais serão ocultados;

Óbito - Ao clicar neste tópico será aberto somente o item G deste questionário, demais serão ocultados.

Paciente perdido do acompanhamento - Ao clicar neste tópico será aberto somente o campo de inclusão de data. Incluir tela de alerta: "Esta opção somente deverá ser escolhida na condição da busca de informações sobre o paciente terem sido esgotadas".

OBS: Se mais de uma opção for escolhida, serão abertos na tela os tópicos relacionados ao itens da opção: Ex: Paciente retornou para acompanhamento, mas teve uma recidiva e veio a óbito, os tópicos a serem marcados serão: 
Recidiva loco-regional ou residual Óbito , esta propriedade não se aplica para os casos da opção escolhida ser :

"Paciente Perdido".

A) RECIDIVAS - Recidiva loco-regional ou residual

Sim Não Q10- Data:
Q9- Tumor

Residual

(tumor

primário): $\mathrm{dd} / \mathrm{mm} / \mathrm{aaaa}$

Q12- Data:

$\mathrm{dd} / \mathrm{mm} / \mathrm{aaaa}$

Q11- Recidiva Sim Não

Local:

Q13-Tumor

Residual Sim Não

Q14- Data:

(doença

regional):

Q16-Data:

Q15-Recidiva Sim Não

$\mathrm{dd} / \mathrm{mm} / \mathrm{aaaa}$

Regional -

Cervical:

Q17-Nível: $\quad$ Q18- Direito Esquerdo

Q19-Nível: $\quad$ Q20-Direito Esquerdo

Q21-Nível: $\quad$ Q22-Direito Esquerdo

B) TRATAMENTO REALIZADO PARA A RECIDIVA - Recidiva loco-regional ou residual

Q23- Notas:

Sim Não

Q25-Se sim, Data: dd/mm/aaaa

Q24-Cirurgia:

Q26-Notas: 
Q27-

Sim Não

Radioterapia:

Q30-Se sim,

tipo de

Radioterapia:

Q31-Se sim

Dose:

Q32-

Quimioterapia:

Sim Não

$\begin{array}{llll}\mathrm{C} 1 & \mathrm{C} 2 & \mathrm{C} 3 & \mathrm{C} 4\end{array}$

C5

\begin{tabular}{l|l|ll||l||l} 
T1 & Drogas & Dose & Ciclos & Data Início & Data Término
\end{tabular}

L1

L2

L3

L4

L5

L6

L7

L8

$\begin{array}{llllll}\text { Ln } & \text { T1_LnC1 } & \text { T1_LnC2 } & \text { T1_LnC3 } & \text { T1_LnC4 } & \text { T1_LnC5 }\end{array}$

OBS: No banco de dados esta tabela acima está codificada da seguinte forma: Tx_LyCz, onde " $x$ ", "y" e " $z$ " representam, respectivamente, "x"

o número da tabela, "y" o número das novas informações incluídas e "z" o número do campo de informações (drogas, dose, $n^{\circ}$ dias,ciclos, data inicio ou data fim). Desta forma, o Ly é a localização de uma nova linha e o Cz é a localização da coluna na tabela. Ex: T1_L3C2 - Tabela1 apresentando informações da linha $3(y=3)$ da tabela de quimioterapia da recidiva, e da $2^{\mathrm{a}}$ coluna (C2), que representa o campo com informações de dose.

Q33 - Tipo de

Quimioterapia

(especificar): 


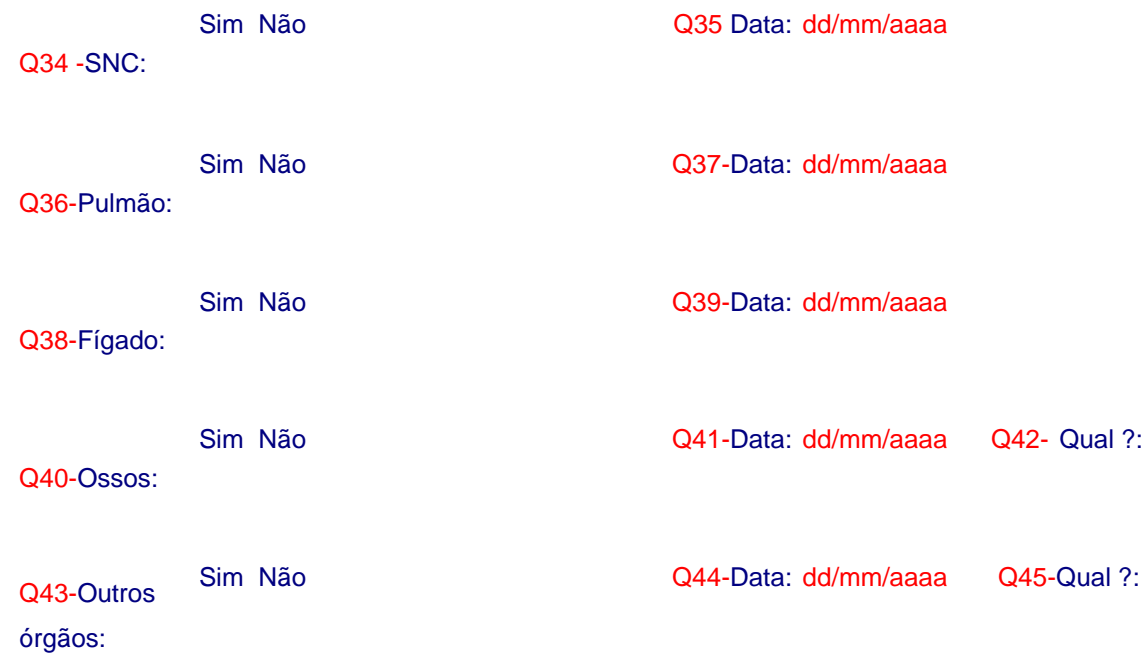

\section{D) TRATAMENTO REALIZADO PARA A METÁSTASES À DISTÂNCIA}

Q46-Notas:

Sim Não

Q47-Cirurgia:

Q49-Notas:

Q50-

Sim Não

Radioterapia:

Q53-Se sim,

tipo de

Radioterapia:

Q54-Se sim,

Dose:

Q55-

Quimioterapia: Sim Não
Q48-Se sim, Data:

$\mathrm{dd} / \mathrm{mm} / \mathrm{aaaa}$

Q51-Se sim, Data Início:

$\mathrm{dd} / \mathrm{mm} / \mathrm{aaaa}$

Q52- Data Fim: 
L1

$\begin{array}{llllll}\text { Ln } & \text { T2_LnC1 } & \text { T2_LnC2 } & \text { T2_LnC3 } & \text { T2_LnC4 } & \text { T2_LnC5 }\end{array}$

OBS: No banco de dados esta tabela acima está codificada da seguinte forma: Tx_LyCz, onde " $x$ ", "y" e " $z$ " representam, respectivamente, " $\mathbf{x}$ "

o número da tabela, "y" o número das novas informações incluídas e "z" o número do campo de informações (drogas, dose, $\mathrm{n}^{\circ}$ dias,ciclos, data inicio ou data fim). Desta forma, o Ly é a localização de uma nova linha e o Cz é a localização da coluna na tabela. Ex: T2_L3C2 - Tabela2 apresentando informações da linha 3 (y=3) da tabela de quimioterapia de metástase, e da $2^{\mathrm{a}}$ coluna (C2), que representa o campo com informações de dose.

Q56-Tipo de

Quimioterapia

(especificar):

\section{E) SEGUNDA LESÃO - $2^{\circ}$ Tumor primário}

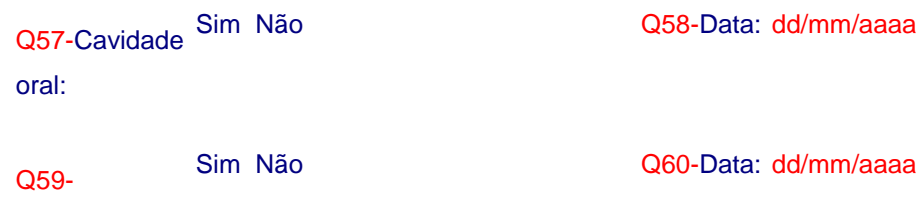

Orofaringe:

Q61- Sim Não Q62-Data: dd/mm/aaaa

Hipofaringe: 
Sim Não

Q63-Laringe:

Sim Não

Q65-Esôfago:

Sim Não

Q67-Pulmão:

Sim Não

Q69-Outros:

\section{F) TRATAMENTO DA SEGUNDA LESÃO - $2^{\circ}$ Tumor primário}

Q72-Notas:

Sim Não

Q73-Cirurgia:

Q75-Notas:

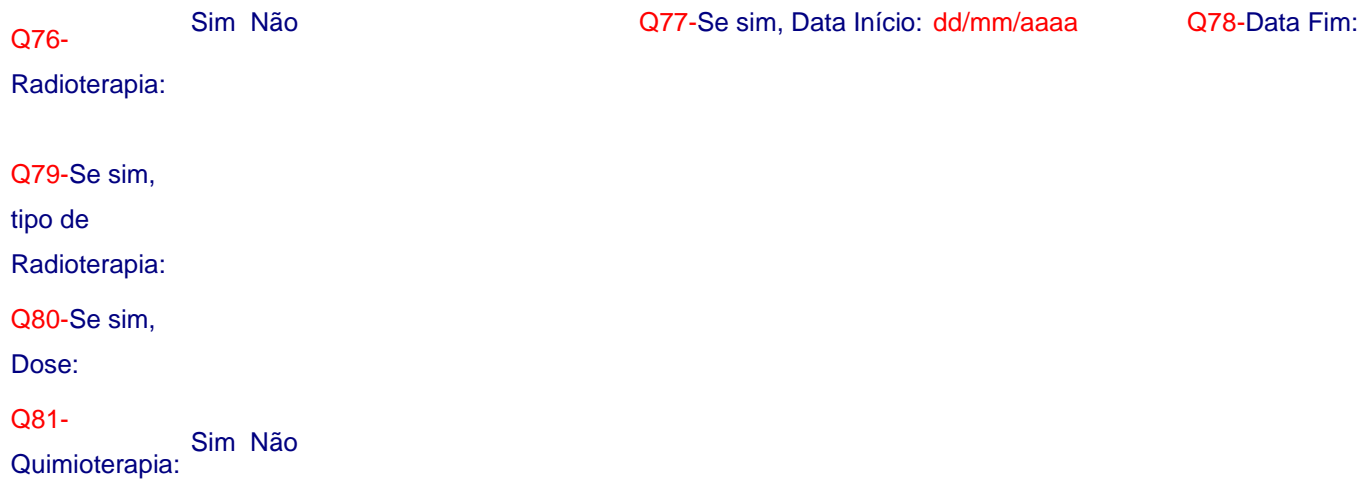

\begin{tabular}{lll|l} 
T3 Drogas Dose Ciclos Data Início & Data \\
Término
\end{tabular}

L1

L2

L3

L4 


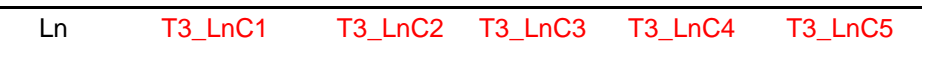

OBS: No banco de dados esta tabela acima está codificada da seguinte forma: Tx_LyCz, onde " $x$ ", "y" e "z" representam, respectivamente, " $\mathbf{x}$ "

o número da tabela, "y" o número das novas informações incluídas e "z" o número do campo de informações (drogas, dose, $n^{\circ}$ dias,ciclos, data inicio ou data fim). Desta forma, o Ly é a localização de uma nova linha e o Cz é a localização da coluna na tabela. Ex: T3_L3C2 - Tabela3 apresentando informações da linha $3(y=3)$ da tabela de quimioterapia da segunda lesão, e da $2^{a}$ coluna (C2), que representa o campo com informações de dose.

Q82-Tipo de

Quimioterapia

(especificar):

G) INFORMAÇŌES SOBRE O ÓBITO

Q83-Óbito:

Q84-Data Óbito:
Sim Não (preencha os itens abaixo somente se for sim)

$\mathrm{dd} / \mathrm{mm} /$ aaaa

\section{Outra causa Óbito pela neoplasia}

Q85-Tipo de Óbito:

Q86-Se por outra causa

informe qual:

Figura 19 - Formulário para Dados de Seguimento Clínico 


\subsection{ANEXO D}

Tabela 14 - Resultado da avaliação semiquantitativa da imunoexpressão citoplasmática de ciclina D1 em carcinoma epidermóide de laringe.

\begin{tabular}{|c|c|c|c|c|c|c|c|}
\hline & & & & & pressão & itoplas & ática \\
\hline Caso & Prontuário & $\begin{array}{l}\text { Bloco de } \\
\text { parafina }\end{array}$ & $\begin{array}{c}\text { Expressão } \\
\text { nuclear }\end{array}$ & 0 & $<10 \%$ & $\begin{array}{c}10- \\
50 \%\end{array}$ & $>50 \%$ \\
\hline 1 & 66361 & $11569 d$ & Sim & $x$ & & & \\
\hline 2 & 80235 & $14381 c$ & Sim & & $x$ & & \\
\hline 3 & 85773 & $15451 \mathrm{~h}$ & Sim & & $x$ & & \\
\hline 4 & 131929 & $25528 f$ & Sim & & $x$ & & \\
\hline 5 & 119005 & $27738 b$ & Sim & $x$ & & & \\
\hline 6 & 119384 & 28999a & Sim & $x$ & & & \\
\hline 7 & 136391 & 29753b & Sim & $x$ & & & \\
\hline 8 & 148655 & $31247 \mathrm{~g}$ & Sim & $x$ & & & \\
\hline 9 & 145971 & $31379 b$ & Sim & $x$ & & & \\
\hline 10 & 153830 & $32320 \mathrm{e}$ & Sim & $x$ & & & \\
\hline 11 & 156220 & $34211 b$ & Sim & $x$ & & & \\
\hline 12 & 189765 & $40624 h$ & Sim & & $x$ & & \\
\hline 13 & 197825 & $42531 e$ & Sim & $x$ & & & \\
\hline 14 & 197791 & $44123 \mathrm{~h}$ & Sim & $x$ & & & \\
\hline 15 & 208407 & $46034 b$ & Sim & $x$ & & & \\
\hline 16 & 217459 & 48298d & Não & $x$ & & & \\
\hline 17 & 210417 & 49490b & Sim & & $x$ & & \\
\hline 18 & 245004 & $56312 a$ & Sim & & & & $x$ \\
\hline 19 & 106032 & $56461 e$ & Sim & & $x$ & & \\
\hline 20 & 146368 & $56923 a$ & Sim & $x$ & & & \\
\hline 21 & 143240 & $61912 e$ & Sim & & $X$ & & \\
\hline 22 & 261074 & $64426 c$ & Sim & $x$ & & & \\
\hline 23 & 279366 & $65000 \mathrm{e}$ & Sim & $x$ & & & \\
\hline
\end{tabular}




\begin{tabular}{|c|c|c|c|c|c|c|}
\hline 24 & 284732 & $67557 a$ & Sim & & $X$ & \\
\hline 25 & 255046 & $70787 b$ & Sim & $x$ & & \\
\hline 26 & 197819 & $71943 b$ & Sim & & $X$ & \\
\hline 27 & 328101 & $76182 c$ & Sim & $x$ & & \\
\hline 28 & 352406 & $81698 a$ & Sim & $x$ & & \\
\hline 29 & 363256 & $83919 b$ & Sim & $x$ & & \\
\hline 30 & 373592 & $87848 a$ & Sim & & $X$ & \\
\hline 31 & 379520 & $87884 h$ & Sim & $x$ & & \\
\hline 32 & 414287 & $96476 a$ & Sim & $x$ & & \\
\hline 33 & 420444 & $96679 d$ & $\operatorname{Sim}$ & $x$ & & \\
\hline 34 & 425760 & $97362 c$ & Sim & $x$ & & \\
\hline 35 & 381085 & $97365 c$ & Sim & & & $x$ \\
\hline 36 & 424898 & $99347 b$ & Sim & $x$ & & \\
\hline 37 & 432568 & 101796a & $\operatorname{Sim}$ & & $X$ & \\
\hline 38 & 449256 & $103277 b$ & Sim & $x$ & & \\
\hline 39 & 443060 & $104597 a$ & Sim & $x$ & & \\
\hline 40 & 460166 & 107728s & Sim & $x$ & & \\
\hline 41 & 471370 & $108714 \mathrm{C}$ & Sim & $x$ & & \\
\hline 42 & 467080 & 109261c & Sim & & $X$ & \\
\hline 43 & 439555 & 109906b & Sim & & $x$ & \\
\hline 44 & 472461 & $112101 \mathrm{c}$ & $\operatorname{Sim}$ & $x$ & & \\
\hline 45 & 488358 & 113298e & Sim & $x$ & & \\
\hline 46 & 478821 & $115775 a$ & Sim & $x$ & & \\
\hline 47 & 499404 & 116917a & Sim & $x$ & & \\
\hline
\end{tabular}




\subsection{ANEXO E}

Tabela 15 - Quantificação digital randomizada, e cega quanto à ocorrência de metástase linfática, da imunoexpressão nuclear e citoplasmática de ciclina D1 em grupo de 1000 células para cada caso estudado.

\begin{tabular}{|c|c|c|c|c|c|c|c|c|c|c|c|c|c|c|}
\hline \multirow{3}{*}{$\begin{array}{c}\text { Caso } \\
1\end{array}$} & \multirow[b]{2}{*}{ Prontuário } & \multirow[b]{2}{*}{ Expressão } & \multicolumn{12}{|c|}{ Campos microscópicos } \\
\hline & & & 1 & 2 & 3 & 4 & 5 & 6 & 7 & 8 & 9 & 10 & 11 & 12 \\
\hline & \multirow[t]{3}{*}{71943} & $c+$ & 1 & 0 & 0 & 0 & 0 & 1 & 1 & 0 & 1 & 0 & 0 & 0 \\
\hline & & $n+$ & 21 & 18 & 17 & 33 & 26 & 21 & 30 & 32 & 21 & 21 & 21 & 28 \\
\hline & & - & 28 & 22 & 35 & 23 & 23 & 33 & 31 & 21 & 18 & 30 & 25 & 9 \\
\hline \multirow[t]{3}{*}{2} & \multirow[t]{3}{*}{34211} & $c+$ & 0 & 0 & 0 & 0 & 0 & 0 & 0 & 0 & 0 & 0 & 0 & 0 \\
\hline & & $n+$ & 4 & 5 & 8 & 5 & 3 & 54 & 1 & 1 & 5 & 7 & 2 & 3 \\
\hline & & - & 57 & 48 & 44 & 55 & 53 & 21 & 59 & 67 & 65 & 78 & 67 & 82 \\
\hline \multirow[t]{3}{*}{3} & \multirow[t]{3}{*}{61902} & $c+$ & 1 & 1 & 3 & 1 & 1 & 0 & 0 & 2 & 3 & 0 & 2 & 0 \\
\hline & & $\mathbf{n}+$ & 31 & 38 & 29 & 29 & 35 & 54 & 38 & 38 & 28 & 52 & 48 & 32 \\
\hline & & - & 30 & 25 & 24 & 28 & 15 & 21 & 23 & 23 & 33 & 33 & 24 & 25 \\
\hline \multirow[t]{3}{*}{4} & \multirow[t]{3}{*}{109906} & $c+$ & 0 & 0 & 0 & 0 & 1 & 1 & 1 & 2 & 0 & 1 & 0 & 0 \\
\hline & & $\mathbf{n}+$ & 33 & 45 & 30 & 44 & 34 & 25 & 28 & 33 & 46 & 50 & 40 & 40 \\
\hline & & - & 54 & 33 & 40 & 37 & 29 & 51 & 45 & 50 & 29 & 51 & 24 & 29 \\
\hline \multirow[t]{3}{*}{5} & \multirow[t]{3}{*}{97362} & $c+$ & 5 & 8 & 4 & 0 & 1 & 1 & 0 & 0 & 0 & 0 & 0 & 0 \\
\hline & & $n+$ & 14 & 0 & 6 & 17 & 23 & 16 & 26 & 29 & 34 & 11 & 12 & 23 \\
\hline & & - & 41 & 40 & 21 & 32 & 28 & 38 & 32 & 24 & 18 & 56 & 57 & 31 \\
\hline \multirow[t]{3}{*}{6} & \multirow[t]{3}{*}{109261} & $c+$ & 0 & 0 & 0 & 0 & 0 & 2 & 0 & 0 & 0 & 0 & 0 & 1 \\
\hline & & $n+$ & 30 & 48 & 37 & 31 & 26 & 21 & 23 & 19 & 31 & 21 & 39 & 19 \\
\hline & & - & 33 & 13 & 13 & 17 & 10 & 14 & 27 & 47 & 26 & 13 & 27 & 28 \\
\hline \multirow[t]{3}{*}{7} & \multirow[t]{3}{*}{44123} & $c+$ & 0 & 0 & 0 & 0 & 0 & 0 & 0 & 0 & 1 & 1 & 1 & 0 \\
\hline & & $n+$ & 11 & 5 & 14 & 4 & 5 & 3 & 8 & 3 & 3 & 2 & 2 & 3 \\
\hline & & - & 49 & 57 & 44 & 58 & 66 & 62 & 61 & 67 & 39 & 58 & 61 & 37 \\
\hline \multirow[t]{3}{*}{8} & \multirow[t]{3}{*}{107728} & $c+$ & 0 & 0 & 0 & 0 & 0 & 0 & 0 & 0 & 0 & 0 & 0 & 0 \\
\hline & & $n+$ & 29 & 24 & 45 & 30 & 23 & 29 & 22 & 23 & 34 & 28 & 30 & 23 \\
\hline & & - & 29 & 49 & 28 & 26 & 25 & 21 & 47 & 42 & 38 & 30 & 26 & 34 \\
\hline \multirow[t]{3}{*}{9} & \multirow[t]{3}{*}{29753} & $c+$ & 0 & 0 & 0 & 0 & 0 & 0 & 0 & 0 & 0 & 0 & 0 & 0 \\
\hline & & $n+$ & 16 & 16 & 19 & 12 & 15 & 16 & 16 & 14 & 19 & 11 & 10 & 17 \\
\hline & & - & 66 & 42 & 48 & 59 & 62 & 59 & 58 & 52 & 59 & 54 & 53 & 57 \\
\hline \multirow[t]{3}{*}{10} & 14381 & $c+$ & 0 & 1 & 0 & 0 & 0 & 0 & 2 & 0 & 0 & 0 & 0 & 0 \\
\hline & & $n+$ & 41 & 36 & 40 & 40 & 24 & 37 & 26 & 29 & 40 & 34 & 53 & 31 \\
\hline & & - & 18 & 19 & 14 & 16 & 18 & 17 & 9 & 17 & 10 & 8 & 10 & 29 \\
\hline 11 & 15451 & $c+$ & 0 & 0 & 0 & 0 & 0 & 0 & 0 & 0 & 0 & 0 & 0 & 0 \\
\hline & & $n+$ & 12 & 11 & 8 & 14 & 17 & 25 & 18 & 24 & 13 & 5 & 15 & 14 \\
\hline & & - & 53 & 95 & 64 & 82 & 77 & 51 & 72 & 77 & 36 & 69 & 70 & 78 \\
\hline 12 & 96476 & $c+$ & 0 & 0 & 0 & 0 & 0 & 0 & 0 & 0 & 0 & 0 & 0 & 0 \\
\hline & & $n+$ & 5 & 21 & 15 & 22 & 15 & 20 & 28 & 23 & 23 & 14 & 21 & 15 \\
\hline & & - & 78 & 52 & 54 & 69 & 56 & 57 & 42 & 52 & 61 & 71 & 32 & 69 \\
\hline 13 & 103277 & $c+$ & 0 & 0 & 0 & 0 & 0 & 0 & 0 & 1 & 0 & 0 & 1 & 0 \\
\hline & & $n+$ & 26 & 16 & 17 & 25 & 19 & 30 & 28 & 36 & 34 & 27 & 21 & 42 \\
\hline
\end{tabular}




\begin{tabular}{|c|c|c|c|c|c|c|c|c|c|c|c|c|c|c|}
\hline \multirow{3}{*}{14} & \multirow{3}{*}{112101} & \multirow{2}{*}{$\bar{c}+$} & \multirow{2}{*}{$\begin{array}{c}55 \\
0\end{array}$} & \multirow{2}{*}{$\begin{array}{c}70 \\
0\end{array}$} & \multirow{2}{*}{$\begin{array}{c}57 \\
0\end{array}$} & \multirow{2}{*}{$\frac{47}{0}$} & \multirow{2}{*}{$\begin{array}{c}41 \\
0\end{array}$} & \multirow{2}{*}{$\frac{32}{0}$} & \multirow{2}{*}{47} & \multirow{2}{*}{31} & \multirow{2}{*}{$\frac{48}{0}$} & \multirow{2}{*}{41} & \multirow{2}{*}{$\frac{44}{0}$} & 35 \\
\hline & & & & & & & & & & & & & & 0 \\
\hline & & $n+$ & 11 & 15 & 9 & 1 & 4 & 0 & 1 & 5 & 2 & 9 & 3 & 0 \\
\hline & & - & 38 & 33 & 46 & 87 & 55 & 66 & 76 & 54 & 73 & 63 & 79 & 92 \\
\hline & 49490 & $c+$ & 0 & 0 & 0 & 0 & 0 & 0 & 7 & 10 & 11 & 20 & 28 & 17 \\
\hline & & $n+$ & 17 & 1 & 1 & 19 & 27 & 21 & 18 & 7 & 8 & 5 & 10 & 10 \\
\hline & & - & 13 & 80 & 74 & 32 & 30 & 24 & 20 & 12 & 9 & 10 & 18 & 16 \\
\hline & 64428 & $c+$ & 0 & 0 & 0 & 0 & 0 & 0 & 0 & 0 & 0 & 0 & 0 & 0 \\
\hline & & $n+$ & 26 & 22 & 12 & 14 & 11 & 20 & 17 & 18 & 19 & 23 & 15 & 18 \\
\hline & & - & 21 & 15 & 44 & 35 & 38 & 27 & 34 & 19 & 23 & 24 & 41 & 47 \\
\hline & 25528 & $c+$ & 0 & 0 & 0 & 0 & 0 & 0 & 0 & 0 & 0 & 0 & 0 & 0 \\
\hline & & $n+$ & 29 & 28 & 30 & 36 & 30 & 26 & 24 & 24 & 28 & 25 & 31 & 19 \\
\hline & & - & 27 & 38 & 21 & 35 & 35 & 29 & 23 & 25 & 30 & 32 & 28 & 31 \\
\hline & 11569 & $c+$ & 0 & 0 & 0 & 0 & 0 & 0 & 0 & 0 & 0 & 0 & 0 & 0 \\
\hline & & $n+$ & 9 & 11 & 4 & 1 & 3 & 3 & 4 & 2 & 0 & 4 & 3 & 3 \\
\hline & & - & 68 & 60 & 66 & 76 & 84 & 75 & 79 & 58 & 60 & 57 & 72 & 62 \\
\hline & 65000 & $c+$ & 0 & 0 & 0 & 0 & 0 & 0 & 0 & 0 & 0 & 0 & 0 & 0 \\
\hline & & $n+$ & 14 & 12 & 9 & 0 & 1 & 1 & 4 & 3 & 0 & 2 & 1 & 1 \\
\hline & & - & 49 & 42 & 56 & 72 & 71 & 63 & 67 & 56 & 70 & 80 & 75 & 65 \\
\hline & 116917 & $c+$ & 0 & 0 & 0 & 0 & 0 & 0 & 0 & 0 & 0 & 0 & 0 & 0 \\
\hline & & $n+$ & 17 & 16 & 13 & 14 & 18 & 13 & 6 & 4 & 2 & 8 & 5 & 16 \\
\hline & & - & 29 & 33 & 29 & 28 & 37 & 30 & 61 & 57 & 61 & 31 & 29 & 35 \\
\hline & 67557 & $c+$ & 0 & 0 & 0 & 1 & 1 & 0 & 0 & 0 & 0 & 0 & 0 & 0 \\
\hline & & $n+$ & 32 & 24 & 18 & 20 & 18 & 13 & 18 & 22 & 25 & 27 & 28 & 24 \\
\hline & & - & 18 & 5 & 27 & 32 & 42 & 41 & 33 & 24 & 22 & 32 & 24 & 35 \\
\hline & 108714 & $c+$ & 3 & 0 & 0 & 0 & 0 & 0 & 0 & 0 & 0 & 0 & 0 & 0 \\
\hline & & $n+$ & 16 & 20 & 20 & 31 & 9 & 12 & 5 & 18 & 4 & 13 & 3 & 6 \\
\hline & & - & 32 & 35 & 27 & 23 & 54 & 37 & 62 & 54 & 58 & 52 & 57 & 68 \\
\hline & 113298 & $c+$ & 0 & 0 & 0 & 2 & 0 & 0 & 0 & 0 & 0 & 0 & 0 & 0 \\
\hline & & $n+$ & 3 & 3 & 2 & 2 & 2 & 4 & 2 & 4 & 8 & 1 & 13 & 11 \\
\hline & & - & 62 & 76 & 98 & 56 & 54 & 62 & 53 & 63 & 44 & 60 & 38 & 26 \\
\hline & 76182 & $c+$ & 0 & 0 & 0 & 0 & 0 & 0 & 0 & 0 & 0 & 0 & 0 & 0 \\
\hline & & $n+$ & 6 & 3 & 9 & 5 & 17 & 15 & 0 & 7 & 11 & 9 & 14 & 8 \\
\hline & & - & 49 & 42 & 37 & 50 & 25 & 32 & 53 & 45 & 23 & 24 & 42 & 55 \\
\hline & 56461 & $c+$ & 1 & 0 & 0 & 0 & 0 & 0 & 0 & 0 & 0 & 0 & 0 & 0 \\
\hline & & $n+$ & 7 & 27 & 16 & 31 & 19 & 18 & 20 & 3 & 7 & 4 & 41 & 7 \\
\hline & & - & 56 & 48 & 41 & 54 & 62 & 53 & 63 & 48 & 36 & 43 & 30 & 33 \\
\hline & 46034 & $c+$ & 0 & 1 & 1 & 0 & 0 & 1 & 0 & 0 & 0 & 0 & 0 & 0 \\
\hline & & $n+$ & 6 & 17 & 19 & 3 & 33 & 31 & 23 & 32 & 30 & 32 & 15 & 26 \\
\hline & & - & 76 & 53 & 71 & 90 & 60 & 71 & 81 & 50 & 52 & 39 & 35 & 52 \\
\hline & 32320 & $c+$ & 0 & 0 & 0 & 0 & 0 & 0 & 0 & 0 & 0 & 0 & 0 & 0 \\
\hline & & $n+$ & 3 & 5 & 1 & 1 & 3 & 3 & 3 & 7 & 6 & 5 & 1 & 1 \\
\hline & & - & 62 & 58 & 57 & 66 & 62 & 45 & 68 & 50 & 61 & 39 & 64 & 73 \\
\hline & 27738 & $c+$ & 0 & 0 & 0 & 0 & 0 & 0 & 0 & 0 & 0 & 0 & 0 & 0 \\
\hline & & $n+$ & 1 & 1 & 0 & 1 & 0 & 0 & 1 & 0 & 0 & 1 & 0 & 0 \\
\hline & & - & 66 & 57 & 61 & 70 & 64 & 93 & 71 & 51 & 75 & 65 & 51 & 75 \\
\hline & 115775 & $c+$ & 0 & 0 & 0 & 0 & 0 & 0 & 0 & 0 & 0 & 0 & 0 & 0 \\
\hline & & $n+$ & 8 & 5 & 5 & 6 & 6 & 5 & 4 & 4 & 7 & 6 & 7 & 2 \\
\hline & & - & 61 & 64 & 71 & 73 & 60 & 70 & 61 & 62 & 57 & 56 & 68 & 69 \\
\hline & 101796 & $c+$ & 2 & 0 & 0 & 6 & 3 & 4 & 3 & 3 & 1 & 0 & 0 & 0 \\
\hline & & $n+$ & 42 & 26 & 33 & 18 & 24 & 32 & 25 & 27 & 20 & 29 & 44 & 26 \\
\hline
\end{tabular}




\begin{tabular}{|c|c|c|c|c|c|c|c|c|c|c|c|c|c|c|}
\hline \multirow{4}{*}{31} & \multirow{3}{*}{99347} & \multirow{2}{*}{ c } & \multirow{2}{*}{$\begin{array}{c}39 \\
0\end{array}$} & \multirow{2}{*}{$\frac{38}{0}$} & \multirow{2}{*}{$\frac{36}{0}$} & \multirow{2}{*}{$\begin{array}{c}21 \\
0\end{array}$} & \multirow{2}{*}{$\frac{19}{0}$} & \multirow{2}{*}{$\frac{14}{0}$} & \multirow{2}{*}{$\frac{15}{0}$} & \multirow{2}{*}{$\frac{15}{0}$} & \multirow{2}{*}{$\frac{18}{0}$} & \multirow{2}{*}{$\frac{18}{0}$} & \multirow{2}{*}{$\frac{18}{0}$} & \multirow{2}{*}{$\frac{15}{0}$} \\
\hline & & & & & & & & & & & & & & \\
\hline & & $n+$ & 33 & 27 & 37 & 40 & 38 & 43 & 51 & 41 & 39 & 33 & 36 & 40 \\
\hline & & - & 12 & 20 & 15 & 20 & 16 & 20 & 17 & 15 & 17 & 14 & 16 & 16 \\
\hline \multirow[t]{3}{*}{32} & 70787 & $c+$ & 4 & 3 & 2 & 0 & 2 & 1 & 0 & 0 & 1 & 0 & 1 & 0 \\
\hline & & $n+$ & 10 & 8 & 10 & 7 & 3 & 10 & 12 & 12 & 9 & 12 & 6 & 6 \\
\hline & & - & 43 & 36 & 36 & 33 & 42 & 37 & 47 & 31 & 47 & 38 & 42 & 40 \\
\hline 33 & 104597 & $c+$ & 1 & 0 & 1 & 1 & 0 & 1 & 0 & 1 & 0 & 0 & 0 & 0 \\
\hline & & $n+$ & 20 & 20 & 16 & 15 & 12 & 13 & 20 & 12 & 13 & 21 & 14 & 15 \\
\hline & & - & 33 & 22 & 32 & 29 & 23 & 30 & 19 & 20 & 31 & 17 & 31 & 32 \\
\hline 34 & 97365 & $c+$ & 1 & 0 & 3 & 0 & 1 & 9 & 0 & 1 & 0 & 0 & 0 & 1 \\
\hline & & $n+$ & 35 & 34 & 48 & 33 & 25 & 0 & 36 & 26 & 25 & 35 & 39 & 59 \\
\hline & & - & 40 & 4 & 14 & 4 & 25 & 22 & 29 & 1 & 42 & 5 & 3 & 11 \\
\hline 35 & 56312 & $c+$ & 2 & 7 & 1 & 3 & 1 & 9 & 18 & 15 & 15 & 24 & 19 & 16 \\
\hline & & $n+$ & 8 & 1 & 9 & 9 & 6 & 0 & 0 & 0 & 0 & 0 & 0 & 0 \\
\hline & & - & 30 & 21 & 17 & 27 & 26 & 29 & 3 & 19 & 19 & 13 & 15 & 4 \\
\hline 36 & 31379 & $c+$ & 0 & 0 & 0 & 0 & 0 & 0 & 0 & 0 & 0 & 0 & 0 & 0 \\
\hline & & $n+$ & 22 & 33 & 20 & 43 & 41 & 16 & 20 & 13 & 12 & 12 & 36 & 28 \\
\hline & & - & 45 & 36 & 32 & 43 & 47 & 38 & 32 & 50 & 50 & 36 & 41 & 31 \\
\hline 37 & 40624 & $c+$ & 0 & 0 & 0 & 0 & 0 & 1 & 1 & 0 & 1 & 0 & 0 & 0 \\
\hline & & $n+$ & 30 & 26 & 30 & 27 & 32 & 38 & 46 & 37 & 46 & 42 & 45 & 35 \\
\hline & & - & 17 & 17 & 18 & 19 & 24 & 19 & 18 & 19 & 24 & 20 & 16 & 18 \\
\hline 38 & 48298 & c + & 0 & 0 & 0 & 0 & 0 & 0 & 0 & 0 & 0 & 0 & 0 & 0 \\
\hline & & $n+$ & 2 & 0 & 3 & 1 & 0 & 0 & 1 & 3 & 2 & 4 & 3 & 6 \\
\hline & & - & 71 & 69 & 49 & 67 & 79 & 67 & 69 & 68 & 65 & 90 & 89 & 68 \\
\hline 39 & 96679 & c + & 0 & 2 & 0 & 0 & 0 & 0 & 0 & 0 & 0 & 0 & 0 & 0 \\
\hline & & $n+$ & 37 & 27 & 17 & 12 & 22 & 19 & 18 & 16 & 8 & 12 & 14 & 10 \\
\hline & & - & 19 & 26 & 38 & 46 & 38 & 65 & 56 & 69 & 46 & 42 & 41 & 51 \\
\hline 40 & 56923 & c + & 0 & 0 & 0 & 0 & 0 & 0 & 0 & 0 & 0 & 0 & 0 & 0 \\
\hline & & $n+$ & 36 & 20 & 15 & 8 & 32 & 15 & 13 & 23 & 16 & 16 & 10 & 8 \\
\hline & & - & 28 & 27 & 32 & 41 & 15 & 28 & 45 & 24 & 35 & 43 & 40 & 42 \\
\hline 41 & 87884 & $c+$ & 0 & 0 & 0 & 0 & 1 & 0 & 0 & 0 & 0 & 0 & 0 & 0 \\
\hline & & $n+$ & 17 & 19 & 17 & 9 & 14 & 11 & 11 & 12 & 2 & 15 & 13 & 17 \\
\hline & & - & 58 & 89 & 67 & 40 & 25 & 50 & 61 & 67 & 111 & 24 & 27 & 63 \\
\hline 42 & 81698 & $c+$ & 0 & 0 & 0 & 0 & 0 & 0 & 0 & 0 & 0 & 0 & 0 & 0 \\
\hline & & $n+$ & 32 & 29 & 16 & 15 & 11 & 11 & 9 & 10 & 13 & 9 & 13 & 12 \\
\hline & & - & 63 & 59 & 76 & 87 & 35 & 36 & 83 & 90 & 67 & 55 & 51 & 57 \\
\hline 43 & 42531 & $c+$ & 0 & 0 & 0 & 0 & 0 & 0 & 0 & 0 & 0 & 0 & 0 & 0 \\
\hline & & $n+$ & 2 & 1 & 0 & 0 & 1 & 0 & 2 & 3 & 1 & 0 & 7 & 7 \\
\hline & & - & 82 & 71 & 82 & 75 & 67 & 82 & 50 & 52 & 58 & 56 & 55 & 59 \\
\hline 44 & 87848 & c + & 2 & 0 & 0 & 0 & 0 & 0 & 0 & 0 & 0 & 0 & 0 & 0 \\
\hline & & $n+$ & 36 & 44 & 33 & 45 & 27 & 33 & 36 & 29 & 33 & 26 & 39 & 27 \\
\hline & & - & 38 & 33 & 31 & 40 & 40 & 31 & 39 & 47 & 43 & 34 & 47 & 41 \\
\hline 45 & 31247 & c + & 0 & 0 & 0 & 0 & 0 & 0 & 0 & 0 & 0 & 0 & 0 & 0 \\
\hline & & $n+$ & 38 & 24 & 21 & 24 & 23 & 21 & 34 & 35 & 34 & 61 & 48 & 49 \\
\hline & & - & 26 & 30 & 31 & 42 & 36 & 26 & 25 & 29 & 32 & 21 & 27 & 20 \\
\hline 46 & 83919 & c + & 1 & 0 & 0 & 0 & 0 & 0 & 0 & 0 & 0 & 0 & 0 & 0 \\
\hline & & $n+$ & 19 & 14 & 2 & 2 & 17 & 14 & 11 & 23 & 6 & 6 & 5 & 5 \\
\hline & & - & 57 & 50 & 85 & 75 & 45 & 45 & 48 & 35 & 39 & 71 & 82 & 72 \\
\hline 47 & 28999 & c + & 0 & 0 & 0 & 0 & 0 & 0 & 0 & 0 & 0 & 0 & 0 & 0 \\
\hline & & $n+$ & 21 & 28 & 16 & 18 & 19 & 26 & 19 & 21 & 22 & 18 & 24 & 22 \\
\hline & & - & 30 & 21 & 24 & 21 & 24 & 31 & 29 & 36 & 27 & 27 & 33 & 27 \\
\hline
\end{tabular}




\section{Campos microscópicos}

\begin{tabular}{|c|c|c|c|c|c|c|c|c|c|c|c|}
\hline \multirow[b]{2}{*}{ Caso } & \multirow[b]{2}{*}{ Prontuário } & \multirow[b]{2}{*}{ Expressão } & & & & & & & & & \multirow{2}{*}{$\begin{array}{l}\text { IPI Relação } \\
\text { IPc e IPn }\end{array}$} \\
\hline & & & 13 & 14 & 15 & 16 & 17 & 18 & 19 & 20 & \\
\hline \multirow{3}{*}{1} & 71943 & $c+$ & 1 & 1 & 1 & 3 & 0 & 1 & 0 & 3 & $1,4 \%$ \\
\hline & & $n+$ & 23 & 28 & 18 & 19 & 26 & 23 & 29 & 20 & $47,5 \%$ \\
\hline & & - & 24 & 21 & 29 & 26 & 28 & 39 & 31 & 15 & 0,029 \\
\hline \multirow[t]{3}{*}{2} & 34211 & $c+$ & 0 & 0 & 0 & 0 & 0 & & & & 0 \\
\hline & & $n+$ & 5 & 18 & 18 & 8 & 11 & & & & $15,8 \%$ \\
\hline & & - & 46 & 44 & 19 & 22 & 15 & & & & 0 \\
\hline \multirow[t]{3}{*}{3} & 61902 & $c+$ & 3 & 0 & 3 & 3 & & & & & $2,3 \%$ \\
\hline & & $n+$ & 39 & 30 & 29 & 26 & & & & & $57,6 \%$ \\
\hline & & - & 23 & 37 & 22 & 15 & & & & & 0,039 \\
\hline \multirow[t]{3}{*}{4} & 109906 & $c+$ & 1 & & & & & & & & $0,7 \%$ \\
\hline & & $n+$ & 32 & & & & & & & & $48 \%$ \\
\hline & & - & 41 & & & & & & & & 0,014 \\
\hline \multirow[t]{3}{*}{5} & 97362 & $c+$ & 0 & 0 & 0 & 0 & 0 & 0 & 0 & & $1,9 \%$ \\
\hline & & $n+$ & 16 & 4 & 18 & 17 & 14 & 7 & 15 & & $30,2 \%$ \\
\hline & & - & 34 & 41 & 38 & 43 & 30 & 34 & 41 & & 0,062 \\
\hline \multirow[t]{3}{*}{6} & 109261 & $c+$ & 1 & 0 & 0 & 0 & 0 & 0 & 2 & & $0,6 \%$ \\
\hline & & $n+$ & 40 & 40 & 34 & 41 & 8 & 8 & 21 & & $53,7 \%$ \\
\hline & & - & 31 & 17 & 21 & 20 & 29 & 42 & 29 & & 0,011 \\
\hline \multirow[t]{3}{*}{7} & 44123 & $c+$ & 0 & 0 & 0 & 0 & 0 & 0 & & & $0,3 \%$ \\
\hline & & $n+$ & 3 & 9 & 4 & 2 & 6 & 1 & & & $8,8 \%$ \\
\hline & & - & 48 & 45 & 56 & 34 & 18 & 49 & & & 0,034 \\
\hline \multirow[t]{3}{*}{8} & 107728 & $c+$ & 0 & 0 & 0 & 0 & 0 & & & & 0 \\
\hline & & $n+$ & 23 & 22 & 9 & 21 & 23 & & & & $43,8 \%$ \\
\hline & & - & 40 & 34 & 44 & 22 & 27 & & & & 0 \\
\hline \multirow[t]{3}{*}{9} & 29753 & $c+$ & 0 & 0 & & & & & & & 0 \\
\hline & & $n+$ & 22 & 20 & & & & & & & $22,3 \%$ \\
\hline & & - & 47 & 61 & & & & & & & 0 \\
\hline \multirow[t]{3}{*}{10} & 14381 & $c+$ & 0 & 0 & 1 & 0 & 0 & 0 & 0 & 0 & $0,4 \%$ \\
\hline & & $n+$ & 32 & 44 & 30 & 23 & 25 & 21 & 21 & 22 & $64,9 \%$ \\
\hline & & - & 15 & 18 & 13 & 27 & 23 & 16 & 25 & 25 & 0,006 \\
\hline \multirow[t]{3}{*}{11} & 15451 & $c+$ & & & & & & & & & 0 \\
\hline & & $n+$ & & & & & & & & & $17,6 \%$ \\
\hline & & - & & & & & & & & & 0 \\
\hline \multirow[t]{3}{*}{12} & 96476 & $c+$ & 0 & & & & & & & & 0 \\
\hline & & $n+$ & 24 & & & & & & & & $24,6 \%$ \\
\hline & & - & 61 & & & & & & & & 0 \\
\hline \multirow[t]{3}{*}{13} & 103277 & $c+$ & 0 & 0 & & & & & & & $0,2 \%$ \\
\hline & & $n+$ & 14 & 5 & & & & & & & $34 \%$ \\
\hline & & - & 66 & 44 & & & & & & & 0,005 \\
\hline \multirow[t]{3}{*}{14} & 112101 & $c+$ & 0 & 0 & & & & & & & 0 \\
\hline & & $n+$ & 2 & 2 & & & & & & & $6,4 \%$ \\
\hline & & - & 80 & 94 & & & & & & & 0 \\
\hline \multirow[t]{3}{*}{15} & 49490 & $c+$ & 13 & 4 & 0 & 7 & 2 & 12 & 4 & & $13,5 \%$ \\
\hline & & $n+$ & 10 & 26 & 32 & 19 & 33 & 25 & 23 & & $31,2 \%$ \\
\hline & & - & 18 & 24 & 32 & 31 & 28 & 36 & 46 & & 0,43 \\
\hline
\end{tabular}




\begin{tabular}{|c|c|c|c|c|c|c|c|c|c|c|c|}
\hline 16 & 64428 & $\begin{array}{c}c+ \\
n+ \\
-\end{array}$ & $\begin{array}{c}0 \\
15 \\
37\end{array}$ & $\begin{array}{c}0 \\
11 \\
43\end{array}$ & $\begin{array}{c}0 \\
6 \\
52\end{array}$ & $\begin{array}{c}0 \\
14 \\
32\end{array}$ & $\begin{array}{c}0 \\
17 \\
36\end{array}$ & $\begin{array}{c}0 \\
7 \\
40\end{array}$ & $\begin{array}{c}0 \\
6 \\
38\end{array}$ & $\begin{array}{c}0 \\
19 \\
44\end{array}$ & $\begin{array}{c}0 \\
31 \% \\
0\end{array}$ \\
\hline 17 & 25528 & $\begin{array}{c}c+ \\
n+ \\
-\end{array}$ & $\begin{array}{c}0 \\
24 \\
25\end{array}$ & $\begin{array}{c}2 \\
30 \\
27\end{array}$ & $\begin{array}{c}0 \\
34 \\
19\end{array}$ & $\begin{array}{c}1 \\
23 \\
27\end{array}$ & $\begin{array}{c}0 \\
16 \\
41\end{array}$ & $\begin{array}{c}0 \\
21 \\
26\end{array}$ & & & $\begin{array}{c}0,3 \% \\
47,8 \% \\
0,006\end{array}$ \\
\hline 18 & 11569 & $\begin{array}{c}\mathrm{c}+ \\
\mathrm{n}+ \\
-\end{array}$ & $\begin{array}{c}0 \\
14 \\
47\end{array}$ & $\begin{array}{c}0 \\
14 \\
61\end{array}$ & & & & & & & $\begin{array}{c}0 \\
7,5 \% \\
0\end{array}$ \\
\hline 19 & 65000 & $\begin{array}{c}c+ \\
n+ \\
-\end{array}$ & $\begin{array}{c}0 \\
0 \\
70\end{array}$ & $\begin{array}{c}0 \\
1 \\
58\end{array}$ & $\begin{array}{c}0 \\
1 \\
56\end{array}$ & & & & & & $\begin{array}{c}0 \\
5 \% \\
0\end{array}$ \\
\hline 20 & 116917 & $\begin{array}{c}c+ \\
n+ \\
-\end{array}$ & $\begin{array}{c}0 \\
8 \\
47\end{array}$ & $\begin{array}{c}0 \\
15 \\
39\end{array}$ & $\begin{array}{c}0 \\
2 \\
61\end{array}$ & $\begin{array}{c}1 \\
13 \\
28\end{array}$ & $\begin{array}{c}0 \\
14 \\
27\end{array}$ & $\begin{array}{c}0 \\
11 \\
50\end{array}$ & $\begin{array}{c}0 \\
4 \\
42\end{array}$ & $\begin{array}{c}0 \\
7 \\
39\end{array}$ & $\begin{array}{c}0,1 \% \\
20,6 \% \\
0,004\end{array}$ \\
\hline 21 & 67557 & $\begin{array}{c}c+ \\
n+ \\
-\end{array}$ & $\begin{array}{c}0 \\
30 \\
36\end{array}$ & $\begin{array}{c}0 \\
33 \\
28\end{array}$ & $\begin{array}{c}0 \\
6 \\
56\end{array}$ & $\begin{array}{c}0 \\
30 \\
31\end{array}$ & $\begin{array}{c}0 \\
15 \\
48\end{array}$ & $\begin{array}{c}0 \\
21 \\
60\end{array}$ & & & $\begin{array}{c}0,2 \% \\
40,4 \% \\
0,004\end{array}$ \\
\hline 22 & 108714 & $\begin{array}{c}c+ \\
n+ \\
-\end{array}$ & $\begin{array}{c}1 \\
9 \\
48\end{array}$ & $\begin{array}{c}0 \\
13 \\
25\end{array}$ & $\begin{array}{c}2 \\
14 \\
55\end{array}$ & $\begin{array}{c}0 \\
20 \\
44\end{array}$ & $\begin{array}{c}0 \\
18 \\
32\end{array}$ & & & & $\begin{array}{c}0,6 \% \\
23,1 \% \\
0,025\end{array}$ \\
\hline 23 & 113298 & $\begin{array}{c}c+ \\
n+ \\
-\end{array}$ & $\begin{array}{c}0 \\
3 \\
54\end{array}$ & $\begin{array}{c}0 \\
2 \\
44\end{array}$ & $\begin{array}{c}0 \\
7 \\
42\end{array}$ & $\begin{array}{c}0 \\
0 \\
56\end{array}$ & $\begin{array}{c}0 \\
13 \\
30\end{array}$ & & & & $\begin{array}{c}0,2 \% \\
8 \% \\
0,025\end{array}$ \\
\hline 24 & 76182 & $\begin{array}{c}\mathrm{c}+ \\
\mathrm{n}+ \\
-\end{array}$ & $\begin{array}{c}0 \\
11 \\
42\end{array}$ & $\begin{array}{c}0 \\
17 \\
48\end{array}$ & $\begin{array}{c}0 \\
12 \\
39\end{array}$ & $\begin{array}{c}0 \\
16 \\
34\end{array}$ & $\begin{array}{c}2 \\
17 \\
26\end{array}$ & $\begin{array}{c}0 \\
5 \\
74\end{array}$ & $\begin{array}{c}0 \\
4 \\
62\end{array}$ & & $\begin{array}{c}0,2 \% \\
18,7 \% \\
0,01\end{array}$ \\
\hline 25 & 56461 & $\begin{array}{c}c+ \\
n+ \\
-\end{array}$ & $\begin{array}{c}0 \\
31 \\
58\end{array}$ & $\begin{array}{c}0 \\
30 \\
50\end{array}$ & $\begin{array}{c}0 \\
15 \\
48 \\
\end{array}$ & & & & & & $\begin{array}{c}0,1 \% \\
27,6 \% \\
0,003\end{array}$ \\
\hline 26 & 46034 & $\begin{array}{c}c+ \\
n+ \\
-\end{array}$ & & & & & & & & & $\begin{array}{c}0,3 \% \\
26,7 \% \\
0,011\end{array}$ \\
\hline 27 & 32320 & $\begin{array}{c}c+ \\
n+ \\
-\end{array}$ & $\begin{array}{c}0 \\
3 \\
51\end{array}$ & $\begin{array}{c}0 \\
2 \\
64\end{array}$ & $\begin{array}{c}0 \\
2 \\
74\end{array}$ & $\begin{array}{c}0 \\
1 \\
59\end{array}$ & & & & & $\begin{array}{c}0 \\
4,7 \% \\
0\end{array}$ \\
\hline 28 & 27738 & $\begin{array}{c}\mathrm{c}+ \\
\mathrm{n}+ \\
-\end{array}$ & $\begin{array}{c}0 \\
1 \\
71\end{array}$ & $\begin{array}{c}0 \\
0 \\
60\end{array}$ & $\begin{array}{c}0 \\
1 \\
63\end{array}$ & & & & & & $\begin{array}{c}0 \\
0,7 \% \\
0\end{array}$ \\
\hline 29 & 115775 & $\begin{array}{c}c+ \\
n+ \\
-\end{array}$ & $\begin{array}{c}0 \\
2 \\
46\end{array}$ & $\begin{array}{c}2 \\
3 \\
51\end{array}$ & $\begin{array}{c}0 \\
1 \\
58\end{array}$ & & & & & & $\begin{array}{l}0,2 \% \\
7,1 \% \\
0,028\end{array}$ \\
\hline 30 & 101796 & $\begin{array}{c}\mathrm{c}+ \\
\mathrm{n}+ \\
-\end{array}$ & $\begin{array}{c}0 \\
26 \\
27\end{array}$ & $\begin{array}{c}1 \\
23 \\
25\end{array}$ & $\begin{array}{c}0 \\
24 \\
42\end{array}$ & $\begin{array}{c}0 \\
29 \\
28\end{array}$ & $\begin{array}{c}1 \\
14 \\
31\end{array}$ & $\begin{array}{c}4 \\
21 \\
20\end{array}$ & $\begin{array}{c}1 \\
19 \\
30\end{array}$ & & $\begin{array}{c}2,9 \% \\
50,2 \% \\
0,057\end{array}$ \\
\hline 31 & 99347 & $\begin{array}{c}c+ \\
n+ \\
-\end{array}$ & $\begin{array}{c}0 \\
43 \\
10\end{array}$ & $\begin{array}{c}0 \\
38 \\
23\end{array}$ & $\begin{array}{c}0 \\
31 \\
17\end{array}$ & $\begin{array}{c}0 \\
33 \\
18\end{array}$ & $\begin{array}{c}0 \\
49 \\
18\end{array}$ & $\begin{array}{c}0 \\
48 \\
16\end{array}$ & & & $\begin{array}{c}0 \\
70 \% \\
0\end{array}$ \\
\hline 32 & 70787 & $\begin{array}{c}c+ \\
n+ \\
-\end{array}$ & $\begin{array}{c}0 \\
8 \\
50\end{array}$ & $\begin{array}{c}0 \\
8 \\
34\end{array}$ & $\begin{array}{c}0 \\
12 \\
36\end{array}$ & $\begin{array}{c}0 \\
9 \\
37\end{array}$ & $\begin{array}{c}1 \\
8 \\
33\end{array}$ & $\begin{array}{c}0 \\
3 \\
41\end{array}$ & $\begin{array}{c}0 \\
7 \\
44\end{array}$ & $\begin{array}{c}0 \\
7 \\
71\end{array}$ & $\begin{array}{c}1,5 \% \\
16,7 \% \\
0,089\end{array}$ \\
\hline 33 & 104597 & $c+$ & 1 & 0 & 1 & 0 & 1 & 1 & 0 & 0 & $1 \%$ \\
\hline
\end{tabular}




\begin{tabular}{|c|c|c|c|c|c|c|c|c|c|c|c|}
\hline & & $\begin{array}{c}n+ \\
-\end{array}$ & $\begin{array}{l}16 \\
23\end{array}$ & $\begin{array}{l}14 \\
28\end{array}$ & $\begin{array}{l}13 \\
30\end{array}$ & $\begin{array}{l}16 \\
28\end{array}$ & $\begin{array}{l}16 \\
30\end{array}$ & $\begin{array}{l}28 \\
10\end{array}$ & $\begin{array}{l}15 \\
31\end{array}$ & $\begin{array}{l}18 \\
28\end{array}$ & $\begin{array}{c}36,6 \% \\
0,027\end{array}$ \\
\hline \multirow[t]{3}{*}{34} & 97365 & $c+$ & 0 & 1 & 12 & 0 & 0 & 1 & 0 & 1 & $3,1 \%$ \\
\hline & & $n+$ & 48 & 52 & 0 & 33 & 44 & 29 & 20 & 27 & $64,8 \%$ \\
\hline & & - & 4 & 12 & 23 & 39 & 6 & 10 & 18 & 9 & 0,066 \\
\hline \multirow[t]{3}{*}{35} & 56312 & $c+$ & 20 & 9 & 12 & 13 & 11 & 10 & 14 & 16 & $41,6 \%$ \\
\hline & & $n+$ & 0 & 0 & 0 & 0 & 0 & 0 & 0 & 0 & $5,8 \%$ \\
\hline & & - & 4 & 18 & 9 & 10 & 8 & 5 & 8 & 11 & 7,17 \\
\hline \multirow[t]{3}{*}{36} & 31379 & $c+$ & 0 & 0 & 0 & 0 & & & & & 0 \\
\hline & & $n+$ & 26 & 39 & 24 & 2 & & & & & $38,7 \%$ \\
\hline & & - & 30 & 23 & 39 & 40 & & & & & 0 \\
\hline \multirow[t]{3}{*}{37} & 40624 & $c+$ & 0 & 0 & 0 & 0 & 0 & & & & $0,3 \%$ \\
\hline & & $n+$ & 33 & 32 & 38 & 38 & 61 & & & & $63,6 \%$ \\
\hline & & - & 27 & 33 & 32 & 29 & 11 & & & & 0,004 \\
\hline \multirow[t]{3}{*}{38} & 48298 & $c+$ & 0 & 0 & & & & & & & 0 \\
\hline & & $n+$ & 3 & 3 & & & & & & & $3,1 \%$ \\
\hline & & - & 67 & 51 & & & & & & & 0 \\
\hline \multirow[t]{3}{*}{39} & 96679 & $c+$ & 0 & 0 & 0 & 0 & & & & & $0,2 \%$ \\
\hline & & $n+$ & 7 & 16 & 8 & 16 & & & & & $25,9 \%$ \\
\hline & & - & 47 & 56 & 52 & 47 & & & & & 0,007 \\
\hline \multirow[t]{3}{*}{40} & 56923 & $c+$ & 0 & 0 & 0 & 0 & 0 & 0 & 2 & & $0,2 \%$ \\
\hline & & $n+$ & 18 & 9 & 31 & 37 & 27 & 44 & 1 & & $37,9 \%$ \\
\hline & & - & 28 & 37 & 25 & 21 & 30 & 30 & 48 & & 0,005 \\
\hline \multirow[t]{3}{*}{41} & 87884 & $c+$ & 0 & 0 & 0 & & & & & & $0,1 \%$ \\
\hline & & $n+$ & 9 & 4 & 6 & & & & & & $17,6 \%$ \\
\hline & & - & 33 & 55 & 53 & & & & & & 0,005 \\
\hline \multirow[t]{3}{*}{42} & 81698 & $c+$ & 0 & & & & & & & & 0 \\
\hline & & $n+$ & 22 & & & & & & & & $20,2 \%$ \\
\hline & & - & 39 & & & & & & & & 0 \\
\hline \multirow[t]{3}{*}{43} & 42531 & $c+$ & 0 & 0 & 0 & & & & & & 0 \\
\hline & & $n+$ & 0 & 7 & 1 & & & & & & $3,2 \%$ \\
\hline & & - & 56 & 54 & 69 & & & & & & 0 \\
\hline \multirow[t]{3}{*}{44} & 87848 & $c+$ & 0 & 0 & & & & & & & $0,2 \%$ \\
\hline & & $n+$ & 21 & 20 & & & & & & & $44,9 \%$ \\
\hline & & - & 42 & 43 & & & & & & & 0,004 \\
\hline \multirow[t]{3}{*}{45} & 31247 & $c+$ & 0 & 0 & 0 & 0 & 0 & & & & 0 \\
\hline & & $n+$ & 21 & 26 & 26 & 24 & 22 & & & & $53,1 \%$ \\
\hline & & - & 22 & 34 & 16 & 29 & 23 & & & & 0 \\
\hline \multirow[t]{3}{*}{46} & 83919 & $c+$ & 0 & 0 & 0 & & & & & & $0,1 \%$ \\
\hline & & $n+$ & 7 & 8 & 9 & & & & & & $14,8 \%$ \\
\hline & & - & 47 & 58 & 42 & & & & & & 0,006 \\
\hline \multirow[t]{3}{*}{47} & 28999 & $c+$ & 0 & 0 & 0 & 0 & 0 & 0 & 0 & 0 & 0 \\
\hline & & $n+$ & 25 & 3 & 19 & 18 & 12 & 26 & 19 & 14 & $39 \%$ \\
\hline & & - & 17 & 41 & 24 & 41 & 45 & 32 & 42 & 38 & 0 \\
\hline
\end{tabular}

Legenda: $(c+)$ imunorreação citoplasmática, $(n+)$ imunorreação nuclear, (-) ausência de imunorreação celular, IPc índice de positividade citoplasmática, IPn índice de positividade nuclear. 


\subsection{ANEXO $F$}

Tabela 16 - Dados de sobrevivência global em casos sem expressão citoplasmática de ciclina D1.

\begin{tabular}{|c|c|c|c|c|c|c|c|}
\hline & $\begin{array}{c}\text { Tempo de } \\
\text { Sobrevivência }\end{array}$ & Indivíduos vivos & Ocorrências & $\begin{array}{c}\text { Sobrevivência } \\
\text { no tempot }\end{array}$ & $\begin{array}{l}\text { Sobrevivência } \\
\text { até o tempot }\end{array}$ & Estimação do Risco & IC (95\%) \\
\hline Evento 1 & 89 & 32 & 0 & 1,0000 & 1,0000 & 0,0000 & 0.9994 a 1.0000 \\
\hline Evento 2 & 98 & 32 & 0 & 1,0000 & 1,0000 & 0,0000 & 0.9991 a 1.0000 \\
\hline Evento 3 & 148 & 32 & 0 & 1,0000 & 1,0000 & 0,0000 & 0.9989 a 1.0000 \\
\hline Evento 4 & 163 & 32 & 0 & 1,0000 & 1,0000 & 0,0000 & 0.9988 a 1.0000 \\
\hline Evento 5 & 210 & 32 & 0 & 1,0000 & 1,0000 & 0,0000 & 0.9986 a 1.0000 \\
\hline Evento 6 & 237 & 32 & 0 & 1,0000 & 1,0000 & 0,0000 & 0.9985 a 1.0000 \\
\hline Evento 7 & 290 & 32 & 0 & 1,0000 & 1,0000 & 0,0000 & 0.9984 a 1.0000 \\
\hline Evento 8 & 303 & 32 & 0 & 1,0000 & 1,0000 & 0,0000 & 0.9982 a 1.0000 \\
\hline Evento 9 & 356 & 32 & 0 & 1,0000 & 1,0000 & 0,0000 & 0.9981 a 1.0000 \\
\hline Evento 10 & 356 & 32 & 0 & 1,0000 & 1,0000 & 0,0000 & 0.9980 a 1.0000 \\
\hline Evento 11 & 377 & 32 & 0 & 1,0000 & 1,0000 & 0,0000 & 0.9979 a 1.0000 \\
\hline Evento 12 & 379 & 32 & 0 & 1,0000 & 1,0000 & 0,0000 & 0.9978 a 1.0000 \\
\hline Evento 13 & 398 & 32 & 0 & 1,0000 & 1,0000 & 0,0000 & 0.9978 a 1.0000 \\
\hline Evento 14 & 427 & 31 & 1 & 0,9677 & 0,9677 & 0,0323 & 0.9055 a 1.0000 \\
\hline Evento 15 & 450 & 31 & 0 & 1,0000 & 0,9677 & 0,0000 & 0.9055 a 1.0000 \\
\hline Evento 16 & 460 & 31 & 0 & 1,0000 & 0,9677 & 0,0000 & 0.9055 a 1.0000 \\
\hline Evento 17 & 482 & 31 & 0 & 1,0000 & 0,9677 & 0,0000 & 0.9055 a 1.0000 \\
\hline Evento 18 & 512 & 31 & 0 & 1,0000 & 0,9677 & 0,0000 & 0.9054 a 1.0000 \\
\hline Evento 19 & 540 & 30 & 1 & 0,9667 & 0,9354 & 0,0333 & 0.8489 a 1.0000 \\
\hline Evento 20 & 561 & 30 & 0 & 1,0000 & 0,9354 & 0,0000 & 0.8489 a 1.0000 \\
\hline Evento 21 & 566 & 30 & 0 & 1,0000 & 0,9354 & 0,0000 & 0.8489 a 1.0000 \\
\hline Evento 22 & 620 & 30 & 0 & 1,0000 & 0,9354 & 0,0000 & 0.8489 a 1.0000 \\
\hline Evento 23 & 697 & 30 & 0 & 1,0000 & 0,9354 & 0,0000 & 0.8489 a 1.0000 \\
\hline Evento 24 & 1060 & 30 & 0 & 1,0000 & 0,9354 & 0,0000 & 0.8489 a 1.0000 \\
\hline Evento 25 & 1146 & 30 & 0 & 1,0000 & 0,9354 & 0,0000 & 0.8489 a 1.0000 \\
\hline Evento 26 & 1258 & 30 & 0 & 1,0000 & 0,9354 & 0,0000 & 0.8489 a 1.0000 \\
\hline Evento 27 & 1305 & 30 & 0 & 1,0000 & 0,9354 & 0,0000 & 0.8489 a 1.0000 \\
\hline Evento 28 & 1496 & 30 & 0 & 1,0000 & 0,9354 & 0,0000 & 0.8489 a 1.0000 \\
\hline Evento 29 & 1641 & 29 & 1 & 0,9655 & 0,9032 & 0,0345 & 0.7990 a 1.0000 \\
\hline Evento 30 & 1980 & 29 & 0 & 1,0000 & 0,9031 & 0,0000 & 0.7990 a 1.0000 \\
\hline Evento 31 & 2001 & 29 & 0 & 1,0000 & 0,9031 & 0,0000 & 0.7990 a 1.0000 \\
\hline Evento 32 & 2065 & 29 & 0 & 1,0000 & 0,9031 & 0,0000 & 0.7990 a 1.0000 \\
\hline Média & 708,47 & 30,84 & 0,09 & & & & \\
\hline Desvio padrão & 587,72 & 1,11 & 0,3 & & & & \\
\hline
\end{tabular}




\subsection{ANEXO G}

Tabela 17 - Dados de sobrevivência global em casos com superexpressão citoplasmática de ciclina D1.

\begin{tabular}{|c|c|c|c|c|c|c|c|}
\hline & \begin{tabular}{|} 
Tempode \\
Sobreviviênáa
\end{tabular} & Indivíduos vivos & Ocorrências & $\begin{array}{l}\text { Sobrevivência } \\
\text { notempot }\end{array}$ & $\begin{array}{l}\text { Sobreviviência } \\
\text { atée otempot }\end{array}$ & Estimaçäo do Risoo & $\operatorname{IC}(95 \%)$ \\
\hline Evento 1 & 58 & 15 & 0 & 1,0000 & 1,0000 & 0,0000 & 0.9987 a 1.0000 \\
\hline Evento2 & 65 & 15 & $\overline{0}$ & 1,0000 & 1,0000 & 0,0000 & 0.9981 a 1.0000 \\
\hline Evento3 & 109 & 15 & 0 & 1,0000 & 1,0000 & 0,0000 & 0.9977 a 1.0000 \\
\hline Evento 4 & 122 & 14 & 1 & 0,9286 & 0,9286 & 0,0714 & 0.7936 a 1.0000 \\
\hline Evento5 & 146 & 13 & 1 & 0,9231 & 0,8571 & 0,0769 & 0.6738 a 1.0000 \\
\hline Evento 6 & 186 & 13 & 0 & 1,0000 & 0,8571 & 0,0000 & 0.6738 a 1.0000 \\
\hline Evento 7 & 263 & 12 & 1 & 0,9167 & 0,7857 & 0,0833 & 0.5707 a 1.0000 \\
\hline Evento8 & 366 & 12 & 0 & 1,0000 & 0,7857 & 0,0000 & 0.5707 a 1.0000 \\
\hline Eento9 & 477 & 12 & $\overline{0}$ & 1,0000 & 0,7857 & 0,0000 & 0.5707 a 1.0000 \\
\hline Elento 10 & 514 & 12 & 0 & 1,0000 & 0,7857 & 0,0000 & 0.5707 a 1.0000 \\
\hline Elento 11 & 799 & 12 & 0 & 1,0000 & 0,7857 & 0,0000 & 0.5707 a 1.0000 \\
\hline Evento 12 & 882 & 11 & $\overline{1}$ & 0,0091 & 0,7142 & 0,0009 & 0.4776 a 0.5509 \\
\hline Elento 13 & 962 & 11 & $\overline{0}$ & 1,0000 & 0,7142 & 0,0000 & 0.4776 a 0.9509 \\
\hline Elento 14 & 2293 & 11 & 0 & 1,0000 & 0,7142 & 0,0000 & 0.4776 a 0.5509 \\
\hline Elento 15 & 2300 & 11 & $\overline{0}$ & 1,0000 & 0,7142 & 0,0000 & 0.4776 a 0.5509 \\
\hline Média & 634,13 & 12,6 & 0,27 & & & & \\
\hline Desvio padriäo & 737,52 & 1,5 & 0,46 & & & & \\
\hline
\end{tabular}




\subsection{ANEXO H}

Tabela 18 - TNM: grupamento por estádios de carcinoma laríngeo.

\begin{tabular}{|llcl||}
\hline \multicolumn{3}{|c||}{ ESTADI AMENTO } \\
Estádio 0 & Tis & N0 & M0 \\
Estádio I & T1 & N0 & M0 \\
Estádio II & T2 & N0 & M0 \\
Estádio III & T1 & N1 & M0 \\
& T2 & N1 & M0 \\
& T3 & N0, N1 & M0 \\
Estádio IVA & T1 & N2 & M0 \\
& T2 & N2 & M0 \\
& T3 & N2 & M0 \\
Estádio IVB & T4a & N0, N1, N2 & M0 \\
& T4b & Qualquer N & M0 \\
Estádio IVC & Qualquer T & N3 & M0 \\
\hline
\end{tabular}


Referências 102

9. REFERÊNCIAS 


\section{REFERÊNCIAS}

Aburad AT. Expressão das proteínas ciclina D1, c-jun e do retinoblastoma e pesquisa do HPV em carcinomas epidermóides bucais [tese]. São Paulo: Faculdade de Odontologia, Universidade de São Paulo; 2006.

Academia Brasileira de Letras. Vocabulário ortográfico da língua portuguesa (VOLP). 2ª . ed. Rio de Janeiro: Imprensa Nacional; 1998.

Alao JP, Gamble SC, Stavropoulou AV, Pomeranz KM, Lam EW, Coombes RC and Vigushin DM. The cyclin D1 proto-oncogene is sequestered in the cytoplasm of mammalian cancer cell lines. Molecular Cancer. 2006, 5: 7 doi:10.1186/1476-4598-5-7.

Alt JR, Cleveland JL, Hannink M, Diehl JA. Phosphorilationdependent regulation of cyclin D1 nuclear export and cyclin-D1 dependent cellular transformation. Genes Dev 2000; 14:31023114.

Bartkova J, Lukas J, Guldber P, Alsner J, Kirkin AF, Zurthen J et al.. The p16-cyclin D/Cdk4-pRb pathway as a functional unit frequently altered in melanoma prognosis. Cancer Res. 1996; 56:5475-83.

Batsakis JG. Tumor of Head and Neck: clinical and pathological considerations. Baltimore: Williams and Wilkins; 1979. p.574.

Bellacosa A, Almodori G, Cavallo S, Cadoni G, Galli J, Ferrandina $G$, et al. Cyclin D1 gene amplification in human laryngeal squamous cell carcinomas: prognostic significance and clinical implications. Clin Cancer Res. 1996;2:175-80.

Boffetta P, Richiardi L, Berrino F, et al. Occupation and larynx and hypopharynx cancer: an international case-control study in France, Italy, Spain and Switzerland. Cancer Causes Control. 2003; 14(3):203-12.

Bosetti C, La Vecchia C, Talamini R, et al. Food groups and laryngeal cancer risk: a case-control study from Italy and Switzerland. Int J Cancer. 2002; 100(3):355-60. 
Bova RJ, Quinn DI, Nankervis JS, Cole IE, Sheridan BF, Jensen $\mathrm{MJ}$, et al. Cyclin D1 and p16 expression predict reduced survival in carcinoma of the anterior tongue. Clin Cancer Res. 1999; 5:2810-9.

Brachman DG. Molecular biology of head and neck cancer. Semin Oncol. 1994;21(3):320-9.

Brasil. Ministério da Saúde. Estimativa 2005: Incidência de Câncer no Brasil. Rio de Janeiro: Inca; 2004.

Brasil. Ministério da Saúde. Secretaria de Atenção à Saúde. Instituto Nacional de Câncer. TNM: classificação de tumores malignos / traduzido por Ana Lúcia Amaral Eisenberg. 6a . ed. Rio de Janeiro: INCA, 2004.

Broders AC. Carcinoma: grading and pratical applications. Arch Pathol Lab Med. 1926; 2: 376-81.

Brine M. Prognostic value of various molecular and cellular features in oral squamous cell carcinoma: a review. J Oral Pathol Med. 1991;20:413-20.

Callender T, El-Naggar AK, Lee MS, Frankenthaler R, Luna MA, Batsakis JG. PRAD (CCND1/cyclin D1) oncogene amplification in primary head and neck squamous cell carcinoma. Cancer. 1994; 74: 145-8.

Capaccio P, Pruneri G, Carboni N, Pagliari AV, Quatela M, Cesana BM, Pitnataro L. Cyclin D1 expression is predictive of occult metastases in head and neck cancer patients with clinically negative cervical lymph nodes. Head and Neck. 2000; 5: 234-40.

Cataltepe S, Gornstein ER, Upton MP. Co-expression of the squamous cell carcinoma antigens 1 and 2 in normal adult human tissues and squamous cell carcinomas. J Histochem Cytochem. 2000; 48: 113-122.

Chen FF, Yan JJ, Yin YT, Su IJ. Detection of bcl-2 and p53 in thymoma: expression of bcl-2 as a reliable marker of tumor aggressiveness. Hum Pathol. 1996; 27: 1089-92.

Cervantes O, Inoue DP, Amar A. Marcadores tumorais no câncer da laringe. Revista Brasileira de Cirurgia de Cabeça e Pescoço. 2005; Vol. 34 / №. 1. 
Ciechanover A. The ubiquitin-proteasome pathway: on protein death and cell life. Embo J ournal. 1998; 17:7151-60.

Ciemerych MA, Kenney AM, Sicinska $E$, et al. Development of mice expressing a single D-type cyclin. Genes Dev. 2002; 16: 3277-3289.

ClOMS. International ethical guidelines for biomedical research involving humans subjects. Geneva: WHO, 1993.

Collins K, Jacks T, Pavletich NP. The cell cycle and cancer. Proc Natl Acad Sci . 1997; 94:2776-8.

Declaração de Helsinki V. Adotada na 18ạ. Assembléia Médica Mundial, Helsinki, Finlândia (1964), alterada na 29ạ. Assembléia, em Tóquio, Japão (1975), 35ạ. em Veneza, Itália (1983), 41ạ . em Hong Kong (1989) e 48a. Sommerset West/ África do Sul.

De Falco $M$, Fedele $V$, Cobellis $L$, et al. Pattern of expression of cyclin D1/CDK4 complex in human placenta during gestation. Cell Tissue Res. 2004; 317: 187-194.

Dias FL, Kligerman J, Cervantes O, Tavares MR, Carvalho MB, Freitas EQ. Projeto Diretrizes. Associação Médica Brasileira e Conselho Federal de Medicina, 2001.

Dietz A, Ramroth $\mathrm{H}$, Urban $\mathrm{T}$, Ahrens W, Becher $\mathrm{H}$. Exposure to cement dust, related occupational groups and laryngeal cancer risk: results of a population based case-control study. Int J Cancer. 2004; 108(6): 907-11.

Dong Y, Sui L, Sugimoto K, Tai Y, Tokuda M. Cyclin D1-Cdk4 complex, a possible critical factor for cell proliferation and prognosis in laryngeal squamous cell carcinomas. Int J Cancer. 2001; 95:209-15.

Dworkin JP, Kewson DT, Stachler RJ, Hill SL. Functional outcome following nonsurgical treatment for advanced-stage laryngeal carcinoma. Laryngoscope. 2003; 113: 720-8.

El-Naggar AK, Lai S, Cayman GL, Zhou J, Tucker SA, Myers J, Luna MA, Benedict WF. Expression of p16, Rb and Cyclin D1 gene products in oral and laryngeal squamous carcinoma: biological and clinical implications. Human Pathol. 1999; 30: 1013-8. 
Fetsch PA, Abati A. Overview of the clinical immunohistochemistry laboratory: regulations and troubleshooting guidelines. Methods Mol Biol. 1999; 115:405-14.

Fracchiolla, N.S.; Pruneri, G.; Pignataro, L.; Carboni, N.; Capaccio, P.; Boletini, A.; Buffa, R.; Neri, A. Molecular and imunohistochemical analysis of the bcl-1/cyclin D1 gene in laryngeal squamous cell carcinoma. Cancer. 1997; 79: 1114-21.

Franklin DS, Godfrey VL, Lee H, Kovalev GI, Schoonhoven R, Chen-kiang S, et al. CDK inhitors p18 and p27 mediate two separate pathways to collaboratively suppress pituitary tumorigenesis. Genet Dev. 1998; 12:2899-911.

Fu M, Wang C, Li Z, Sakamaki T, Pestell RG. Cyclin D1: normal and abnormal functions. Endocrinology 2004. doi: 10.1210/en.2004-0959.

Fuji M, Ishiguro R, Yamamita T, Tashiro M. Cyclin D1 amplification correlates with early recurrence of squamous cell carcinoma of the tongue. Cancer Lett. 2001;172:187-92.

Galli J, Cammarota G, Calò L, et al. The role of acid and alkaline reflux in laryngeal squamous cell carcinoma. Laryngoscope. 2002; 112(10): 1861-5.

Gallus S, Bosetti C, Franceschi S, Levi F, Negri E, La Vecchia C. Laryngeal cancer in women: tobacco, alcohol, nutritional, and hormonal factors. Cancer Epidemiol Biomarkers Prev. 2003; 12(6): 514-7

Gillet CE, Barnes DM. Desmystified cell cycle. Mol Pathol. 1998; 51(6):310-6.

Gladden AB, Diehl JA. The cyclin D1-dependent kinase associates with the pre-replication complex and modulates RB/MCM7 binding. J. Biol. Chem. 2003;278: 9754-9760.

Gleich LL, Salamone FN. Molecular Genetics of Head and Neck Cancer. Cancer Control. 2002. Vol. 9, №. 5.

Gluckman JL, Crissman JD. Survival rates in 548 patients with multiple neoplasms of the upper aerodigestive tract, Laryngoscope. 1983; 93: 71-4. 
Gundersen HJ, Bendtsen TF, Korbo L, Marcussen N, Moller A, Nielsen K. Some new, simple and efficient stereological methods and their use in pathological research and diagnosis. APMIS. 1988; 96(5): 379-94.

Han S, Kim H, Park K. Expression of p27 and cyclin D1 proteins is inversely correlated and associated with poor clinical outcome in human gastric cancer. J Surg Oncol. 1999; 71:147-54.

Herrero R. Human papillomavirus and cancer of the upper aerodigestive tract. J Natl Cancer Inst Monogr. 2003; (31):47-51.

Herwig, S. \& Strauss, M. The retinoblastoma protein: master regulator of cell cycle, differentiation and apoptosis. Eur J Biochem. 1997; 246: 581-601.

Holley SL, Parkes G, Matthias C, Bockmul U, Jahnke V, Leder K, Strange RS, Fryer AA, Hoban PR. Cyclin D1 Polymorphism and Expression in Patients with Squamous Cell Carcinoma of the Head and Neck. American Journal of Pathology. 2001; Vol. 159, №. 5 .

Hunter T, Pines J. Cyclins and cancer II: cyclin D and CDK inhibitors come of age. Cell. 1994; 79:573-82

Ino H, Chiba T. Cyclin-dependent kinase 4 and cyclin D1 are required for excitotoxin-induced neuronal cell death in vivo. J Neurosci 2001; 21: 6086-6094.

Ioachim E, Peschos D, Goussia A, Mittari E, Charalabopoulos K, Michael $M$ et al.. Expression patterns of cyclin $D 1$ and $E$ in laryngeal epithelial lesions: correlation with other cell cycle regulators ( $\mathrm{p53}, \mathrm{pRb}, \mathrm{Ki}-67$ and PCNA) and clinicopathological features. J Exp Clin Cancer Res. 2004; 23:277-83.

I shikawa T, Furihata M, Ohtsuki $\mathrm{Y}$, Murakami $\mathrm{H}$, Inoue A, Ogoshi $\mathrm{S}$ : Cyclin D1 overexpression related to retinoblastoma protein expression as a prognostic marker in human esophageal squamous cell carcinoma. Br J Cancer. 1998, 77:92-97.

Jares P, Fernadez PL, Campo E, Nadal A, Bosch F, Aiza G, Nayach I, Trassera J, Cardesa A: PRAD-1/cyclin D1 gene amplification correlates with messenger mRNA overexpression and tumour progression in human laryngeal carcinomas. Cancer Res. 1994, 54:4813-4817. 
Jeannon, J.P. \& Wilson, J.A. Cyclins, cyclin-dependent kinases, cyclin-dependent kinases inhibitors and their role in head and neck cancer. Clin Otolayngol. 1998; 23: 420-4.

Jones P, Fernandez P, Campo P. PRAD /cyclin D1 gene amplification correlates with messenger RNA overexpression and tumor progression in human laryngeal carcinomas. Cancer Res. 1994; 54:4183-7.

Kastan, M.B. \& Skapek, S.X. Molecular biology of cancer: the cell cycle - In DeVita, V.T.; Hellman, S.; Rosenberg, S.A. Cancer: Principles \& Practice of Oncology, 6a . ed. Philadelphia, Lippincott Willians \& Wilkins, 2001, 91-109.

Keyomarsi K, Tucker SL, Buchholz TA, Callister M, Ding $\mathrm{Y}$, Hortobagyi GN, et al. Cyclin $E$ and survival in patients with breast cancer. N Engl J Med. 2002;347:1566-75.

Krecicki T, Smigiel R, Fraczec M, Kowalczyk M, Sasiadek MM. Studies of the cell cycle regulatory proteins p16, cyclin D1 and retinoblastoma protein in laryngeal squamous cell carcinoma tissue. J Laryngol Otol. 2004; 118:676-80.

LaBaer J, Garrett MD, Stevenson LF, Slingerland JM, Sandhu C, Chou HS, Fattaey A, Harlow E. New functional activities for the p21 family of CDK inhibitors. Genes Dev. 1997.

Lazaris AC, Leandri I, Kavantzas N, Kandiloros D, Adamopoulos G, Davaris P. Correlation of tumor markers p53, bcl-2 and cathepsin-D with clinicopathologic features and disease-free survival in laryngeal squamous cell carcinoma. Pathol Int. 2000; 50: 717-24.

Lazarus P, Park JY. Metabolizing enzyme genotype and risk for upper aerodigestive tract cancer. Oral Oncol. 2000;36(5):42131.

Leong AS. Quantitation in immunohistology: fact or fiction? a discussion of variables that influence results. Appl Immunohistochem Mol Morfol. 2004; 12(1): 1-7.

Licitra L, Bernier J, Grandi C, et al. Cancer of the larynx. Crit Rev Oncol Hematol. 2003; 47(1):65-80.

Liu M, Lawson G, Delos $M$, et al. Prognostic value of cell proliferation markers, tumour suppressor proteins and cell 
adhesion molecules in primary squamous cell carcinoma of the larynx and hypopharynx. Eur Arch Otorhinolaryngol. 2003; 260(1):28-34.

Lloyd RV, Erickson LA, J in L, Kulig E, Qian X, Cheville JC, et al. p27: a mutifuctional cyclin-dependent kinase inhibitor with prognostic significante in human cancers. Am J Pathol. 1999: 154: 313-23.

MacLachlan TK, Sang N, Giordano A. Cyclins, cyclin-dependent kinases and cdk inhibitors: implications in cell cycle control. Crit Rev Eukaryot Gene Expr. 1995; 5: 127-156.

Masuda M, Hirakawa N, Nakashima T, Kuratomi Y, Komiyama S. Cyclin D1 overexpression in primary hypofaryngeal carcinomas. Cancer. 1995; 78:390-395.

Michaelses VS, Maahs GS, Machado DC, Jeckel-Neto EA. Expressão de ciclina D1 e presença de metástase cervical de carcinoma epidermóide de boca. Rev Bras Otorrinolaringol. 2007; vol.73, №.1.

Michalides R, Van Neeklan N, Hart A, Loftus B, Wientjens E, Balm A. Overexpression of cyclin D1 correlates with recurrence in a group of 47 operable squamous cell carcinomas of the head and neck. Cancer Res. 1995; 55:975-8.

Michaluart Junior, P. . Biologia molecular dos tumores de cabeça e pescoço. In: Vergilius J.F. Araújo Filho; Lenine Garcia Brandão; Alberto R. Ferraz. (Org.). Manual do Residente de Cirurgia de Cabeça e Pescoço. 1a. ed. São Paulo: Keyla \& Rosenfeld, 1999, v. , p. 199-202.

Michaluart Junior P, Carvalho MB, Góis-Filho JF, Nóbrega FG, Lehn C, Cury PM, Alves VAF, Ferraz AR, Fukuyama EE, Wunsch Filho $\mathrm{V}$. Identificação de marcadores tumorais para o carcinoma epidermóide de cabeça e pescoço e avaliação de sua relevância clínica. In: XX Congresso Brasileiro de Cirurgia de Cabeça e Pescoço, 2005, Salvador, BA.

Mineta H, Miura K, Takebayashi S, Ueda Y, Misawa K, Harada H. Cyclin D1 overexpression correlates with poor prognosis in patients with tongue squamous cell carcinoma. Oral Oncol. $2000 ; 36 ; 194-8$. 
Monteiro E, Varzim G, Pires AM, Teixeira M and Lopes C. Cyclin D1 A870G polymorphism and amplification in laryngeal squamous cell carcinoma: implications of tumor localization and tobacco exposure. Cancer Detection and Prevention. 2004. Volume 28, Issue 4, 2004, Pages 237-243.

Motokura AA. Cyclin D1 and oncogenesis. Curr Opin Genet Dev. 1993; 3:5-10.

Motokura T, Bloom T, Kim HG. A novel cyclin encoded by a bcl1linked candidate oncogene. Nature. 1991;350:512-5.

Murray AW. Recycling the cell cycle: cyclins revisited. Cell. 2004; 116:221-234

Musgrove EA, Lee CSL, Buckley MF, Sutherland RL: Cyclin D1 induction in breast cancer cells shorten $\mathrm{Gl}$ and is sufficient for cells arrested in G1 to complete the cell cycle. Proc Natl Acad Sci USA. 1994, 91:8022-8026.

Nagasawa S, Onda M, Sasajima K, Makino H, Yamashita K, Takubo K, et al. Cyclin D1 overexpression as a prognostic factor in patients with esophageal carcinoma. J Surg Incool. 2001; 78: 208-14.

Nakamura T, Sanokawa R, Sasaki YF, Ayusawa D, Oishi M, Mori $N$. Cyclin I: a new cyclin encoded by a gene isolated from human brain. Exp Cell Res. 1995;221:534-42.

Nakashima T, Clayman GL. Antisense inhibition of cyclin D1 in human head and neck squamous cell carcinoma. Arch Otolaryngol. 2000, 126:957-961.

Parkin DM, Whelan SL, Ferlay J, Teppo L, Thomas DB, editors. Cancer incidence in five continents. v.8. Lyon: International Agency for Research on Cancer; 2002. (Scientific Publication, 155).

Perez RO. Determinação da expressão da ciclina G no câncer do reto. São Paulo: Faculdade de Medicina, Universidade de São Paulo; 2006.

Pignatora L, Pruneri G, Carboni N, Capaccio P, Cesana BM, Neri A, Buffa R. Clinical relevance of cyclin D1 protein overexpression in laryngeal squamous cell carcinoma. J Clin Oncol. 1998, 16: 3069-3077. 
Pisani P, Parkin DM, Bray F, Ferlay J. Estimates of the worldwide mortality from 25 cancers in 1990. Int J Cancer 1999; 83:18-29.

Pruneri G, Pignataro L, Valentini S, Fabris $S$, Maisonneuve $\mathrm{P}$, Carboni N, Pece S, Capra M, Del Curto B, Neri A, Viale G. Cyclin D3 immunoreactivity is an independent predictor of survival in laryngeal squamous cell Carcinoma. Clinical Cancer Research. 2005; 11:242-248.

Quelle DE, Ashmun RA, Shurtleff SA, Kato JY, Bar-Sagi D, Roussel MF, Sherr CJ. Overexpression of mouse D-type cyclins accelerates G1 phase in rodent fibroblasts. Genes Dev. 1993; 7: 1559-1571.

Quon H, Liu FF, Cummings BJ. Potential molecular prognostic marker in head and neck squamous cell carcinomas. Head Neck. 2001; 23(2): 147-59.

Radu A, Neubauer V, Akagi T, Hanafusa H, Georgescu MM. PTEN induces cell cycle arrest by decreasing the level and nuclear localization of cyclin D1. Mol Cell Biol. 2003;23:6139-6149.

Rishi M, Schwarting R, Kovatich AJ, Ehya H. Detection of growth fraction in tumors by $\mathrm{Ki} 67$ monoclonal antibody in cytologic smears: a prospective study of 40 cases. Diagn Citopathol. 1993; 9(1): 52-6.

Rodrigo JP, Suarez C, Ferlito A, Devaney KO, Petruzzelli GJ, Rinaldo A. Potential molecular prognostic markers for lymph node metastasis in head and neck squamous cell carcinoma. Acta Otolaryngol. 2003; 123:100-5.

Seidal T, Balaton AJ, Battifora $\mathrm{H}$. Interpretation and quantification of immunostains. Am J Surg Pathol. 2001; 25(9): 1204-7.

Sherr CJ. Cancer cell cycles. Science. 1996;274:1672-1677.

Sherr CJ. G1 phase progession: cyclins on cue. Cell. 1994; 79:551-5.

Simone C, Giordano A. New insight in CDK9 function: from Tat to MyoD. Front Biosci. 2001;6: d1073-d1082. 
Spafford MF, Koeppe J, Pan Z, Archer PG, Meyers AD, Franklin WA. Correlation of tumor marker p53, bcl-2, CD34, CD44H, CD44v6 and Ki-67 with survival and metastasis in laryngeal squamous cell carcinoma. Arch Otolaryngol Head and Neck Surg. 1996; 122:627-32.

Spruck $\mathrm{CH}$, Strohmaier $\mathrm{H}$, Sangfelt $\mathrm{O}$, Muller HM, Hubalek $\mathrm{M}$, Muller-Holzner E. hCDC4 gene mutations in endometrial cancer. Cancer Res. 2002; 62:4535-9.

Stabenow E. Predição do risco de metástase do carcinoma bem diferenciado da glândula tireóide pela quantificação digital da imunoexpressão da galectina-3 nos compartimentos do tireócito maligno [tese]. São Paulo: Faculdade de Medicina, Universidade de São Paulo; 2006.

Sumrejkanchanakij P, Tamamori-Adachi M, Matsunaga $Y$, Eto K, I keda M-A. Role of cyclin D1 cytoplasmic sequestration in the survival of postmitotic neurons. Oncogene. 2003;22:8723-8730.

Tajara EH, Rocha JC, Ferreira CG. Oncologia molecular. São Paulo: Editora Atheneu, 2004.

Thelander L. Ubiquitin-mediated proteolysis. Advanced information on the Nobel Prize in Chemistry (2004).

Vielba R, Bilbao J, Ispizua A, Zabalza I, Alfaro J, Rezola R, et al. TP53 and cyclin D1 as prognostic factors in squamous cell carcinoma oft the larynx. Laryngoscope. 2003; 113:167-72.

Wang C, Li Z, Fu M, Bouras T, Pestell RG. Signal transduction mediated by cyclin D1: from mitogens to cell proliferation a molecular target with therapeutic potential. Cancer Treat Res. 2004; 119:217-237.

Wang XF, Nakashima T, Masuda M, Matsui K, Yamamoto T, Komiyama S. Cyclin D1 overexpression in laryngeal carcinomas. Nippon J ibinkoka Gakkai Kaiho. 1998; 101:212-5.

Weaver EM. Association between gastroesophageal reflux and sinusitis, otitis media, and laryngeal malignancy: a systematic review of the evidence. Am J Med. 2003;115(Supp 13A):81S895 . 
Weinberg RA. The molecular basis of carcinogenesis; understanding the cell cycle clock. Cytokines Mol Ther. 1996; 2:105-10.

Weinberg RA. The retinoblastoma protein and cell cycle control. Cell. 1995; 81:323-30.

Wunsch V. Epidemiologia do câncer de laringe no Brasil. Sao Paulo Med J. 2004, vol.122, no.5, p.188-194.

Ziwei Y, Weinberger PM, Haffty BG, Sasaki C, Zerillo C, Joe J, Kowalski D, Dziura J, Camp RL, Rimm DL, Psyrri A. Cyclin D1 is a valuable prognostic marker in oropharyngeal squamous cell carcinoma. Clinical Cancer Research. 2005; 11:1160-1166. 
Apêndice

APÊNDICE 


\section{APÊNDI CE I}

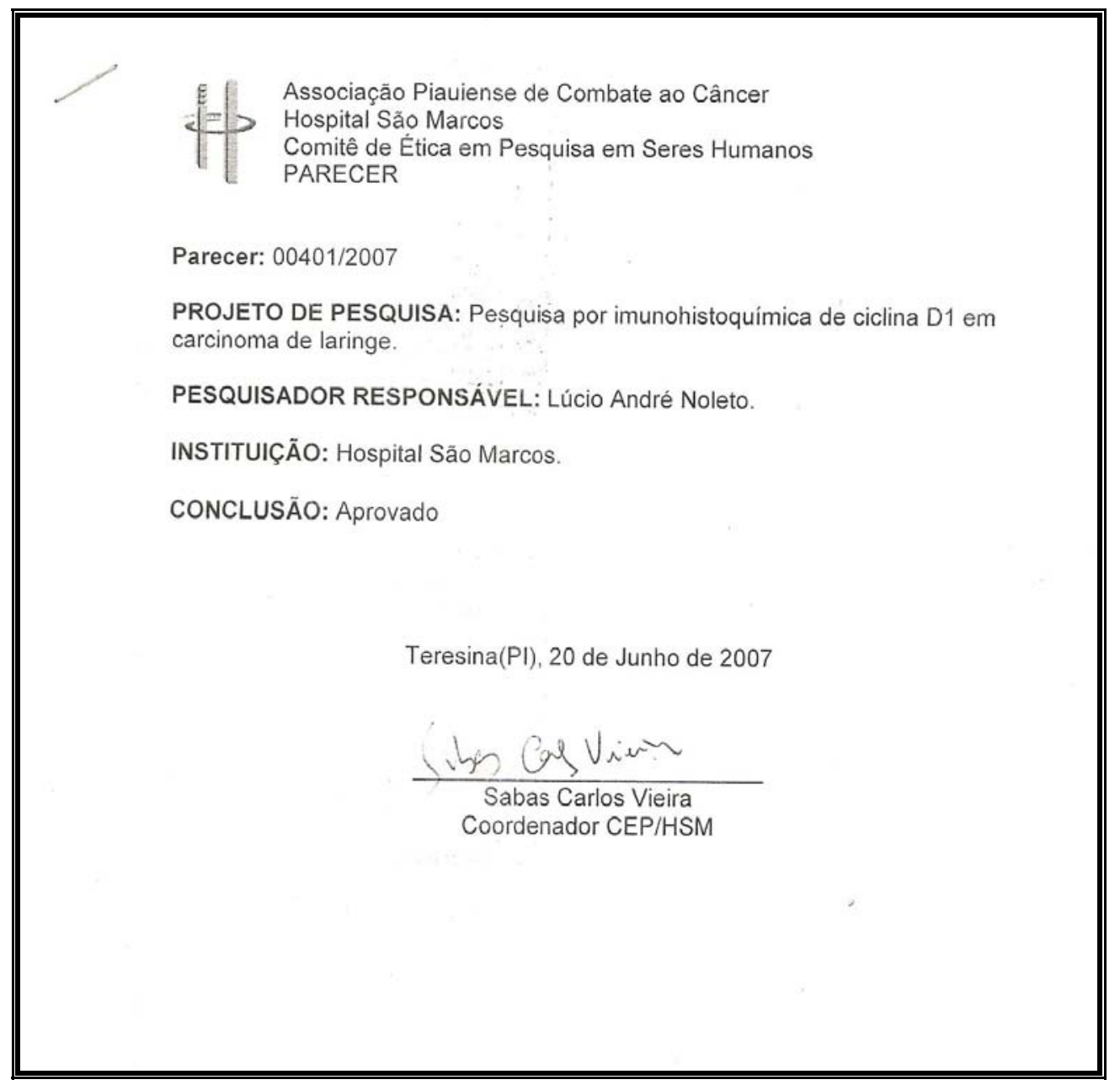

Figura 20 - Parecer do Comitê de Ética em Pesquisa em Humanos da Associação Piauiense de Combate ao Câncer. 


\section{APÊNDICE I I}

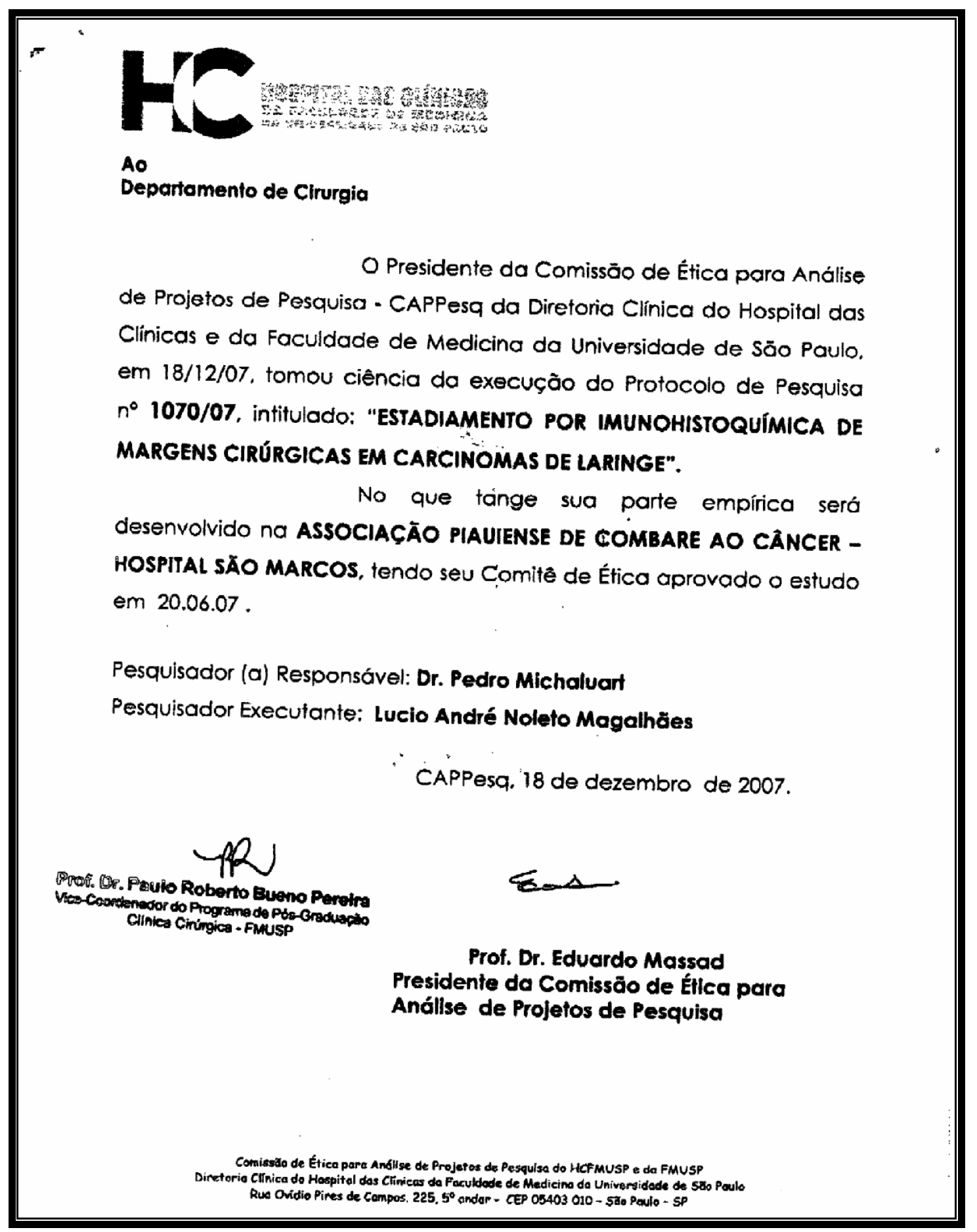

Figura 21 - Parecer da Comissão para Avaliação de Ética em Pesquisa da Faculdade de Medicina da Universidade de São Paulo (Protocolo de pesquisa no. 1070/07). 